Sabrina Thalita dos Reis

\title{
Análise da Expressão de MMP-2, MMP-9, MT1-MMP (MMP-14), TIMP-1, TIMP-2, RECK, TGF-Beta e Interleucina-8 em Câncer de Próstata
}

Tese apresentada à Faculdade de Medicina da Universidade de São Paulo para obtenção de título de Doutor em Ciências.

Área de concentração: Urologia

Orientador: Profa. Dra. Katia Ramos Moreira

Leite

Co-orientador: Dr. Alberto Azoubel Antunes

São Paulo

2011 
Dados Internacionais de Catalogação na Publicação (CIP)

Preparada pela Biblioteca da

Faculdade de Medicina da Universidade de São Paulo

Creprodução autorizada pelo autor

Reis, Sabrina Thalita dos

Análise da expressão de MMP-2, MMP-9, MT1-MMP (MMP-14), TIMP-1,

TIMP-2, RECK, TGF-Beta e interleucina-8 em câncer de próstata / Sabrina

Thalita dos Reis. -- São Paulo, 2011.

Tese(doutorado)--Faculdade de Medicina da Universidade de São Paulo.

Programa de Urologia.

Orientadora: Katia Ramos Moreira Leite.

Co-orientador: Alberto Azoubel Antunes.

Descritores: 1.Próstata 2.Neoplasias prostáticas 3.Prognóstico

4.Expressão gênica 5.Metaloproteinases 6.MMP-2 7.MMP-9

USP/FM/DBD-268/11 
"A Deus, aos meus pais Geraldo e Neuza e ao meu amor Leandro por estarem sempre ao meu lado, me dedicando amor imenso" 


\section{Agradecimentos}

A minha orientadora, Profa. Dra. Katia Ramos Leite, com quem aprendi não só como ser uma pesquisadora científica, mas também que é possível, ser uma excelente profissional, mãe e mulher. Tenho em você, um espelho a ser seguido, sou muito feliz em trabalhar ao seu lado e muito grata por todas as considerações que sempre tem comigo. Você é a grande responsável por eu amar o que faço.

Ao Prof. Dr. Miguel Srougi, agradeço a oportunidade de trabalhar ao seu lado, e todo apoio dado a mim desde o meu primeiro ano aqui na FMUSP. O senhor é um exemplo a ser seguido, pelo caráter incontestável, determinação e pelo respeito com o próximo.

Ao Prof. Dr. Marcos Francisco Dall'Oglio, agradeço também imensamente por poder trabalhar junto ao seu grupo de uro-oncologia, onde posso conviver não só com o senhor, por quem tenho imensa admiração, mas também com pessoas super especiais, como o Dr. Alexandre Crippa, Dr. Maurício Cordeiro Dr. Daher Chade, Poliana Machado, Sanarelly Pires Adonias e Camila Marin.

Aos meus queridos amigos, Dr. José Pontes Junior, Dr. Alberto Azoubel Antunes, Dr. Carlo Camargo Passerotti, Dr. José Arnaldo Shiomi da Cruz, Dr. Adriano Nesrallah, Dr. Daniel Abe e Dr. Alcides Mosconi, que sempre estão dispostos a me ajudar e me ouvir, sempre torcendo por mim e acompanhando de perto todos os momentos importantes da minha vida. 
Aos meus pupilos do LIM55, Iran Amorim Silva, Nayara Izabel Viana, Luciana Timoszczuk, Camila Piantino, Denis Reis Moraes, Caio Moura, Fábio Watanabe, Felipe Bernardes, Michele Silva, Nelson Dip a vocês devo grande agradecimento, pois fazem os meus dias de trabalho divertidos e repletos de paz, mesmo quando as circunstâncias querem o contrário.

A todos os colegas da clínica urológica, especialmente ao Prof Dr. Homero Bruschini, por permitir a minha pós-graduação, e as minhas queridas amigas que sempre estão facilitando a minha vida: Elisa, Aparecida, Iones e a Inisabete.

A todos do Laboratório de Patologia do Hospital Sírio Libânes e Genoa Biotecnologia, especialmente a Dra Juliana Canavez, que tanto me ensina. Aos meus amigos pessoais, que contribuem para minha felicidade e tranquilidade fora do laboratório, Carolina, Marcelo, Cintia, Tiago, Queóps, Marli, Natália e a Nayara novamente, por vocês tenho grande amor e respeito. Ao meu tio Francisco e tias, Geni, Lilia, Maria das Graças e Maria Geralda, em especial a minha Madrinha Aparecida, minha segunda mãe. Aos meus primos e primas, especialmente a Gorete, Felipe, Isabela, Edson, Bruna, Henrique, Lázaro, Vânia e Sandra.

Aos meus irmãos, Sandro e Alessandra, por serem meus amigos e companheiros fiéis. As minhas sobrinhas, Geovana, Mariana, Valkiria e Isabela por tornarem a minha vida mais feliz.

Aos meus pais, Geraldo e Neuza, que me proporcionaram tudo de mais precioso que eu tenho na vida, que são meus princípios, minha fé e minha 
educação. Por vocês tenho admiração e gratidão imensa. Você são os melhores pais do mundo. Amo demais vocês dois.

Ao Bob, que me dispensa tanto amor e companheirismo todos os dias.

Ao meu marido, Leandro, meu companheiro de todas as horas, por estar sempre ao meu lado e apoiar todas as minhas decisões. Você é um anjo que Deus colocou na minha vida, e eu sou completamente apaixonada por você!

E a Deus, por guiar meus caminhos, me proporcionando tudo que eu preciso para ser feliz e colocando todas estas pessoas maravilhosas na minha vida! 
Esta tese está de acordo com as seguintes normas, em vigor no momento desta publicação:

Documentação. Guia de apresentação de dissertações, teses e monografias. Elaborado por Anneliese Carneiro da Cunha, Maria Julia de A. L. Freddi, Maria F. Crestana, Marinalva de Souza Aragão, Suely Campos Cardoso, Valéria Vilhena. $2^{\underline{a}}$ ed, São Paulo: Serviço de Biblioteca e Documentação; 2005

Referências: adaptado de International Committe of Medical Journals Editors (Vancouver)

Abreviaturas dos títulos dos periódicos de acordo com List of Journals Indexed in Index Medicus 
Sumário

Lista de abreviaturas, símbolos e siglas

Lista de figuras

Lista de tabelas

Resumo

Summary

1. Introdução 18

1.1 Considerações Gerais 19

1.1.1 Câncer de Próstata 19

1.1.2 Marcadores Moleculares do CaP 22

1.1.3 Metaloproteinase da Matriz 24

1.1.4 Justificativa 33

2. Objetivos 35

3. Material e Métodos 37

3.1 Pacientes 38

3.2 Ética 40

3.3 Processamento da Amostra 40

3.4 Extração de RNA 40

3.5 Síntese de cDNA 41

3.6 qRT-PCR 42

3.7 Microarranjo Tecidual 44

3.8 Imuno-histoquímica 46 
4. Resultados 49

4.1 Expressão dos genes das metaloproteinases e de seus reguladores e a graduação histológica de Gleason 51

4.2 Expressão dos genes das metaloproteinases e de seus reguladores e o estágio tumoral 52

4.3 Expressão dos genes das metaloproteinases e de seus reguladores e o nível pré-operatório de PSA pré operatório 52

4.4 Expressão dos genes das metaloproteinases e de seus reguladores e a recidiva bioquímica 54

4.5 Expressão Proteica 56

4.6 Expressão das proteínas metaloproteinases e de seus reguladores e os fatores prognósticos do câncer de próstata 60

4.7 Expressão das proteínas metaloproteinases e de seus reguladores e a recidiva bioquímica

5. Discussão 65

6. Conclusões 77

7. Perspectivas 79

8.Anexos 81

9. Referências Bibliográficas 87

10. Apêndices 99 


\section{Lista de Abreviaturas}

CaP - Câncer de Próstata

PSA - Antígeno Prostático Específico

HPB - Hiperplasia Prostática Benigna

BTRUS - Biópsia Transretal da próstata guiada por Ultra-som

MEC - Matriz Extracelular

MB - Membrana Basal

MI - Matriz Intersticial

MMP - Metaloproteinase da Matriz

MT1-MMP - Metaloproteinase da Matriz tipo membrana 1 ou Metaloproteinase da Matriz 14 (MMP-14)

TIMP-1 - Inibidor de Metaloproteinase

RECK - Reversion-inducing-cysteine-rich protein with kazal motifs

IL-8 - Interleucina 8

TGF $\beta$ - Fator de crescimento transformante beta

B2M - beta-2-microglobulin

qRT-PCR - Reação em cadeia da polimerase quantitativa em tempo real

RNA - Ácido Ribonucleico

cDNA - Ácido desoxirribonucléico complementar 


\section{Lista de Figuras}

Figura 1. Estrutura geral das MMP 28

Figura 2. Papel das MMP no Câncer 33

Figura 3. Genes envolvidos nas vias de indução e inibição dos genes das MMP2 e MMP-9 34

Figura 4. Sistema TaqMan® 48

Figura 5. Perfil da expressão gênica dos 8 genes em 79 pacientes com Câncer de Próstata 50

Figura 6. Curvas de sobrevida livre de recidiva de acordo com a expressão dos genes estudados 55

Figura 7. Fotomicrografia ilustrativa das reações imuno-histoquímicas. A e B exemplos de reação positiva de MMP9. C e D reação positiva e negativa de MMP2 respectivamente 57

Figura 8. Fotomicrografia exemplificando a positividade citoplasmática, granular, fina de MMP14 (A) e a eventual positividade intersticial (B) 57

Figura 9. Fotomicrografia exemplificando a positividade granular citoplasmática de TIMP-1 (A) e IL-8 (B) 58

Figura 10. Fotomicrografia demonstrando a positividade citoplasmática e nuclear de TGF- $\beta$ (A e B) 58

Figura 11. TIMP-2 foi negativa em todos os casos estudados. A figura demonstra o controle positivo presente dentro do TMA, caracterizado por tecido 
medular renal normal com positividade citoplasmática, granular nas células epiteliais tubulares (A) e a reação negativa no caso (B) 59

Figura 12. Curva de sobrevida livre de recidiva de acordo com a expressão da proteína TIMP-1 


\section{Lista de Tabelas}

Tabela 1. Dados demográficos dos pacientes com CaP e do grupo controle 39

Tabela 2. Primers utilizados para quantificação da expressão dos genes MMP-2 e MMP-9 e seus reguladores no câncer de próstata 43

Tabela 3. Anticorpos utilizados para análise da expressão proteica de MMP-2 e MMP-9 e seus reguladores no câncer de próstata 43

Tabela 4. Média de expressão dos genes estudados nos 79 pacientes com CaP, comparados com 11 pacientes com HPB utilizados como controle_51

Tabela 5. Expressão dos 8 genes de acordo com o escore de Gleason, estadiamento patológico e valor de PSA pré operatório 53

Tabela 6. Expressão dos 8 genes de acordo com o recidiva bioquímica_54 Tabela 7. Porcentagem de positividade por imuno-histoquímica das proteínas estudadas em 40 pacientes com CaP 59

Tabela 8. Expressão gênica em relação a positividade ou negatividade imunohistoquímica de 6 genes analisados 60

Tabela 9. Expressão das proteínas de acordo com o escore de Gleason, estadiamento patológico e valor de PSA 61

Tabela 10. Expressão imuno-histoquímica das proteínas de acordo com recidiva bioquímica 63 


\section{Resumo}

Reis ST. Análise da Expressão de MMP-2, MMP-9, MT1-MMP (MMP-14), TIMP-1, TIMP-2, RECK, TGF-Beta e Interleucina-8 em câncer de Próstata [tese]. São Paulo: Faculdade de Medicina, Universidade de São Paulo; 2011.

Introdução: $O$ câncer de próstata $(\mathrm{CaP})$ é o tumor mais freqüente do homem no Brasil tendo sido estimados mais de 52.350 novos casos em 2010, sendo a segunda causa de óbito por câncer em homens. O prognóstico depende fundamentalmente dos níveis séricos de Prostatic Specific Antigen (PSA) estádio tumoral (TNM) e grau de diferenciação histológica (Gleason). Porém esses têm sido insuficientes na definição do prognóstico da neoplasia. Por isso pesquisas têm sido direcionadas para a identificação de alterações moleculares que possam prever o potencial de agressividade do câncer de próstata. Metaloproteinases da matriz (MMP) são proteínas pertencentes a uma família de aproximadamente 30 enzimas proteolíticas ou endoproteinases que degradam vários componentes da matriz extracelular. A detecção de sua expressão tem sido estudada como marcador sensível e específico de vários tumores, principalmente as MMP pertencentes ao grupo das gelatinases MMP-2 e MMP-9. Objetivo: o objetivo deste nosso trabalho foi avaliarmos pela técnica de qRT-PCR e imuno-histoquímica os níveis de expressão dos genes das MMP pertencentes ao grupo das gelatinases, MMP-2 e MMP-9, bem como outros sabidamente envolvidos em suas vias de ativação (MMP-14, IL-8) e inibição (TIMP-1, TIMP-2, RECK e TGF- $\beta$ ) no câncer localizado de próstata. Material e Métodos: $O$ estudo consistiu na análise de espécimes de 79 pacientes com câncer da próstata submetidos a prostatectomia radical entre setembro de 1997 e fevereiro de 2000. Esses oito genes foram então testados quanto a seu valor prognóstico no câncer da próstata através da técnica de reação em cadeia da polimerase quantitativa com transcriptase reversa (qRT-PCR). Análise proteica foi feita a partir de 40 pacientes deste pool. O grupo controle foi composto de tecido de 11 pacientes com hiperplasia benigna da próstata (HPB) tratados cirurgicamente com prostatectomia retropúbica. Resultados: MMP-9 esteve superexpressa e MMP-2, TIMP-1, TIMP-2, MMP 14, IL-8, TGF- $\beta$ e RECK se mostraram subexpressos em tecido representativo de $\mathrm{CaP}$ quando comparado com HPB. A análise dos níveis de expressão dos genes com o escore de Gleason, mostrou que MMP-2 e TIMP-2 mesmo mantendo-se subexpressos, tiveram uma expressão maior entre os pacientes que apresentavam Gleason $\geq$ 7 ( $p=0,04$ e $p=0,02$ respectivamente). De acordo com 0 valor de PSA préoperatório, encontramos diferenças na expressão de MMP-9. Pacientes que apresentavam um PSA pré-operatório $\geq 10 \mathrm{ng} / \mathrm{mL}$ possuíam uma mediana de expressão maior que aqueles cujo PSA pré-operatório $<10 \mathrm{ng} / \mathrm{mL}$ com medianas de expressão de 5,62 e 2,76 respectivamente $(p=0,033)$. Não encontramos diferenças estatísticas entre pacientes que apresentavam ou não recidiva bioquímica quanto a expressão dos 8 genes estudados. Porém o gene da MMP-9 apresentou uma diferença estatística marginal apresentando uma 
mediana de expressão de 6,29x nos pacientes que apresentaram recidiva bioquímica e de 3,25 nos pacientes que não apresentaram recidiva bioquímica $(p=0,090)$. De acordo com a expressão proteica, encontramos uma maior positividade em MMP-9, MMP-2, TGF- $\beta$, IL-8 e MMP-14. De acordo com os fatores prognósticos encontramos associação de TIMP-1 com recidiva bioquímica. Conclusão: Encontramos uma superexpressão de MMP-9 e uma subexpressão de MMP-2, TIMP-1, TIMP-2, MMP-14, RECK, IL-8 e TGF- $\beta$ no $\mathrm{CaP}$. Considerando os fatores prognósticos encontramos que aumentados níveis de expressão do gene da MMP-9 associou-se a aumentados níveis de PSA, e mostrou uma tendência de associação com recidiva bioquímica. De acordo com a expressão proteica encontramos que a ausência de TIMP-1 pode ser um indicativo de recidiva bioquímica.

Descritores: próstata, neoplasias prostáticas, prognóstico, expressão gênica, Metaloproteinases, MMP-2, MMP-9 


\section{Summary}

Reis ST. Expression of MMP-2, MMP-9, MT1-MMP (MMP-14), TIMP-1, TIMP-2, RECK, TGF-Beta e Interleucina-8 genes in the Prostate Cancer [thesis]. São Paulo: Faculdade de Medicina, Universidade de São Paulo; 2011.

Introduction: Currently, Prostate cancer $(\mathrm{PCa})$ is the most common tumor in men in Brazil. It was estimated that more than 52,350 new cases were diagnosed in 2010, being the second cause of death by cancer in man. The prognosis depends mainly on Prostate Specific Antigen (PSA) serum levels, tumor stage (TNM) and histological grade (Gleason), but these parameters, even combined, are insufficient to define the correct prognosis of PCa. Therefore research has been directed towards the identification of molecular alterations that may predict potential aggressiveness of $\mathrm{PCa}$. Matrix metalloproteinases (MMPs) are proteins that belong to a family of about 30 proteolytic enzymes that degrade various components of the extracellular matrix. The analysis of MMPs expression has been studied as a sensitive and specific marker of prognosis of several tumors, and special attention was focused in the group of gelatinases, MMP-2 and MMP-9.Objective: The aim of this study was to evaluate the expression levels of MMP-2 and MMP-9 genes and proteins by quantitative real-time polymerase chain reaction (qRT-PCR) and immunohistochemistry in localized $\mathrm{PCa}$. We also evaluated the expression of genes that are involved in the control of MMP-2 and MMP as activators (MMP14, IL-8) or inhibitors (TIMP-1, TIMP-2, RECK and TGF- $\beta$ ).Materials and Methods: The casuistic consisted of 79 surgical specimens from patients with localized PCa who underwent radical prostatectomy between September 1997 and February 2000. The control group was composed of specimens from 11 patients with benign prostatic hyperplasia (BPH) treated surgically with retropubic prostatectomy. The results of the 8 genes expression, through qRTPCR and immunohistochemistry, were correlated to the diagnosis and prognosis of PCa. The protein expression analysis was carried out in 40 patients of the casuistic. Results: The MMP-9 was overexpressed, while MMP-2, TIMP-1, TIMP-2, MMP-14, RECK, IL-8, and TGF- $\beta$ were underexpressed in malignant prostate tissue compared to $\mathrm{BPH}$. Patients with Gleason $\geq 7$ had higher expression of MMP-2 and TIMP-2 ( $p=0.04, p=0.02$ respectively). According to the preoperative PSA value, we found that patients with preoperative PSA $\geq 10$ $\mathrm{ng} / \mathrm{mL}$ had a median of expression of 5.62 compared to 2.76 when $P S A<10$ $\mathrm{ng} / \mathrm{mL}(\mathrm{p}=0.033)$. There were no statistical differences between expression of the eight genes and biochemical recurrence during follow up. However, the higher MMP-9 expression was marginally associated with recurrence, the median was of 6.29 in recurrence patients compared to 3.25 in those without recurrence $(p=0.090)$. Regarding the protein expression, we found a higher positivity of MMP-9, MMP-2, TGF- $\beta$, IL-8 e MMP-14 expression in PCa, and a correlation between the lack of TIMP-1 and tumor recurrence. Conclusion: 
MMP-9 is overexpressed while MMP-2, TIMP-1, TIMP-2, MMP-14, RECK, TGF$\beta$ and IL-8 are underexpressed in CaP. According to the prognostic factors, we observed that increased level of MMP-9 was associated with pre-surgical $P S A \geq 10 \mathrm{ng} / \mathrm{mL}$. Also there was a tendency of association between higher MMP9 expression and biochemical recurrence. Overexpression of MMP-9 can be explained by the underexpression of their major inhibitors TIMP-1 and RECK. According to protein expression we found that absence of TIMP-1 is correlated with biochemical recurrence in the PCa.

Descriptors: prostate, prostate neoplasms, prognosis, gene expression, MMP-

2, MMP-9 
1. Introdução 


\subsection{Considerações GERAIS}

\subsubsection{Câncer de próstata}

O câncer de próstata (CaP) é o tumor mais freqüente do homem no Brasil tendo sido estimados mais de 52.350 novos casos em 2010, sendo o segundo em causa de óbito por câncer em homens (www.inca.gov.br). No mundo, os casos esperados de CaP representam 15,3\% de todos os cânceres. A incidência apresenta variações regionais e raciais, provavelmente, devido a condições genéticas e ambientais, principalmente alimentares distintas entre os indivíduos (Nelson et al., 2003). Histórico familiar de pai ou irmão com câncer de próstata antes dos 60 anos de idade aumenta o risco em 3 a 10 vezes em relação à população geral (Crawford, 2003).

O consumo de frutas, vegetais ricos em carotenóides como tomates e cenouras, e leguminosas como feijão, ervilha e soja; vitaminas do tipo A, D e E, e minerais como o selênio parecem que diminuem o risco de desenvolvimento do CaP. Um alto consumo energético total e ingestão de grande quantidade de carne vermelha, gorduras e derivados do leite tem sido relacionado a aumento da probabilidade de desenvolvimento do $\mathrm{CaP}$. Aminas heterocíclicas e hidrocarbonetos policíclicos aromáticos, fator de crescimento análogo à insulina (IGF-1), consumo excessivo de álcool e tabagismo também são tidos como responsáveis pelo aumento do risco (Schulman et al., 2001). 
A detecção precoce do $\mathrm{CaP}$ se dá pelo exame de toque retal (TR) e determinação da concentração sérica do antígeno prostático específico (PSA) (Carter, Person,1999). É importante à associação da dosagem de PSA ao TR, já que o TR tem alta especificidade (94\%), porém baixa sensibilidade $(50 \%)$, assim como baixo valor preditivo positivo (21\%-53\%) (Perrer et al., 1996). O nível de PSA no sangue se eleva em casos de hiperplasia prostática benigna (HPB), prostatite e CaP. Normalmente, é encontrado em baixos níveis, menor que 4,0ng/ml (Catalona et al., 1991). Elevados níveis séricos de PSA são indicação de biópsia prostática guiada pela ultra-sonografia transretal (BTRUS), único método diagnóstico da neoplasia (Gann et al., 1995). Devido a sua baixa especificidade, quando uma biópsia prostática é realizada em pacientes com níveis de PSA entre 3,0 e $10,0 \mathrm{ng} / \mathrm{ml}$ são observadas taxas de resultados negativos de aproximadamente 70 a 80\% (Djavan et al., 2000). Devido à baixa sensibilidade do ultra-som, os protocolos convencionais de biópsia têm demonstrado taxas elevadas de resultados falso-negativos (Welsh et al., 2007).

O diagnóstico do CaP tem que ser feito na fase inicial, para que se possa obter maior sucesso no tratamento. O tratamento do carcinoma localizado na próstata é a prostatectomia radical e a radioterapia e, em doença avançada, metastática, a chance de cura é diminuta e o tratamento é baseado na supressão androgênica (Brawer et al., 2001).

O prognóstico depende fundamentalmente do estádio tumoral (TNM) e grau de diferenciação histológica (Gleason). A progressão do CaP, entretanto, é 
variada; existem tumores de baixo grau que têm evolução indolente enquanto outros possuem alta capacidade de progressão (Konishi et al., 1995). Atualmente, não há nenhum marcador definitivo que permita a diferenciação entre estas formas de tumores. Os principais fatores prognósticos para o $\mathrm{CaP}$ então estão descritos abaixo:

\section{Graduação histológica de Gleason}

Um dos mais importantes fatores prognósticos é a graduação histológica, sendo a graduação de Gleason a mais utilizada. Existem cinco padrões na escala de graduação de Gleason para o CaP considerando o padrão glandular e a sua relação com o estroma prostático. O diagnóstico final é dado pela soma dos valores dos dois focos neoplásicos mais representativos do tumor, de forma que as neoplasias serão classificadas em um escore de 2 a 10 (Gleason, 1992; Epstein et al., 2005). Tumores com escore de Gleason 2-6 são considerados bem diferenciados e têm um comportamento mais indolente enquanto os tumores com escore de 7 a 10 são mais agressivos (Gleason, 1992).

2. Volume tumoral

Um segundo valor prognóstico importante é o volume tumoral, que pode ser avaliado na biópsia prostática ou na peça cirúrgica após a prostatectomia radical. Porém tumores de qualquer tamanho apresentando Gleason $>7$ tendem a evoluir agressivamente com recorrência à distância (Leite et al., 2005).

\section{Estádio Patológico}


O estadiamento patológico é um dos principais fatores prognósticos. A classificação TNM no câncer de próstata segue a recomendação da AJCC (2010).

Atualmente são estes os parâmetros que norteiam a escolha dos tratamentos primário e adjuvante, porém esses têm sido insuficientes para identificação de indivíduos susceptíveis ao desenvolvimento bem como na definição do prognóstico dessa neoplasia. Por isso pesquisas têm sido direcionadas para a identificação de alterações moleculares que possam prever o desenvolvimento e potencial biológico do câncer de próstata.

\subsubsection{Marcadores moleculares do CaP}

A descoberta e a utilização de marcadores tumorais têm influenciado positivamente a detecção precoce, o diagnóstico e o estadiamento de uma série de neoplasias. A busca e a identificação de novos marcadores no CaP tem sido razão de pesquisas em vários laboratórios, inclusive o nosso (LIM 55), e resultados promissores têm sido descritos.

Com o intuito de melhorar as taxas de diagnóstico do CaP, vários marcadores biológicos têm sido isolados e testados no tecido prostático no sangue e na urina, como por exemplo PSCA (Prostate stem cell antigen) uma glicoproteína específica expressa na superfície celular, e a AMACR (Alphamethyl coenzyme-A racemase) que também tem papel na avaliação das 
biópsias prostáticas de difícil interpretação. Um estudo realizado em nosso Laboratório (LIM-55) através do método de qRT-PCR mostrou que o PSMA (Prostate Specific Membrane Antigen) apresentou-se sempre super-expresso e o PGC sempre sub-expresso em todos os casos de CaP quando comparados com os casos de HPB, além disso esse padrão de expressão se manteve em tecido normal de paciente com CaP, podendo também ajudar na avaliação de biópsias de difícil interpretação (Antunes e cols, 2009).

O mecanismo de progressão do CaP ainda é pouco compreendido, mas acredita-se que envolva um acúmulo de alterações genéticas, como por exemplo, a fusão do gene TMPRSS2 ao fator de transcrição $E R G$ que tem sido identificado como uma alteração molecular frequentemente observada no $\mathrm{CaP}$ (Nam e cols, 2007), ou a hipermetilação do gene GSTP1 que é observada em mais de $90 \%$ dos casos (Kang e cols, 2004).

A alteração da adesão celular também é evento crucial na invasão e progressão tumoral. Demonstramos, no maior estudo de metástases ósseas de CaP já publicado que a perda da E-caderina e Beta-catenina nas metástases ocorria em cerca de $90 \%$ dos casos, quando comparado ao tumor primário. Mostramos também em estudo de "Tissue Micro Array" com 112 casos submetidos à cirurgia, que a expressão forte da integrina alfa 3 triplicava a chance da recidiva tumoral (Pontes e cols, 2010). 
MicroRNAs são pequenas moléculas endógenas de RNA não codificadoras de proteínas que são responsáveis pela regulação de $30 \%$ da expressão gênica. Avaliando a expressão por PCR em tempo real de 14 microRNAs que controlam a expressão de genes relacionados ao $\mathrm{CaP}$ observamos que os miR-let7c, miR-100 e miR-218 apresentaram menor expressão no CaP metastático quando comparado ao tumor localizado, sugerindo que a perda de expressão destes microRNAs esteja relacionada à progressão do CaP (Leite e cols, 2009).

Baseado na larga amplitude clínica do CaP, é improvável a idéia de que um marcador molecular isoladamente possa determinar o prognóstico do CaP. Talvez perfis de expressão de vários genes em conjunto possam auxiliar no entendimento do mecanismo responsável pelo desenvolvimento e progressão dessa neoplasia.

\subsubsection{Metaloprotease da Matriz}

Proteases extracelulares são necessárias em diversos processos relacionados com o desenvolvimento normal e com doenças. A habilidade de degradar proteínas extracelulares é essencial para células individuais interagirem com o microambiente e para organismos multicelulares se desenvolverem e funcionarem normalmente. Uma família de enzimas identificada em diferentes espécies foi chamada de metaloproteases da matriz, 
dada sua dependência de íons metálicos para atividade catalítica e sua habilidade em degradar proteínas estruturais da MEC. Metaloproteinases da matriz (MMP) são proteínas pertencentes a uma família de aproximadamente trinta enzimas proteolíticas ou endoproteinases que degradam vários componentes da matriz extracelular (MEC) (Nagase, Woessner, 1999).

A MEC é definida como uma rede complexa de componentes protéicos, proteoglicanos e glicoproteínas secretados, que circundam os fibroblastos, unindo as células e mantendo a estrutura tridimensional do corpo. Uma rede dinâmica de macro moléculas interativa com o colágeno e elastina, embutida em proteoglicans e glicoproteínas. Era vista inicialmente como um substrato estável para as células e como determinante da arquitetura tecidual, porém mais funções foram definidas como um papel instrutivo, provendo informações estruturais para integrinas e outras moléculas da superfície celular, servindo também como um reservatório de fatores de crescimento (Pupa e cols, 2002).

Estas macromoléculas reúnem-se em duas organizações que são denominadas matriz intersticial (MI) e membrana basal (MB). A MI compreende todo o espaço existente entre as células mesenquimais, e a MB é representada pela matriz extracelular em forma de lâmina constituída por colágeno tipo IV e glicoproteínas que separa duas camadas celulares como o epitélio do endotélio e o epitélio do tecido conjuntivo. Durante o processo de invasão tumoral, as células neoplásicas atravessam os dois tipos de matriz, $\mathrm{MB}$ e $\mathrm{Ml}$, e reações bioquímicas entre células normais e a MEC têm influência no processo de 
invasão tumoral em neoplasias (Liotta, 1986). Células tumorais possuem a habilidade de invadir os tecidos através da produção de proteinases extracelulares que clivam componentes da MEC (van-Kempen et al., 2002). Tais proteinases incluem as serina-proteases, cisteína-proteases e as MMP (Stetler-Stevenson et al., 1989).

As MMP são enzimas chave na renovação da MEC, e por isso exercem importante papel no desenvolvimento e progressão de patologias humanas, incluindo o câncer onde promovem a degradação de componentes da matriz extracelular permitindo a migração das células tumorais (Vlermincvkx, 1991). A detecção de sua expressão tem sido estudada como marcador sensível e específico de tumores de esôfago (Yu et al., 2004), pulmão (Su et al., 2005), cabeça e pescoço (O-Charoenrat et al., 2006), ovário (Li et al., 2006), cólon e reto (Zinzindohoue et al., 2005), condrossarcoma (Fong et al., 2004) e fígado (Xiang e cols, 2011).

As MMP estão subdivididas em cinco grupos, baseados na especificidade do substrato e na sua homologia interna (figura 1):

1- Matrilisinas são as mais simples, possuem um domínio propeptídeo, peptídeo sinal e um domínio catalítico com o sítio ligante de zinco. Fazem parte deste grupo MMP-7 e MMP-26 (Lynch, Matrisian, 2002). 
2- Colagenases contêm um domínio simples de hemopexina conectado ao domínio catalítico através de uma região de dobradiça rica em prolina, estas MMP degradam a hélice nativa de colágeno tipo I, II e III entre outros. São estas: MMP-1, MMP8 e MMP-13 (Curran, Murray, 1999).

3- Estromelisinas são semelhantes as colagenases, mas como as matrilisinas possuem um substrato específico e degradam muitas proteínas da matriz extracelular, como os proteoglicans, fibronectina e laminina. São estas: MMP-3, MMP-10 e MMP-12 (Nagase, Woessner, 1999).

4- Gelatinases contêm uma região adicional de três repetições de fibronectina tipo II, que possuem preferência por colágeno desnaturado (gelatinases) e também degradam colágenos tipos IV, V, VII e X, além de fibronectinas e lamininas. São estas: MMP-2 e MMP-9 (Kleiner, Stetler-Stevenson, 1999).

5- $\quad$ MMP tipo membrana (MMP-TM) é o quinto e maior grupo das metaloproteinases que degrada gelatina, fibronectina e agrecan assim como outros substratos da matriz extracelular, estas MMP estão limitadas à superfície das células através de um domínio transmembrana c-terminal. São estas: MMP-14 (MT1- 
MMP), MMP-15, MMP-16, MMP-17, MMP-24 e MMP-25 (Seiki, 1999).

Existem ainda a MMP19, MMP-23 e epilisina (MMP-28) que não estão em nenhum destes grupos (McCawley, 2001). Entre outras metaloproteinases estão as metaloelastase (MMP-12) e enamelisina (MMP-20) que possuem função especializada em migração e proteólise de macrófagos mediadores e formação do esmalte do dente respectivamente (Caterina et al., 2002).
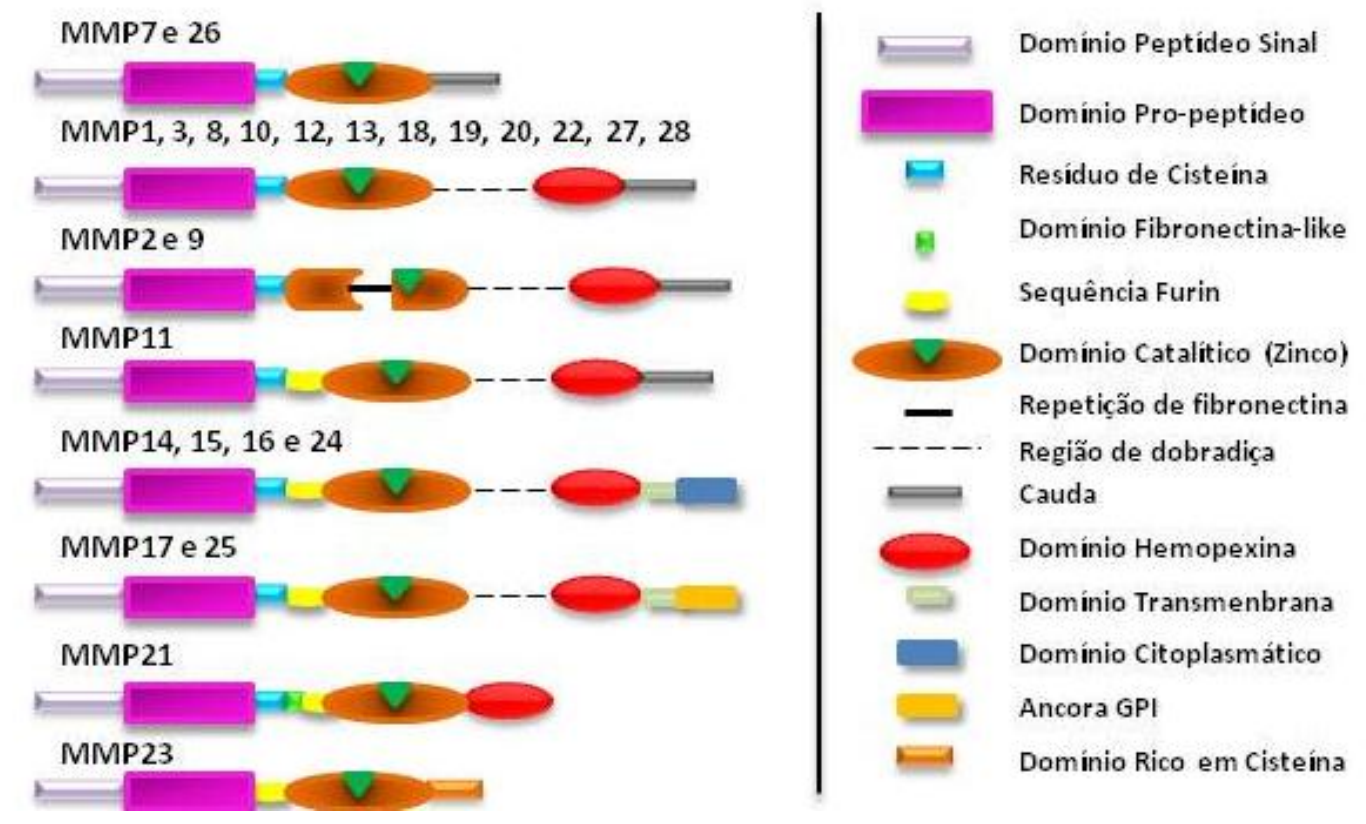

Figura 1. Estrutura geral das metaloproteinases. As MMP possuem um domínio pro-peptídeo responsável pela latência da enzima, e um domínio catalítico, portador de um íon zinco, estas estruturas estão sempre presentes e caracterizam estas enzimas. Um domínio hemopexina determina susbtratos e inibidores de cada MMP. 
O pro-peptídeo de todas as metaloproteinases contêm um resíduo de cisteína conservado, unido ao íon zinco no sítio catalítico das MMP (Nagase, Woessner, 1999). O rompimento desta ligação zinco-cisteína por fatores físicos ou químicos é o primeiro passo para ativação das MMP (Stamenkovic, 2003). O domínio hemopexina forma uma estrutura propulsora de quatro hélices feitas de Beta sheets, que confere a propriedade colagenolítica das MMP (Lauer-Fields et al., 2002). Gelatinases são distinguidas pela inserção de três repetições cabeça-cauda ricas em cisteína, em seus domínios catalíticos que é importante por se ligar à gelatina (Lauer-Fields et al., 2002).

O domínio Pex é necessário para ligar MMP a outras proteínas como as integrinas, receptores de superfície celular e TIMP (Tecidos Inibidores de MMP) (Baker et al., 2002). Todas as MMP-TM, estromelisina-3 (MMP-11), MMP-23 e epilisina (MMP-28) têm também uma seqüência de reconhecimento furin entre o pro-peptídeo e o domínio catalítico, permitindo assim ativação e clivagem por enzimas convertase no aparelho de golgi (Lee et al., 2004).

Além da degradação de componentes da matriz extracelular e ativação de outras metaloproteinases, as MMP são responsáveis pela ativação de fatores de crescimento e citocinas (Stamenkovic, 2003). Por exemplo, a MMP-9 cliva o sítio pro-inflamatório da citocina Interleucina 8 (IL-8), aumentando sua atividade em 10 vezes, degradando e inativando assim o fator 4 de plaqueta que é um inibidor de angiogênese (Opdenakker et al., 2001). 
A atividade das MMP é regulada por inibidores endógenos. Primeiramente estão os quatros inibidores de metaloproteinases (TIMP), onde cada um consiste de um domínio $\mathrm{N}$-terminal responsável pela atividade inibitória da MMP, e um domínio C-terminal. Embora todas as TIMP liguem-se firmemente a maioria das MMP, elas possuem diferente atividade inibitória contra diferentes MMP (Brew et al., 2001).

Recentemente, um novo inibidor de MMP, chamado RECK (proteína indutora de reversão rica em cisteína com domínio Kazal) foi identificado. RECK é uma glicoproteína de ancoragem em membranas celulares, cuja estrutura é diferente das TIMP, expressa em vários tecidos normais, mas não identificada em células derivadas de tumores. A RECK inibe MMP-9, 2 e 14, funcionando também, como um regulador estrutural de processo de renovação (turnover) da matriz extracelular (Chang e cols, 2008). A RECK inibe a MMP-9 de dois modos, supressão da sua secreção e direta inibição de sua atividade enzimática. Durante o processo de transformação celular a expressão do gene RECK é inibida liberando MMP-9, contribuindo assim para o comportamento invasivo de células cancerosas (Baker et al., 2002).

As MMP são também reguladas em níveis transcricional e pós transcricional. A expressão da maioria das MMP é baixa em tecido normal e acima do normal quando há remodelamento. A expressão pode ser induzida por citocinas, fatores de crescimento, agentes químicos, estresse físico, oncogenes e interações com a matriz extracelular (Westermarck et al., 1999). 
As MMP ampliam o processo de invasão tumoral, não só através da degradação das proteínas da MEC, como também ativando as cascatas de transdução de sinal que promovem motilidade e a solubilização de fatores de crescimento ligados à MEC (Mc Cawley \& Matrisian, 2001). Estudos in vitro mostraram que as MMP-2 e MMP-9 são capazes de clivar proteoliticamente TGF- $\beta$. MMP-9 induz ativação de TGF- $\beta$ na superfície de queratinócitos normais bem como de células malignas, sugerindo que ativação de TGF- $\beta$ mediada por MMP pode possuir um importante papel no remodelamento tecidual tanto em situações fisiológicas como em patologias como o câncer, facilitando a invasão tumoral e angiogênese (Yu, Stamenkovic, 2000).

Diferenças na expressão de várias MMP estão sendo encontradas em vários tipos de tumores e têm sido correlacionadas tanto com o desenvolvimento, quanto ao pior prognóstico relacionadas com invasão, estágio avançado e propriedades metastáticas de diversas neoplasia (Coussens et al., 2002) (Egeblad, Werb, 2002) (Xiang e cols, 2001).

Um aumento na expressão de MMP acontece nas próprias células tumorais ou em células estromais vizinhas, que ajudam a remodelar a MEC de forma a providenciar um ambiente favorável para o estabelecimento do tumor primário. Estão também envolvidas na migração celular ajudando na remoção de sítios de adesão, e expondo novos sítios de migração, através da clivagem de receptores que promovem a ligação entre as células e destas com a MEC, 
além de degradar componentes da membrana basal permitindo que células tumorais invadam o estroma adjacente (McCawley, 2001).

As MMP também participam do processo de angiogênese, facilitando a ligação aos receptores da membrana de fatores proangiogênicos e suprimindo a ligação de inibidores da angiogênese. Na circulação de células tumorais as MMP ajudam a quebrar a membrana basal associada com capilares e vasos linfáticos permitindo que células tumorais entrem na circulação, e depois saiam dos vasos sanguíneos para sítios metastáticos (Chambers, Matrisian, 1997). Em sítios distantes, MMP são requeridas novamente para todos os processos descritos acima, migração, estabelecimento do microambiente necessário para crescimento metastático, e angiogênese. Enfim, as MMP contribuem em múltiplos estágios para o processo carcinogênico (Egeblad, Werb, 2002) (figura 2). 

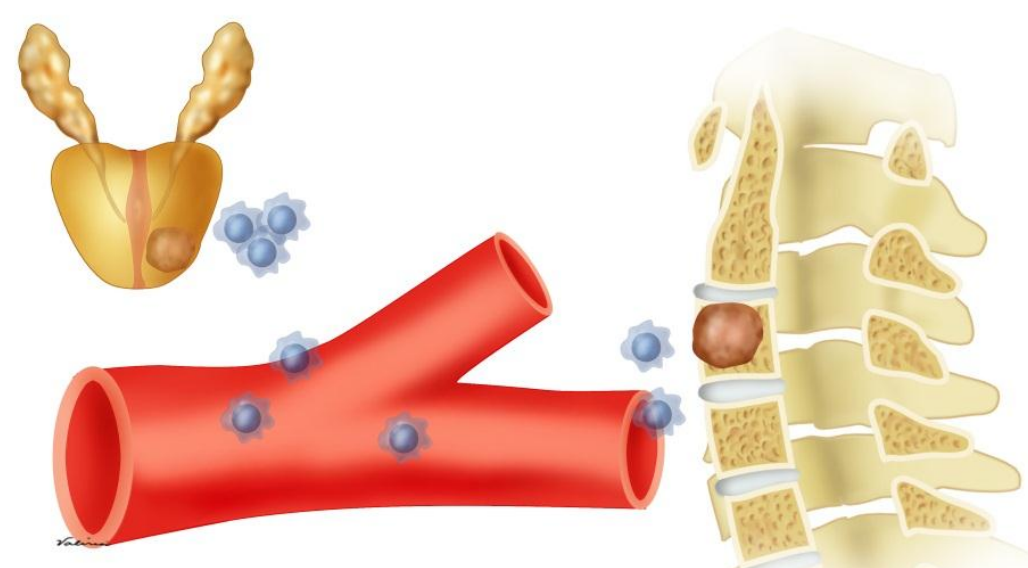

Figura 2. Papel das MMP no Câncer: MMP contribuem em várias etapas no processo carcinogênico, incluindo: o estabelecimento de um microambiente para o crescimento do tumor primário; em angiogênese tumoral e na habilidade de invasão e migração das células tumorais; na quebra da membrana basal de vasos sangüíneos permitindo a entrada ("intravasamento") e saída (extravasamento) de células tumorais; modificação do microambiente em sítios distantes, permitindo o estabelecimento, sustentação e crescimento de células tumorais.

\subsubsection{Justificativa}

Demonstramos recentemente que o polimorfismo R279Q no gene da MMP-9 está associado a um aumento no risco de desenvolvimento desta neoplasia (Dos Reis e cols, 2009). Por outro lado o polimorfismo $1306 \mathrm{C} / \mathrm{T}$ do gene da MMP-2 associou-se a tumores não órgão-confinados e de alto grau de Gleason (Dos Reis e cols, 2008).

Sabendo que os polimorfismos genéticos são capazes de alterar a expressão gênica, nosso objetivo foi avaliarmos pela técnica de qRT-PCR os níveis de expressão dos genes das MMP pertencentes ao grupo das 
gelatinases, MMP-2 e MMP-9, bem como outros sabidamente envolvidos em suas vias de ativação e inibição e sua relação com os fatores prognósticos e evolução clínica do câncer localizado de próstata (figura 3).

Ativação de MMP9 e MMP2

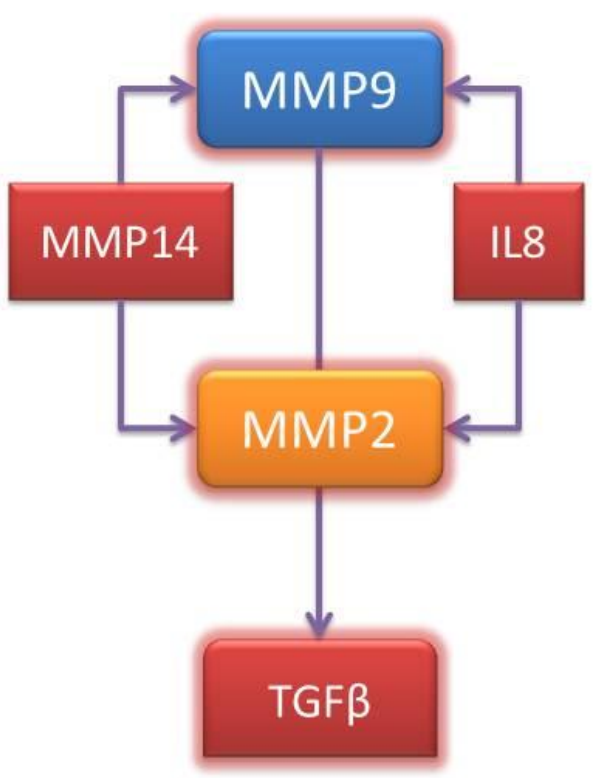

Inibição de MMP9 e MMP2

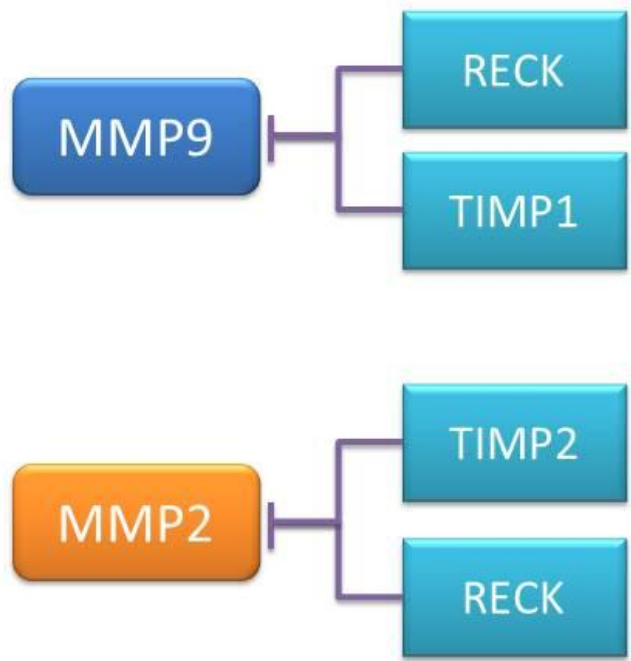

Figura 3. Genes envolvidos nas vias de indução e inibição dos genes das MMP-2 e MMP-9. Onde na ativação a MMP-14 e IL-8 ativam MMP-9, mas principalmente MMP-2. A MMP-9, ativa TGF- $\beta$. Na inibição TIMP2 e RECK 
2. Objetivos 


\section{Objetivos}

\section{Objetivo primário}

Avaliar a expressão dos genes e proteínas das MMP-2, MMP-9 e de seus reguladores MMP-14, RECK, TIMP-1, TIMP-2, TGF- $\beta$ e IL-8 no câncer de próstata localizado.

\section{Objetivos secundários}

Comparar os perfis de expressão dos genes e proteínas das MMP e de seus reguladores com os fatores prognósticos clássicos do carcinoma de próstata, grau histológico de Gleason e estágio patológico e com a evolução da neoplasia avaliando a recidiva bioquímica. 
3. Material e Métodos 


\subsection{Pacientes}

O estudo consistiu na análise de espécimes cirúrgicos de 79 pacientes com diagnóstico de CaP clinicamente localizado submetidos à prostatectomia radical entre setembro de 1997 e fevereiro de 2000 no Hospital Sírio Libanês pela equipe do Prof. Dr. Miguel Srougi. Os genes descritos foram avaliados através da técnica de reação em cadeia da polimerase quantitativa em tempo real (qRT-PCR).

Os pacientes foram subdivididos em grupos de acordo com as características clínico-patológicas. Foram analisados o grau histológico de Gleason que foi dividido como de Gleason $<7$ e Gleason $\geq 7$, o estágio patológico que foi classificado como tumores órgão-confinados (pT2) e não órgão-confinados (pT3), e os níveis séricos de PSA pré operatório, $P S A \leq 10 \mathrm{ng} / \mathrm{mL}$ e $P S A>10 \mathrm{ng} / \mathrm{mL}$. Também avaliamos a evolução dos pacientes considerando a recidiva bioquímica com índices de PSA superiores a 0,2 ng/mL com acompanhamento médio de 92,5 meses.

Os dados demográficos dos pacientes e dos controles estão expostos na tabela 1. Tanto o grupo de casos como o grupo controle, procedem de centros de referência no tratamento do câncer urológico no Brasil. 
Tabela 1. Dados demográficos dos pacientes com CaP e do grupo controle

\begin{tabular}{lcc} 
& $\begin{array}{c}\text { Casos de CaP } \\
(\mathbf{N}=79)\end{array}$ & $\begin{array}{c}\text { Controles HPB } \\
(\mathrm{N}=11)\end{array}$ \\
Idade (anos) & 63,2 & 67,8 \\
Média & 64 & 68 \\
Mediana & $41-79$ & $60-77$ \\
Variação & & \\
PSA (ng/mL) & & \\
Média & 10,4 & 7,3 \\
Mediana & 9,0 & 8,0 \\
Variação & $2,0-37,0$ & \\
$<$ 10 N(\%) & $47(59,5)$ & \\
$\geq 10$ N(\%) & $32(40,5)$ & \\
Estágio patológico (TNM 2010) & & \\
pT2 N(\%) & $38(48,1)$ & \\
pT3 N(\%) & $41(51,9)$ & \\
Escore de Gleason & & \\
Média & 6,8 & \\
Mediana & 7,0 & \\
Variação & $4-9$ & \\
$\leq 6$ N(\%) & $33(41,8)$ & \\
$\geq 7$ N(\%) & $46(58,2)$ & \\
\hline
\end{tabular}




\section{2 Ética}

Todas as amostras utilizadas neste estudo foram codificadas, garantindo sua confidencialidade. Este projeto foi submetido ao comitê de ética em pesquisas do HCFMUSP, tendo sido aprovado na reunião de 16/07/2008 (protocolo $\left.\mathrm{n}^{0} 0453 / 08\right)$.

\subsection{Processamento da amostra}

Dez cortes de $10 \mu \mathrm{m}$ dos tecidos tumorais e controles foram feitos em criostato, com temperatura de $-20^{\circ} \mathrm{C}$, e acondicionados em microtubos de $1,5 \mathrm{~mL}$, autoclavados, sendo tomados todos os cuidados para evitar a contaminação entre as amostras ou degradação do RNA. Foram mantidos a $80^{\circ} \mathrm{C}$ até o momento do processamento. Um dos cortes foi colocado em lâmina, fixado em formalina 10\%, corado pela hematoxilina e eosina e examinado ao microscópio para comprovação da existência de tumor com a porcentagem mínima de 75\% nos casos de câncer, e ausência de tumor nos casos de HPB.

\subsection{Extração de RNA}

Ao tecido cortado foi adicionado 10x o seu volume de solução de lise e igual volume de etanol $64 \%$. Repassamos a solução para uma coluna GFX, e centrifugamos a $10.000 \mathrm{~g}$ por 1 minuto. À coluna adicionamos $700 \mu \mathrm{l}$ de uma solução de lavagem própria do Kit. Centrifugamos novamente nas mesmas condições e fizemos duas lavagens com $500 \mu$ l de outra solução de lavagem do 
Kit. Descartamos o filtrado, centrifugamos por mais $1 \mathrm{~min}$ a $10.000 \mathrm{~g}$ para secagem da coluna, repassamos a coluna para um novo tubo e adicionamos $50 \mu l$ de solução de eluição pré aquecida no centro da coluna. Após 1 min a temperatura ambiente, centrifugamos a coluna e o RNA foi armazenado a $-80^{\circ} \mathrm{C}$ até sua utilização.

A pureza e concentração do RNA foram mensuradas em espectrofotômetro (260/280 nM). E a integridade verificada em Agilent 2100 Bioanalyzer (Agilent technologies, CA, USA).

\subsection{Síntese de cDNA}

A síntese do cDNA foi realizada a partir de $5 \mu \mathrm{g}$ de RNA utilizando-se o Kit High-Capacity cDNA Reverse Transcription (Applied Biosystems) o qual utiliza a Transcriptase reversa MultiScribe ${ }^{\mathrm{TM}}$ e primers randômicos.

O RNA total foi diluído em $\mathrm{H}_{2} \mathrm{O}$ livre de nucleases em um volume final de $20 \mu \mathrm{L}$. A este volume foram acrescentados $4 \mu \mathrm{L}$ de oligonucleotídeos randômicos (10X), $1,6 \mu \mathrm{L}$ do mix de dNTPs (25X), $4 \mu \mathrm{L}$ do tampão da enzima (10X), $2 \mu \mathrm{L}$ $(50 \mathrm{U} / \mu \mathrm{l})$ da enzima transcriptase reversa e $8,4 \mu \mathrm{l}$ de água nuclease free. A solução foi então submetida a ciclos de temperaturas $\left(25^{\circ} \mathrm{C}\right.$ por $10 \mathrm{~min}, 37^{\circ} \mathrm{C}$ por $120 \mathrm{~min}$ e $85^{\circ} \mathrm{C}$ por $5 \mathrm{~min}$ ) em um termociclador Veridi (Applied Biosystems). Ao final da reação o cDNA foi armazenado a $-20^{\circ} \mathrm{C}$ até o uso. 


\section{6 qRT-PCR}

A expressão dos genes estudados foi avaliada a partir do cDNA utilizando a metodologia de transcrição reversa seguida de reação em cadeia da polimerase quantitativa em tempo real (qRT-PCR) (plataforma Abi7500) utilizando-se o protocolo TaqMan® (Applied Biosystems). Este protocolo utiliza dois iniciadores não fluorescentes e uma sonda com dupla marcação que se anela à região localizada entre os iniciadores. Esta marcação dupla é formada por um fluoróforo que emite luz quando excitado e um quencher que absorve a luz emitida pelo fluoróforo. Durante os ciclos da PCR, a sonda é quebrada pela Taq polimerase na etapa de extensão do iniciador anelado. Esta quebra da sonda elimina a absorção pelo quencher da fluorescência emitida que pode ser então medida através de uma câmera situada na parte superior do equipamento. A quantificação da emissão absorvida pela câmera após quebra da sonda permite a quantificação indireta do RNA alvo contido na reação após cada ciclo da PCR (figura 4).

Experimentos iniciais de quantificação absoluta com o gene controle $\beta 2$ microglobulina (B2M) validaram o cDNA antes da realização dos experimentos de quantificação do gene de interesse. Para quantificação relativa dos genes em estudo normalizamos a expressão destes em relação à expressão do gene controle B2M. A tabela 2 descreve os genes estudados. Como grupo controle, estudamos onze amostras de tecido prostático benigno, provenientes de glândulas hiperplásicas de pacientes submetidos a prostatectomia retropúbica. 
Tabela 2. Primers utilizados para quantificação da expressão dos genes MMP-2 e MMP-9 e seus reguladores no câncer de próstata.

\begin{tabular}{cc} 
Gene & Ensaio \\
MMP-2 & Hs00234422_m1 \\
MMP-9 & Hs00957562_m1 \\
TIMP-1 & Hs00212624_m1 \\
TIMP-2 & Hs00234278_m1 \\
MMP-14 & Hs00237119_m1 \\
RECK & Hs01019179_m1 \\
IL-8 & HS99999034_m1 \\
TGF- $\beta$ & Hs00852894_m1 \\
B2M & Hs99999907_m1 \\
\hline
\end{tabular}

Para amplificação dos fragmentos desejados utilizamos as seguintes condições de reação: 5,0 $\mu \mathrm{l}$ do master mix taqman, $0,5 \mu \mathrm{l}$ de primer (contendo a sonda marcada) (tabela 2), 3,5 $\mu \mathrm{l}$ de água destilada deionizada e 1,0 $\mu \mathrm{l}$ de cDNA, somando um total de $10 \mu \mathrm{l}$ para cada reação. A condição usual de programação dos ciclos foi um passo a $50^{\circ} \mathrm{C}$ por dois minutos, um passo a $94^{\circ} \mathrm{C}$ por 10 minutos seguidos de 40 ciclos de $95^{\circ} \mathrm{C}$ por 30 segundos e $60^{\circ} \mathrm{C}$ por 60 segundos.

Para calcular a expressão relativa dos oito genes alvo foi utilizado o método $\Delta \Delta \mathrm{C}_{\mathrm{T}}$, que utiliza a seguinte fórmula: $\Delta \Delta \mathrm{C}_{\mathrm{T}}=\left(\mathrm{C}_{\mathrm{T}}\right.$ do gene alvo, amostra de Cap $-\mathrm{C}_{\mathrm{T}}$ do controle endógeno, amostra de $\left.\mathrm{CaP}\right)-\left(\mathrm{C}_{\mathrm{T}}\right.$ do gene alvo, 
amostra de HPB $-\mathrm{C}_{\mathrm{T}}$ do controle endógeno, amostra de HPB). O número de vezes que ocorre a mudança da expressão gênica é calculado como $2^{-\Delta \Delta C T}$ (Livak et al., 2001).

\subsection{Microarranjo tecidual}

A expressão das MMP e seus reguladores foi avaliada através de IHQ pela técnica de microarranjo tecidual ou "tissue microarray" (TMA) com espécimes de quarenta pacientes desse pool inicial de 79 que analisamos 0 RNA, a expressão das proteínas foi verificada por imuno-histoquímica (IHQ). A tabela 3 descreve os anticorpos utilizados bem como suas diluições.

Tabela 3. Anticorpos utilizados para análise da expressão proteica de MMP-2 e MMP-9 e seus reguladores no câncer de próstata.

\begin{tabular}{ccc} 
Anticorpo & Fabricante & Diluição \\
MMP-9 & ABnova & $1: 10$ \\
MMP-2 & Abcam & $1: 100$ \\
TIMP-1 & Abcam & $1: 100$ \\
TIMP-2 & Abcam & $1: 100$ \\
MMP-14 & Abcam & $1: 100$ \\
IL-8 & Abcam & $1: 100$ \\
TGF- $\beta$ & Abcam & $1: 100$ \\
\hline
\end{tabular}


O TMA é uma coleção organizada de amostras teciduais dispostas sob a forma de uma matriz, onde cada amostra é suficientemente grande para ser representativa, e convenientemente pequena para permitir o uso não predatório do bloco doador, permitindo utilização racional dos reagentes a serem aplicados na amostra em condições experimentais homogêneas. A principal vantagem do TMA reside na análise simultânea de vários cortes histológicos arranjados em apenas uma lâmina.

O primeiro passo da confecção do TMA é a separação dos blocos de parafina contendo o $\mathrm{CaP}$ e sua respectiva lâmina corada em hematoxilinaeosina. A lâmina é analisada em microscópio óptico para localização e marcação da área representativa do tumor a ser amostrada. Por justaposição da lâmina com o respectivo bloco, marca-se neste último a área de interesse (bloco doador).

A seguir, emprega-se aparelho específico que através de agulha coleta pequena amostra de tecido da área marcada do bloco de parafina doador e o insere no bloco receptor. Em nosso estudo empregamos um sistema mecanizado de precisão da marca Beecher que coleta cilindros de $1 \mathrm{~mm}$ de diâmetro e os insere no bloco receptor em intervalos de 0,3mm.

A realização de reações de IH em lâminas com TMA permite a avaliação da expressão de uma proteína em inúmeros casos em uma única reação, o que 
confere homogeneidade a avaliação, uma vez que todos os espécimes foram preparados e avaliados em condição idêntica.

\subsection{Imuno-histoquímica}

As amostras foram submetidas à recuperação antigênica pelo calor utilizando tampão citrato ( $1 \mathrm{mM}, \mathrm{pH} 6,0)$ e aquecidas por 30 minutos em panela de pressão elétrica. As lâminas foram incubadas por uma noite a $4^{\circ} \mathrm{C}$, com os anticorpos monoclonais especificados na Tabela 2. O sistema LSAB foi utilizado para a imunocoloração (LSAB; Dako Cytomation, CA, E.U.A.). A coloração foi desenvolvida por uma solução substrato-cromógena 3,3'-diaminobenzidina, seguida por contracoloração com hematoxilina de Harris. As lâminas foram desidratadas, montadas com lamínulas e observadas em microscópio óptico.

A expressão de cada anticorpo foi avaliada pela mesma patologista Dra. Katia R. M. Leite. A análise foi semiquantitativa sendo que a expressão das MMP e seus reguladores foi considerada como positiva ou negativa.

\subsection{Análise Estatística}

As variáveis quantitativas foram resumidas através da mediana, variação inter-quartil (Q1-Q3) e valores de mínimo e máximo. Já as variáveis qualitativas foram expressas através do número e porcentagem.

Para análise dos níveis de expressão dos oito genes de acordo com o estádio patológico, escore de Gleason, e PSA pré operatório foi utilizado o teste de Mann-Whitney. Curvas de Kaplan-Meier foram realizadas para ilustrar a 
sobrevida livre de doença e o teste log-rank para mostrar as diferenças entre as curvas.

Para análise estatística foi utilizado o software SPSS 19.0. Em toda análise estatística foi adotado um nível de significância de $5 \%$, ou seja, foram considerados como estatisticamente significantes os resultados que apresentaram $p$-valor inferior a $5 \%(p<0,05)$. 


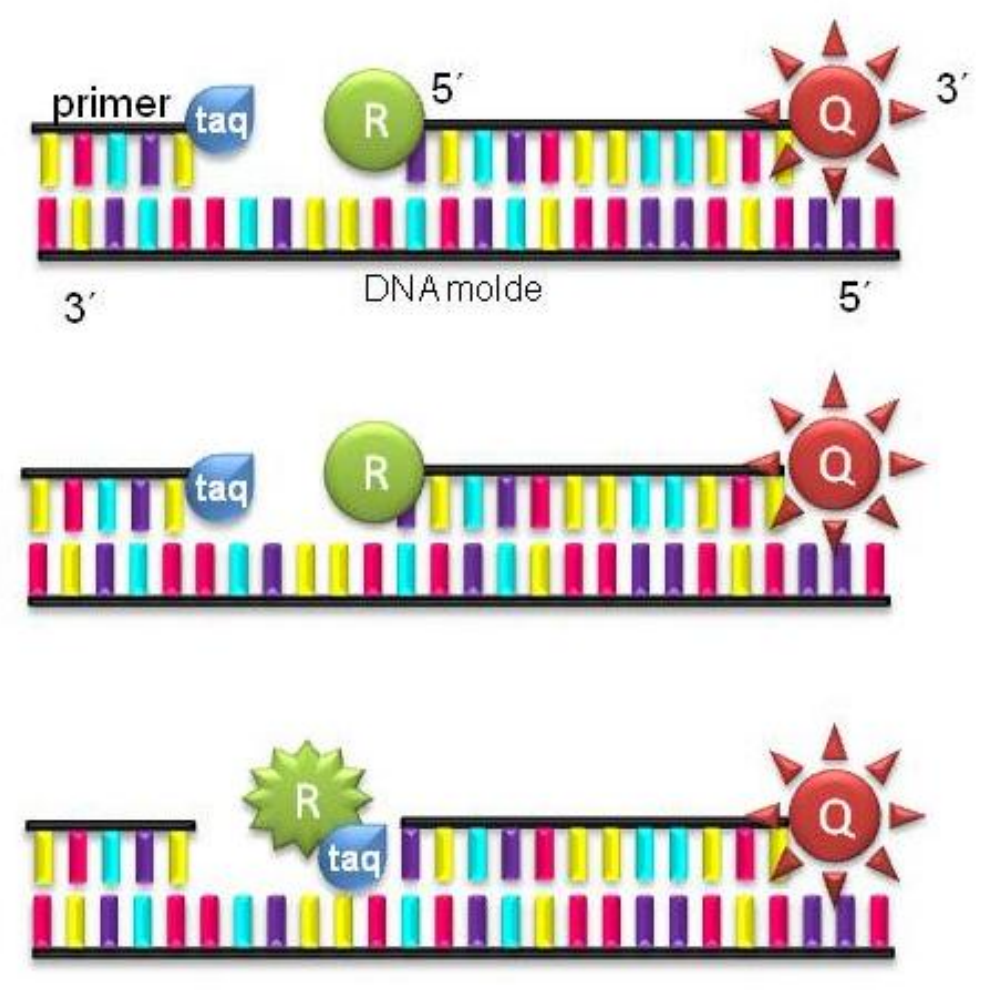

Figura 4. Sistema TaqMan®: Este protocolo utiliza dois iniciadores não fluorescentes e uma sonda com dupla marcação que se anela à região localizada entre os iniciadores. Esta marcação dupla é formada por um fluoróforo que emite luz quando excitado e um quencher que absorve a luz emitida pelo fluoróforo. Durante os ciclos da PCR, a sonda é quebrada pela Taq polimerase na etapa de extensão do iniciador anelado. Esta quebra da sonda elimina a absorção pelo quencher da fluorescência emitida que pode ser então medida através de uma câmera situada na parte superior do equipamento. A quantificação da emissão absorvida pela câmera após quebra da sonda permite então a detecção do produto do PCR em tempo Real. 
4. Resultados 


\section{Resultados}

A análise dos oitos genes através do método de qRT-PCR no tecido maligno demonstrou que a MMP-9 está superexpressa e MMP-2, TIMP-1, TIMP-2, MMP-14, IL-8, TGF- $\beta$ e RECK estavam subexpressos em tecido malignos da próstata, em comparação a HPB (figura 5) (tabela 4). A superexpressão de MMP-9 ocorreu em $82,3 \%$ dos casos, se tratando da diferença mais significante encontrada.

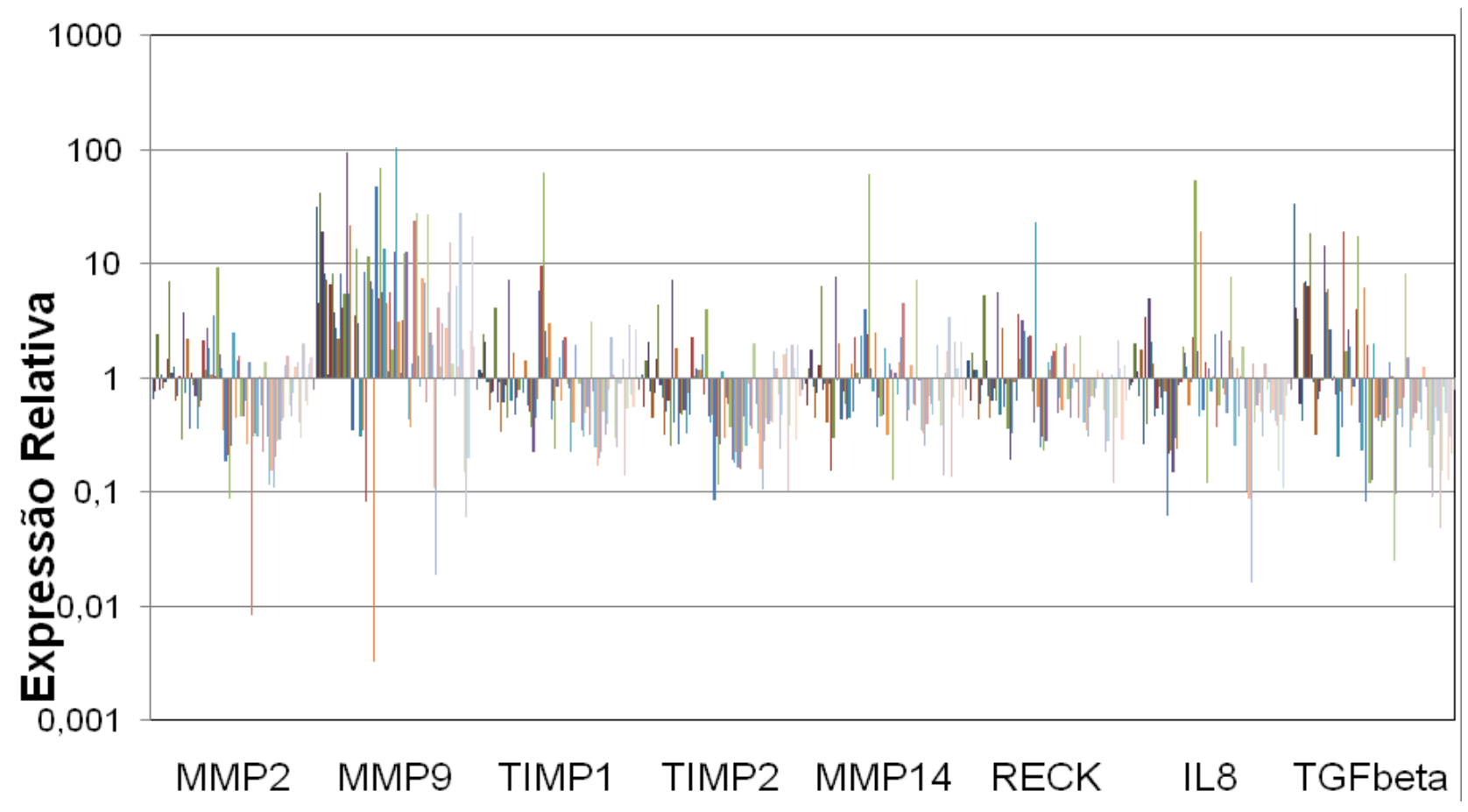

Figura 5. Perfil da expressão dos 8 genes em 79 pacientes com câncer de próstata 
Tabela 4. Média de expressão dos genes estudados nos 79 pacientes com $\mathrm{CaP}$, comparados com 11 pacientes com HPB utilizados como controle.

$\begin{array}{lcccccccc} & \text { MMP-2 } & \text { MMP-9 } & \text { TIMP-1 } & \text { TIMP-2 } & \text { MMP-14 } & \text { RECK } & \text { IL-8 } & \text { TGF- } \beta \\ \text { Média } & 1,10 & 9,23 & 2,00 & 0,88 & 2,03 & 1,39 & 1,92 & 2,57 \\ \text { Mediana } & 0,69 & 4,12 & 0,75 & 0,48 & 0,83 & 0,80 & 0,71 & 0,61 \\ \text { Superexpressão } & 40,0 \% & 82,3 \% & 30,0 \% & 27,8 \% & 38,0 \% & 35,4 \% & 34,2 \% & 33,0 \% \\ \text { Subexpressão } & 60,0 \% & 17,7 \% & 70,0 \% & 72,2 \% & 62,0 \% & 64,6 \% & 65,8 \% & 67,0 \%\end{array}$

\subsection{Expressão dos genes das metaloproteinases e de seus reguladores e a graduação histológica de Gleason}

A análise da expressão dos 8 genes de acordo com os fatores prognósticos clássicos do CaP está demonstrada na tabela 5. Observamos que a maior expressão dos genes MMP-2, TIMP-2 e TGF- $\beta$ relacionou-se com maior escore de Gleason.

MMP-2 mesmo mantendo-se subexpresso, teve uma expressão maior entre os pacientes que apresentavam Gleason $\geq 7$ (mediana 0,84) quando comparado com aqueles que apresentavam Gleason $<7$ (mediana 0,520) $(p=0,04)$. O gene TIMP-2 também apresentou uma mediana de expressão maior entre os pacientes que apresentavam Gleason $\geq 7$ (mediana 0,59) quando comparado com aqueles que apresentavam Gleason $<7$ (mediana 0,39) 
$(p=0,021)$. $O$ gene de TGF- $\beta$ também mostrou uma relação com um fator de mau prognóstico. A sua expressão foi de 0,94 nos casos com Gleason $\geq 7$ versus 0,46 nos casos com Gleason $<7(p=0,006)$.

Os genes da MMP-14 e RECK, também apresentaram uma expressão maior entre os pacientes que apresentavam Gleason $\geq 7$ (medianas: 0,$89 ; 0,92$ respectivamente) quando comparados com aqueles que apresentavam Gleason $<7 \quad(0,66 ; 0,66$ respectivamente), entretanto nestes dois genes a diferença encontrada foi apenas marginal do ponto de vista estatístico $(p=0,081$; $\mathrm{p}=0,068$ respectivamente).

\subsection{Expressão dos genes das metaloproteinases e de seus reguladores e o estágio tumoral}

De acordo com estadiamento patológico não encontramos nenhuma diferença estatística significante quando comparamos a expressão dos genes MMP-2, MMP-9 e seus reguladores TIMP-1, TIMP-2, RECK, MMP-14, IL-8 e TGF- $\beta$ entre os pacientes que apresentavam tumores órgão confinado (pT2) e aqueles que apresentavam tumor não órgão-confinado (pT3).

\subsection{Expressão dos genes das metaloproteinases e de seus reguladores e o nível pré-operatório de PSA}


De acordo com o valor de PSA pré-operatório, encontramos diferenças estatísticas apenas no gene da MMP-9. Pacientes que apresentavam um PSA pré-operatório $\geq 10 \mathrm{ng} / \mathrm{mL}$ possuíam uma mediana de expressão de 5,62 enquanto aqueles que possuíam um PSA pré-operatório $<10 \mathrm{ng} / \mathrm{mL}$ possuíam uma mediana de expressão de $2,76(p=0,033)$.

Tabela 5. Expressão dos oito genes de acordo com o escore de Gleason, estadiamento patológico e valor de PSA pré operatório.

\begin{tabular}{|c|c|c|c|c|c|c|c|c|c|}
\hline \multirow[b]{2}{*}{ Genes } & \multicolumn{3}{|c|}{$\begin{array}{c}\text { Gleason } \\
\text { Mediana (Q1-Q3) }\end{array}$} & \multicolumn{3}{|c|}{$\begin{array}{l}\text { Estágio Patológico } \\
\text { Mediana (Q1-Q3) }\end{array}$} & \multicolumn{3}{|c|}{$\begin{array}{c}\text { PSA } \\
\text { Mediana (Q1-Q3) }\end{array}$} \\
\hline & $<7(\mathrm{n}=32)$ & $\geq 7(n=46)$ & $p$ & pT2 (n=37) & pT3 $(n=40)$ & $p$ & $<10(n=45)$ & $\geq 10(n=33)$ & $p$ \\
\hline MMP-2 & $\begin{array}{c}0,52 \\
(0,30-1,04)\end{array}$ & $\begin{array}{c}0,84 \\
(0,38-1,45)\end{array}$ & 0,048 & $\begin{array}{c}0,74 \\
(0,35-1,33)\end{array}$ & $\begin{array}{c}0,63 \\
(0,31-1,28)\end{array}$ & 0,510 & $\begin{array}{c}0,66 \\
(0,35-1,27)\end{array}$ & $\begin{array}{c}0,69 \\
(0,30-1,34)\end{array}$ & 0,831 \\
\hline MMP-9 & $\begin{array}{c}3,64 \\
(1,04-8,02)\end{array}$ & $\begin{array}{c}4,20 \\
(1,36-9,92)\end{array}$ & 0,410 & $\begin{array}{c}4,94 \\
(1,30-12,8)\end{array}$ & $\begin{array}{c}2,67 \\
(1,13-6,76)\end{array}$ & 0,134 & $\begin{array}{c}2,76 \\
(0,97-7,04)\end{array}$ & $\begin{array}{c}5,62 \\
(2,27-13,1)\end{array}$ & 0,033 \\
\hline TIMP-1 & $\begin{array}{c}0,64 \\
(0,31-0,98)\end{array}$ & $\begin{array}{c}0,75 \\
(0,49-1,46)\end{array}$ & 0,308 & $\begin{array}{c}0,84 \\
(0,35-2,01)\end{array}$ & $\begin{array}{c}0,72 \\
(0,48-1,00)\end{array}$ & 0,585 & $\begin{array}{c}0,75 \\
(0,37-1,11)\end{array}$ & $\begin{array}{c}0,71 \\
(0,45-1,50)\end{array}$ & 0,448 \\
\hline TIMP-2 & $\begin{array}{c}0,39 \\
(0,24-0,71)\end{array}$ & $\begin{array}{c}0,59 \\
(0,39-1,22)\end{array}$ & 0,021 & $\begin{array}{c}0,49 \\
(0,25-1,23)\end{array}$ & $\begin{array}{c}0,47 \\
(0,32-0,74)\end{array}$ & 0,955 & $\begin{array}{c}0,48 \\
(0,28-0,88)\end{array}$ & $\begin{array}{c}0,48 \\
(0,32-1,20)\end{array}$ & 0,738 \\
\hline MMP-14 & $\begin{array}{c}0,66 \\
(0,38-1,22)\end{array}$ & $\begin{array}{c}0,89 \\
(0,52-1,69)\end{array}$ & 0,081 & $\begin{array}{c}0,89 \\
(0,50-1,75)\end{array}$ & $\begin{array}{c}0,69 \\
(0,44-1,32)\end{array}$ & 0,332 & $\begin{array}{c}0,78 \\
(0,45-1,30)\end{array}$ & $\begin{array}{c}0,89 \\
(0,46-2,08)\end{array}$ & 0,616 \\
\hline RECK & $\begin{array}{c}0,66 \\
(0,44-1,05)\end{array}$ & $\begin{array}{c}0,92 \\
(0,50-1,86)\end{array}$ & 0,068 & $\begin{array}{c}0,89 \\
(0,52-1,56)\end{array}$ & $\begin{array}{c}0,64 \\
(0,44-1,20)\end{array}$ & 0,262 & $\begin{array}{c}0,80 \\
(0,45-1,18)\end{array}$ & $\begin{array}{c}0,81 \\
(0,46-2,09)\end{array}$ & 0,418 \\
\hline IL-8 & $\begin{array}{c}0,84 \\
(0,49-1,34)\end{array}$ & $\begin{array}{c}0,69 \\
(0,38-1,33)\end{array}$ & 0,274 & $\begin{array}{c}0,77 \\
(0,43-1,28)\end{array}$ & $\begin{array}{c}0,63 \\
(0,41-1,30)\end{array}$ & 0,537 & $\begin{array}{c}0,58 \\
(0,30-1,19)\end{array}$ & $\begin{array}{c}0,77 \\
(0,46-1,54)\end{array}$ & 0,195 \\
\hline TGF- $\beta$ & $\begin{array}{c}0,46(0,33- \\
0,64)\end{array}$ & $\begin{array}{c}0,94 \\
(0,42-3,40)\end{array}$ & 0,006 & $\begin{array}{c}0,66 \\
(0,43-2,64)\end{array}$ & $\begin{array}{c}0,49 \\
(0,27-1,12)\end{array}$ & 0,251 & $\begin{array}{c}0,55 \\
(0,36-1,12)\end{array}$ & $\begin{array}{c}0,67 \\
(0,33-3,30)\end{array}$ & 0,511 \\
\hline
\end{tabular}




\subsection{Expressão dos genes das metaloproteinases e de seus reguladores e a recidiva bioquímica}

De acordo com a recidiva bioquímica, os resultados estão expostos na tabela 6. Não encontramos diferenças estatísticas entre pacientes que apresentavam ou não recidiva bioquímica quanto a expressão dos 8 genes estudados. Porém o gene da MMP-9 apresentou uma diferença estatística marginal apresentando uma mediana de expressão de 6,29 nos pacientes que apresentavam recidiva bioquímica e 3,25 nos pacientes que não apresentavam recidiva bioquímica $(p=0,090)$.

Tabela 6. Expressão dos 8 genes de acordo com o recidiva bioquímica

\begin{tabular}{lccc} 
& \multicolumn{3}{c}{$\begin{array}{c}\text { Recidiva Bioquímica } \\
\text { Mediana (Q1-Q3) }\end{array}$} \\
MMP-2 & Sim $(\mathrm{n}=29)$ & Não $(\mathrm{n}=28)$ & p-valor \\
MMP-9 & $0,99(0,45-1,52)$ & $0,87(0,41-1,17)$ & 0,482 \\
TIMP-1 & $6,28(2,04-14,5)$ & $3,25(1,10-7,85)$ & $\mathbf{0 , 0 9 0}$ \\
TIMP-2 & $0,87(0,41-2,17)$ & $0,78(0,59-1,07)$ & 0,731 \\
MMP-14 & $0,59(0,30-1,65)$ & $0,52(0,35-0,81)$ & 0,518 \\
RECK & $1,04(0,46-2,20)$ & $0,88(0,55-1,23)$ & 0,538 \\
IL-8 & $1,04(0,50-2,16)$ & $0,69(0,40-1,42)$ & 0,201 \\
TGF- $\boldsymbol{\beta}$ & $0,91(0,46-1,35)$ & $0,53(0,28-1,05)$ & 0,148 \\
\hline
\end{tabular}


Foram construídas curvas de sobrevida livre de recidiva (Kaplan-Meyer) para os genes estudados. A média de expressão foi estabelecida como ponto de corte. Não encontramos diferenças significativas no tempo médio de recidiva entre os pacientes considerados como tendo expressão forte dos genes e aqueles considerados como tendo expressão fraca (figura 6).
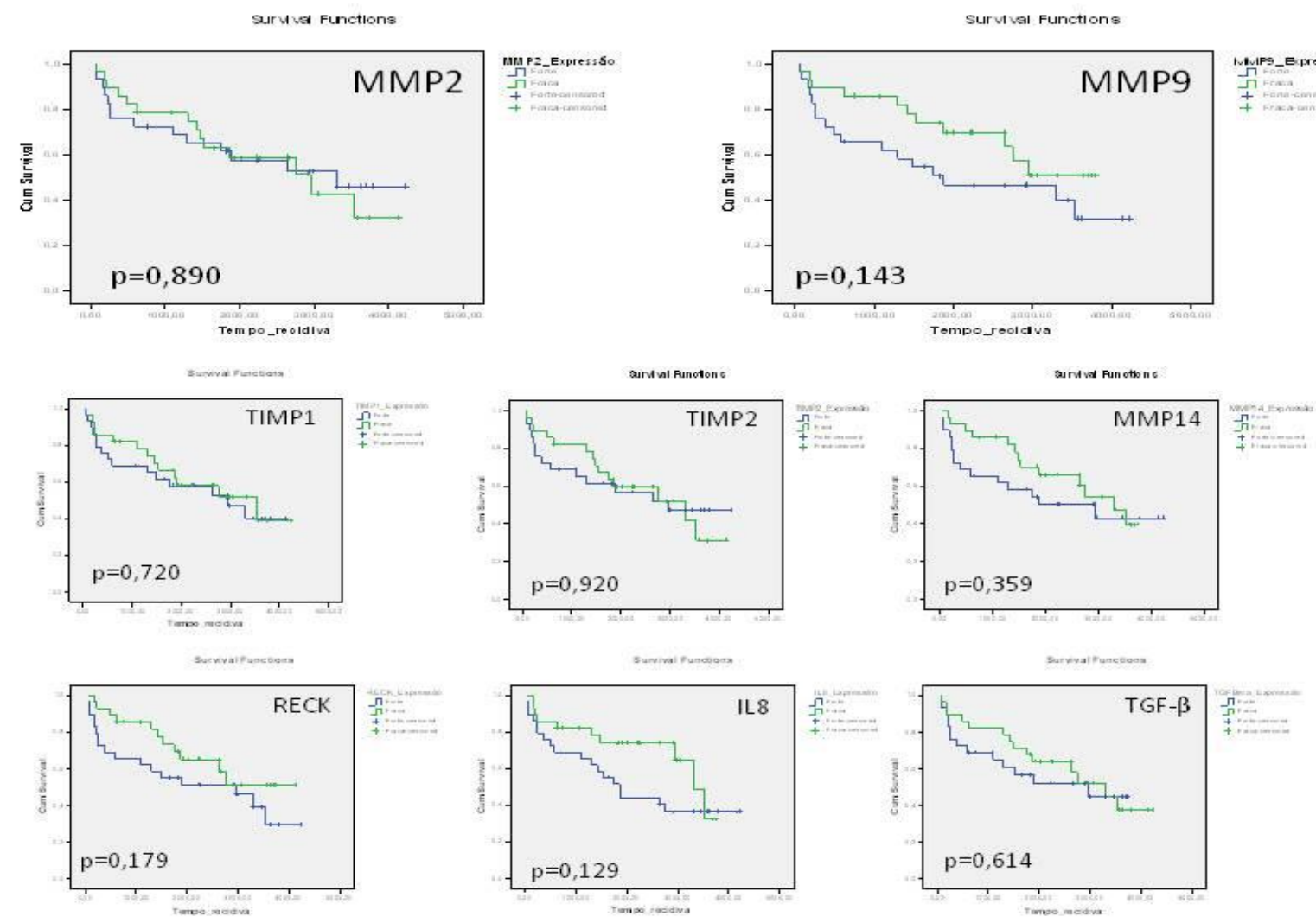

Figura 6. Curvas de sobrevida livre de recidiva de acordo com a expressão dos genes estudados 


\subsection{Expressão Proteica}

A análise das sete proteínas através do método de imuno-histoquímica no TMA demonstrou positividade de MMP-9 em 91,4\% dos casos e MMP-2 em $77,7 \%$ dos casos (Figura 7 ). A positividade de seus reguladores foi de $47,2 \%$, 0\%, 65,7\%, 63,9\% e 78,3\% para TIMP-1, TIMP-2, MMP-14, IL-8, TGF- $\beta$ (Tabela 7). RECK não foi estudado, pois não existe anticorpo comercialmente disponível.

Não houve diferença estatística quando correlacionamos os níveis de expressão gênica com os resultados imuno-histoquímicos (Tabela 8).

A expressão de MMP2 e MMP9 foi citoplasmática, regular e difusa. Raramente houve positividade nuclear de MMP9. MMP14 também mostrou positividade citoplasmática, porém de padrão granular fino. Em alguns casos houve expressão intersticial de MMP14 que quando isolada não foi considerada como positiva (Figura 8). 

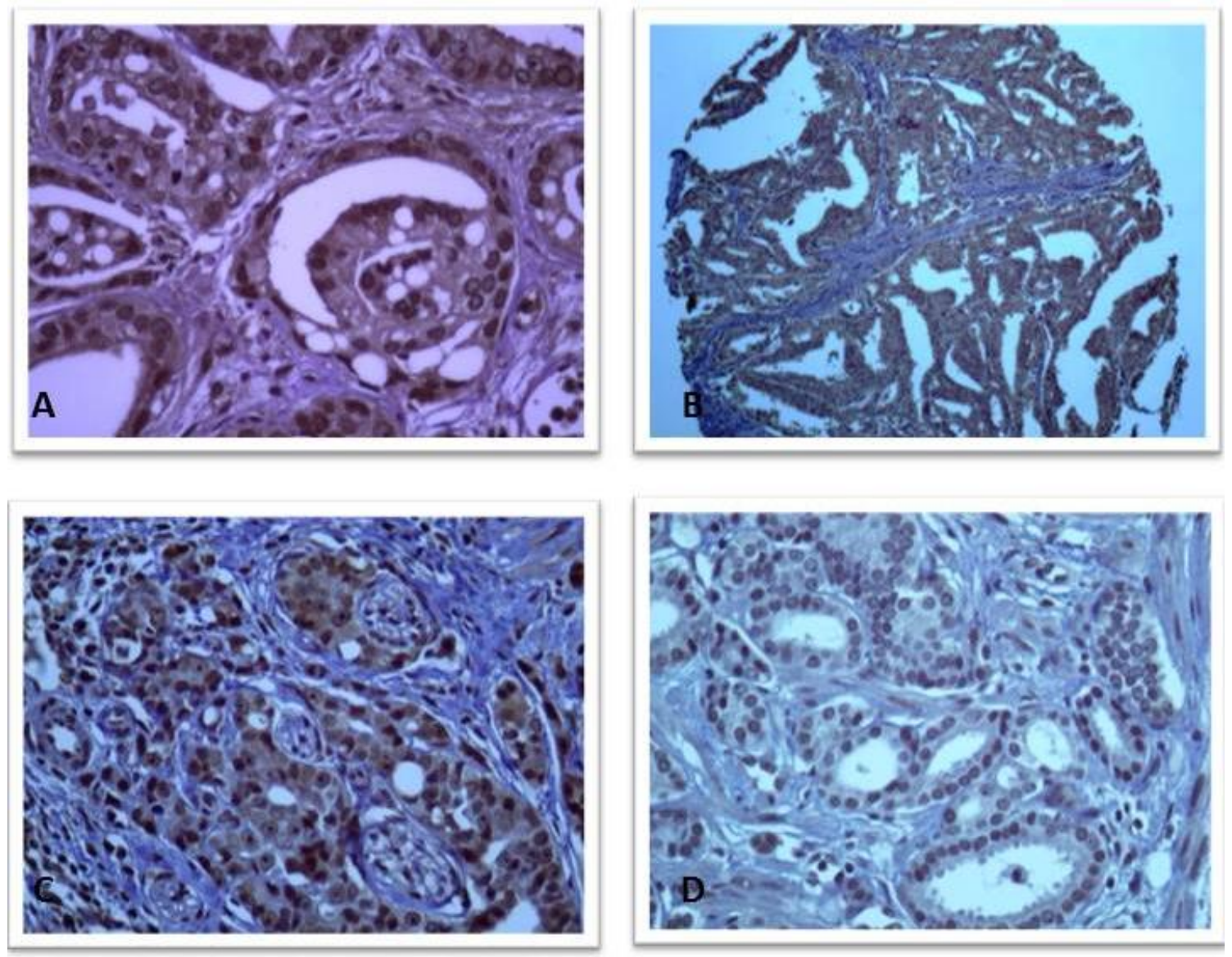

Figura 7. Fotomicrografia ilustrativa das reações imuno-histoquímicas. A e B exemplos de reação positiva de MMP9. C e D reação positiva e negativa de MMP2 respectivamente.
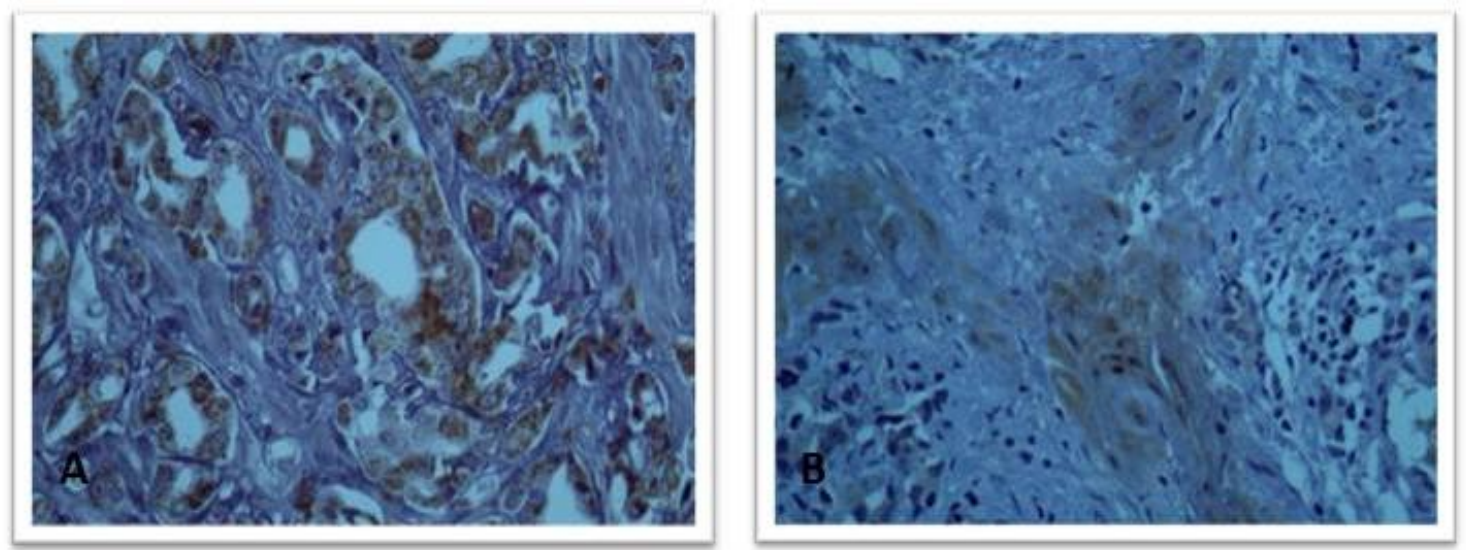

Figura 8. Fotomicrografia exemplificando a positividade citoplasmática, granular, fina de MMP14 (A) e a eventual positividade intersticial (B). 
A expressão de TIMP-1 e IL-8 também teve padrão granular fino intracitoplasmático (Figura 9). TGF- $\beta$ assemelhou-se a MMP-9 com positividade citoplasmática e eventual expressão nuclear (Figura 10). TIMP-2 foi negativa em todos os casos (Figura 11).
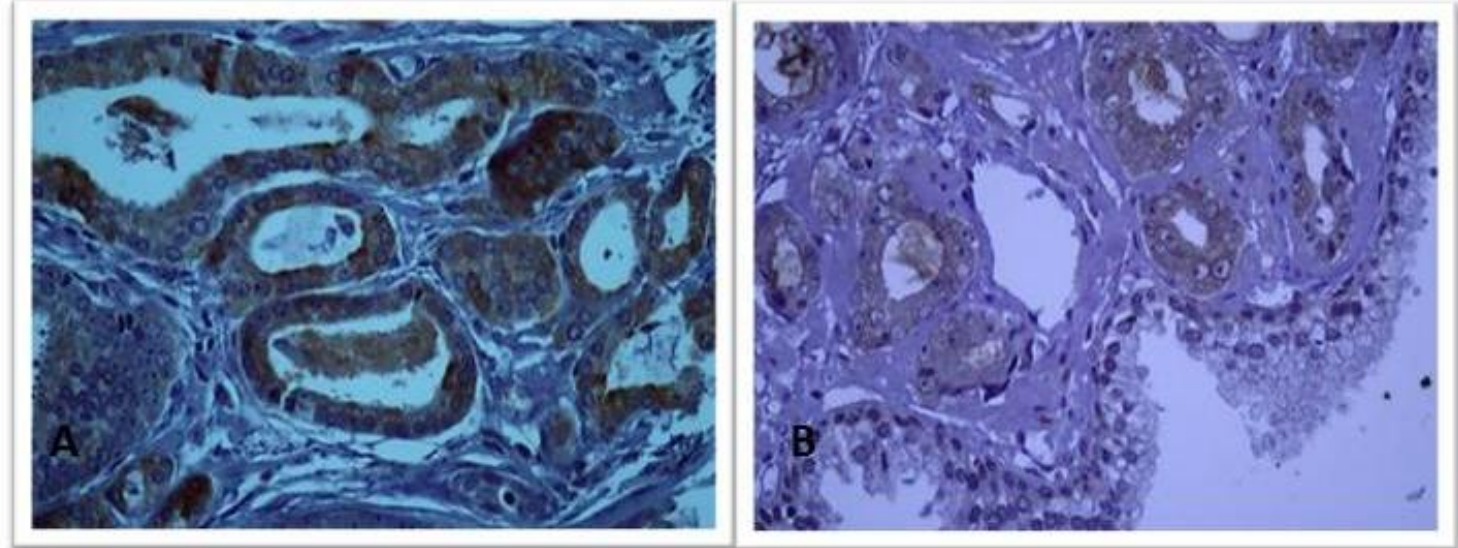

Figura 9. Fotomicrografia exemplificando a positividade granular citoplasmática de TIMP-1 (A) e IL-8 (B).
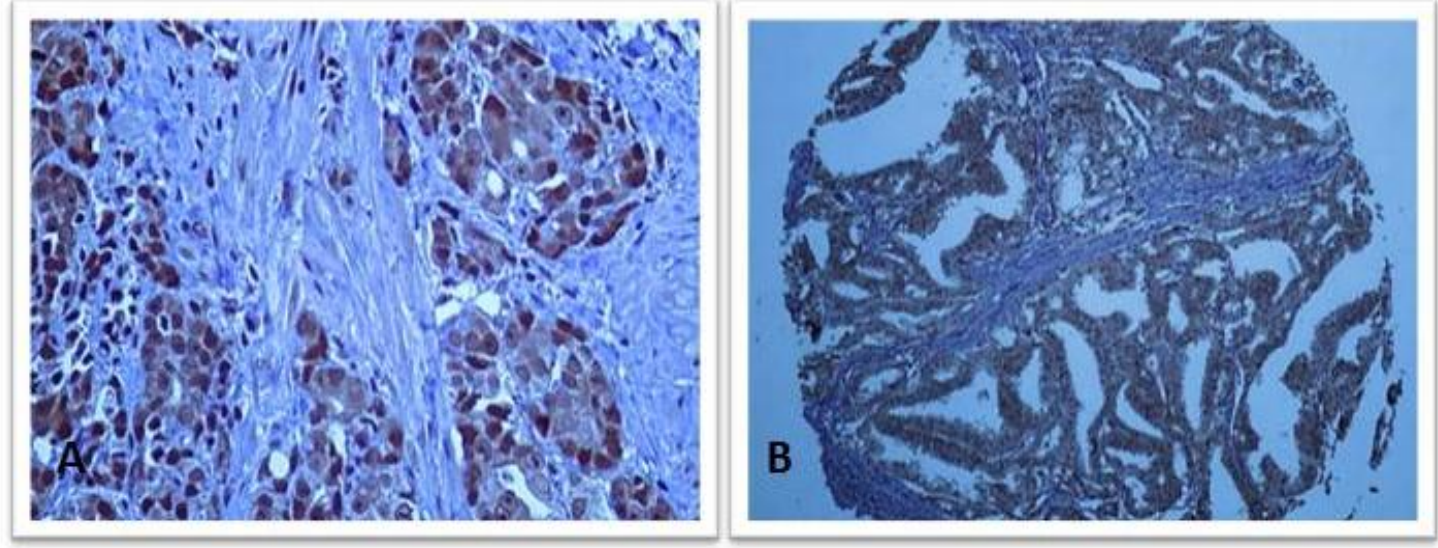

Figura 10. Fotomicrografia demonstrando a positividade citoplasmática e nuclear de TGF- $\beta$ ( $A$ e B). 

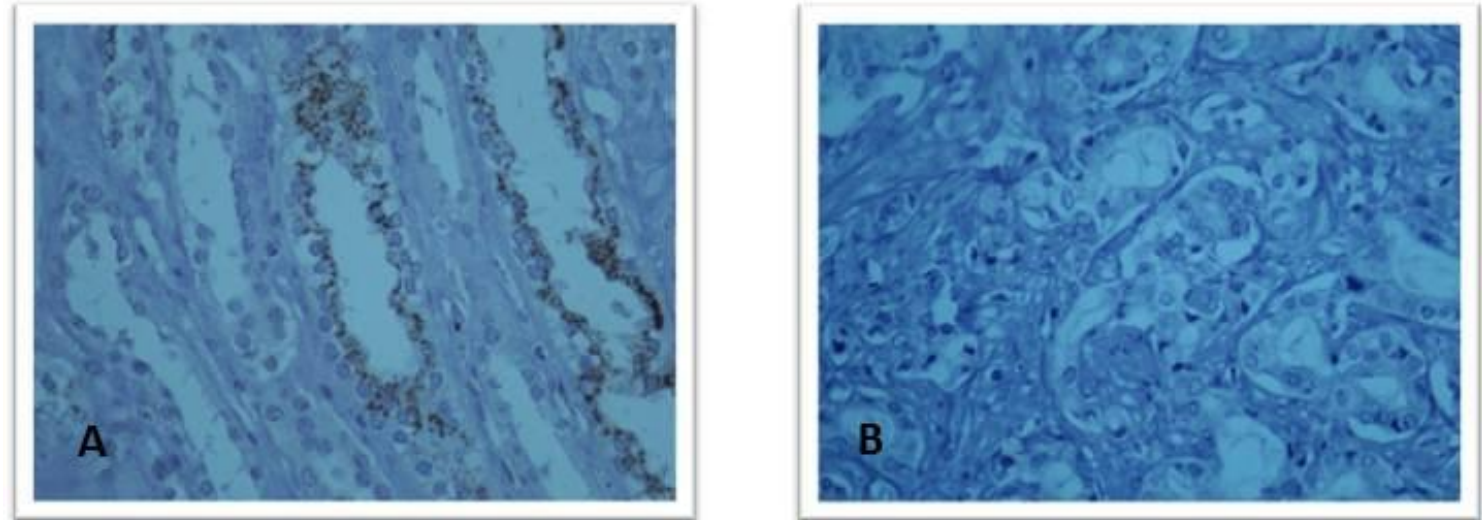

Figura 11. TIMP-2 foi negativa em todos os casos estudados. A figura demonstra o controle positivo presente dentro do TMA, caracterizado por tecido medular renal normal com positividade citoplasmática, granular nas células epiteliais tubulares (A) e a reação negativa no caso (B).

Tabela 7. Porcentagem de positividade por imuno-histoquímica das proteínas estudadas em 40 pacientes com CaP.

\begin{tabular}{llllllll}
$\begin{array}{l}\text { Reação } \\
\text { imuno-histoquímica }\end{array}$ & MMP-2 & MMP-9 & TIMP-1 & TIMP-2 & MMP-14 & IL-8 & TGF- $\beta$ \\
\hline Positiva & $77,7 \%$ & $91,4 \%$ & $47,2 \%$ & $0 \%$ & $65,7 \%$ & $63,9 \%$ & $78,3 \%$ \\
Negativa & $22,3 \%$ & $8,6 \%$ & $52,8 \%$ & $100 \%$ & $34,3 \%$ & $36,1 \%$ & $21,7 \%$ \\
\hline
\end{tabular}


Tabela 8. Expressão gênica em relação a positividade ou negatividade imunohistoquímica de 6 genes analisados.

\begin{tabular}{|lcccccc|}
\multicolumn{7}{c}{ Nível de expressão gênica } \\
& MMP2 & MMP9 & TIMP-1 & MMP-14 & IL-8 & TGF- $\beta$ \\
\hline Positivo & 0,71 & 3,99 & 0,78 & 0,77 & 0,67 & 0,53 \\
\hline Negativo & 0,56 & 1,15 & 0,56 & 0,36 & 0,76 & 0,77 \\
\hline$p$ & 0,86 & 0,57 & 0,17 & 0,90 & 0,57 & 0,31 \\
\hline
\end{tabular}

\subsection{Expressão das proteínas metaloproteinases e de seus reguladores e os fatores prognósticos do câncer de próstata}

A análise da expressão das proteínas de acordo com os fatores prognósticos clássicos do CaP, escore de Gleason, estadiamento patológico e PSA pré operatório, está demonstrada na tabela 9. Não encontramos diferenças estatísticas em relação a expressão de nenhuma das proteínas estudadas de acordo com essas variáveis prognósticas. A análise estatística da proteína TIMP2 não foi possível, pois esta apresentou-se ausente em 100\% dos casos. 
Tabela 9. Expressão das proteínas de acordo com o escore de Gleason, estadiamento patológico e valor de PSA.

\begin{tabular}{|c|c|c|c|c|c|c|c|c|c|}
\hline & \multicolumn{3}{|c|}{$\begin{array}{c}\text { Gleason } \\
\text { Mediana (Q1-Q3) }\end{array}$} & \multicolumn{3}{|c|}{$\begin{array}{c}\text { Estágio Patológico } \\
\text { Mediana (Q1-Q3) }\end{array}$} & \multicolumn{3}{|c|}{$\begin{array}{c}\text { PSA } \\
\text { Mediana (Q1-Q3) }\end{array}$} \\
\hline & $<7(\mathrm{n}=12)$ & $\geq 7(n=24)$ & $p$ & pT2 $(n=20)$ & pT3 $(n=14)$ & $p$ & $<10(n=18)$ & $\geq 10(n=18)$ & $p$ \\
\hline MMP-2 & & & 0,777 & & & 0,288 & & & 1,000 \\
\hline Negativa & $37,5 \%$ & $62,5 \%$ & & $75,0 \%$ & $25,0 \%$ & & $50,0 \%$ & $50,0 \%$ & \\
\hline Positiva & $32,1 \%$ & $67,9 \%$ & & $53,8 \%$ & $46,2 \%$ & & $50,0 \%$ & $50,0 \%$ & \\
\hline MMP-9 & & & 0,266 & & & 0,373 & & & 0,581 \\
\hline Negativa & $66,7 \%$ & $33,3 \%$ & & $33,3 \%$ & $66,7 \%$ & & $33,3 \%$ & $66,7 \%$ & \\
\hline Positiva & $31,3 \%$ & $68,8 \%$ & & $60,0 \%$ & $40,0 \%$ & & $50,0 \%$ & $50,0 \%$ & \\
\hline TIMP-1 & & & 0,637 & & & 0,409 & & & 0,738 \\
\hline Negativa & $29,4 \%$ & $70,6 \%$ & & $66,7 \%$ & $33,3 \%$ & & $47,1 \%$ & $52,9 \%$ & \\
\hline Positiva & $36,8 \%$ & $63,2 \%$ & & $52,6 \%$ & $47,4 \%$ & & $52,6 \%$ & $47,4 \%$ & \\
\hline MMP14 & & & 0,160 & & & 0,298 & & & 0,428 \\
\hline Negativa & $15,4 \%$ & $84,6 \%$ & & $45,5 \%$ & $54,5 \%$ & & $38,5 \%$ & $61,5 \%$ & \\
\hline Positiva & $44,0 \%$ & $56,0 \%$ & & $64,0 \%$ & $36,0 \%$ & & $52,0 \%$ & $48,0 \%$ & \\
\hline IL8 & & & 0,221 & & & 0,297 & & & 0,137 \\
\hline Negativa & $23,1 \%$ & $76,9 \%$ & & $50,0 \%$ & $50,0 \%$ & & $30,8 \%$ & $69,2 \%$ & \\
\hline Positiva & $43,5 \%$ & $56,5 \%$ & & $68,2 \%$ & $31,8 \%$ & & $56,5 \%$ & $43,5 \%$ & \\
\hline TGF- $\beta$ & & & 0,874 & & & 0,642 & & & 0,179 \\
\hline Negativa & $37,5 \%$ & $62,5 \%$ & & $50,0 \%$ & $50,0 \%$ & & $25,0 \%$ & $75,0 \%$ & \\
\hline Positiva & $34,5 \%$ & $65,5 \%$ & & $59,3 \%$ & $40,7 \%$ & & $51,7 \%$ & $48,3 \%$ & \\
\hline
\end{tabular}

\subsection{Expressão dos genes das metaloproteinases e de seus reguladores e a recidiva bioquímica}

A expressão de TIMP1 foi importante em relação a recidiva bioquímica. Quando esta proteína foi positiva $77,8 \%$ dos casos não apresentaram recidiva bioquímica $(p=0,042)$ (Tabela 10). A curva de sobrevida livre de recidiva 
(Kaplan-Meyer) para esta proteína está exposta na figura 12, e mostra uma média de tempo médio de sobrevida de 105 meses para os pacientes com TIMP-1 positiva e de 62,8 meses naqueles que não expressaram TIMP-1 $(p=0,054)$.

Em relação aos demais genes estudados não houve diferença entre pacientes que apresentavam ou não recidiva bioquímica quanto a expressão imuno-histoquímica de MMP-2, MMP9, MMP-14, IL-8 e TGF- $\beta$. 
Tabela 10. Expressão imuno-histoquímica das proteínas de acordo com recidiva bioquímica

\begin{tabular}{|c|c|c|c|}
\hline & \multicolumn{3}{|c|}{ Recidiva Bioquímica } \\
\hline & Não (n=13) & $\operatorname{Sim}(n=21)$ & p-valor \\
\hline MMP-2 & & & 0,248 \\
\hline Negativo & $42,9 \%$ & $57,1 \%$ & \\
\hline Positivo & $66,7 \%$ & $33,3 \%$ & \\
\hline MMP-9 & & & 0,311 \\
\hline Negativo & $33,3 \%$ & $66,7 \%$ & \\
\hline Positivo & $63,3 \%$ & $36,7 \%$ & \\
\hline TIMP-1 & & & 0,042 \\
\hline Negativo & $43,8 \%$ & $56,3 \%$ & \\
\hline Positivo & $77,8 \%$ & $22,2 \%$ & \\
\hline MMP-14 & & & 0,259 \\
\hline Negativo & $54,5 \%$ & $45,5 \%$ & \\
\hline Positivo & $73,9 \%$ & $26,1 \%$ & \\
\hline IL-8 & & & 0,340 \\
\hline Negativo & $54,5 \%$ & $45,5 \%$ & \\
\hline Positivo & $71,4 \%$ & $28,6 \%$ & \\
\hline TGF- $\beta$ & & & 0,279 \\
\hline Negativo & $42,9 \%$ & $57,1 \%$ & \\
\hline Positivo & $65,4 \%$ & $34,6 \%$ & \\
\hline
\end{tabular}




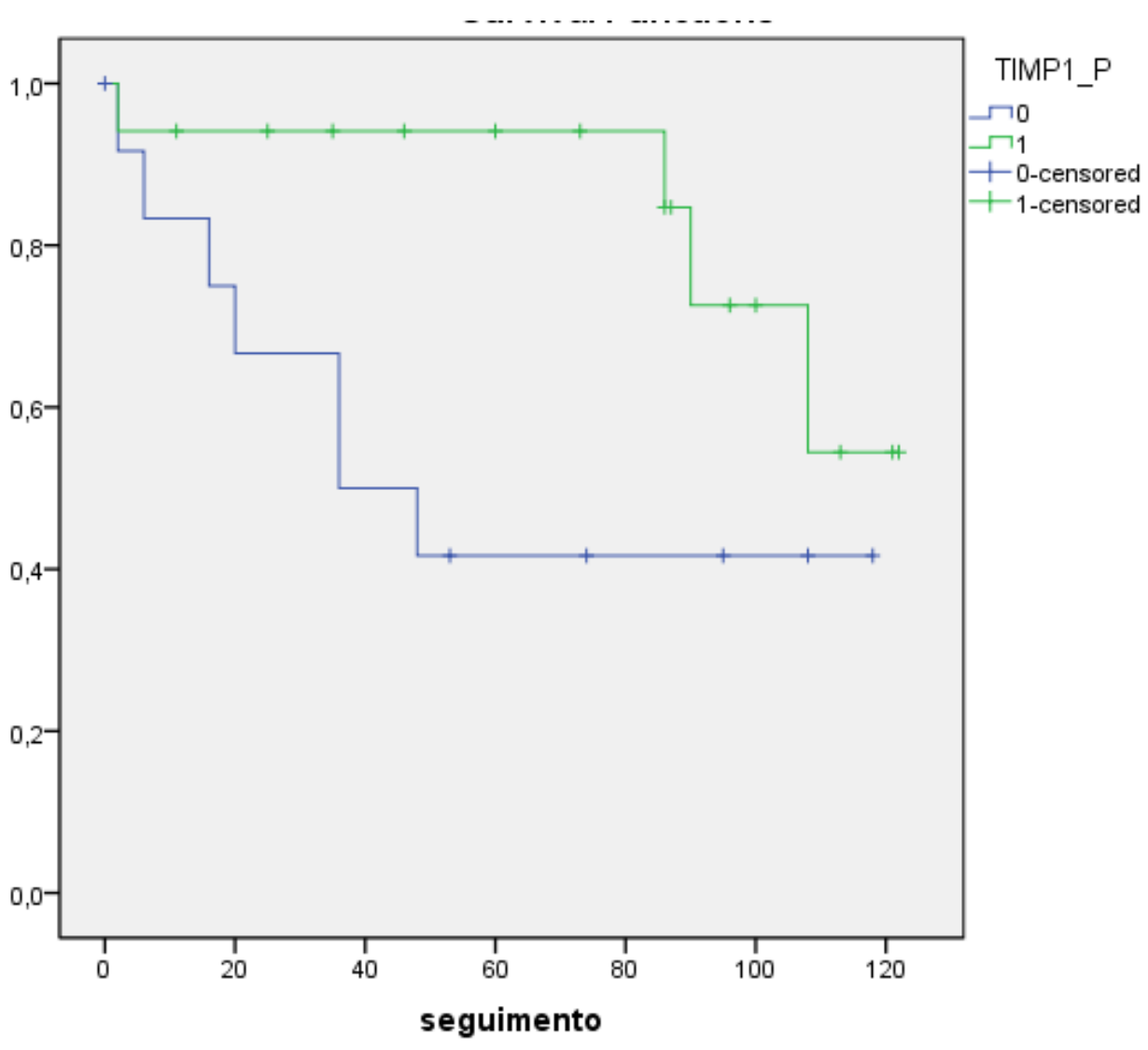

Figura 12. Curva de sobrevida livre de recidiva de acordo com a expressão da proteína TIMP-1. 
5. Discussão 


\section{Discussão}

O gene da MMP-9 esteve superexpresso em 82,3\% dos casos estudados, o mesmo aconteceu com a proteína MMP-9 que foi positiva em 91,4\% dos casos podendo este fenômeno ser considerado um evento frequente no processo de carcinogênese da próstata. O aumento da expressão de MMP-9 também foi encontrado em poucos estudos que avaliaram linhagens de câncer de próstata (Hamdy e cols, 1994). Simi et al. (2004) demonstraram uma superexpressão do RNAm de MMP-9 em pacientes com câncer de pulmão. Devido a seu papel na degradação da matriz extracelular, facilitando a invasão tumoral e o desenvolvimento de metástases, a expressão aumentada de metaloproteinases da matriz está relacionada a diversos processos tumorais (Diamandis et al., 1997). Entretanto, apesar de seu impacto patogênico no câncer humano, um número limitado de estudos está publicado na literatura, sendo que a maioria avalia a expressão protéica por imuno-histoquímica (Zhong et al., 2008).

Considerando os fatores prognósticos, a expressão de MMP-9 associouse a níveis maiores de PSA pré-operatório ( $\geq 10 \mathrm{ng} / \mathrm{mL} ; \mathrm{p}=0,03)$, importante fator prognóstico utilizado para avaliação do grau de agressividade da neoplasia. Esse fato pode significar que o nível de expressão de MMP-9 poderia ser utilizado como mais um fator prognóstico no CaP. Além disso, quando avaliamos a recidiva bioquímica dos pacientes, a mediana de 
expressão de MMP-9 nos pacientes que recidivaram foi de 6,28 , enquanto que nos pacientes que não recidivaram a mediana de expressão foi de quase a metade, 3,24 $(p=0,09)$. Embora a diferença estatística seja apenas marginal, a expressão de quase o dobro nos casos com recidiva bioquímica é um dado biológico relevante que pode se tornar uma ferramenta na identificação de pacientes susceptíveis à recidiva bioquímica pós prostatectomia radical. De acordo com a expressão proteica e os fatores prognósticos, não encontramos diferenças significativas, nem mesmo com a recidiva bioquímica, porém devemos ressaltar que analisamos por imuno-histoquímica um número menor de pacientes $(n=40)$.

O gene de MMP-2 mostrou-se subexpresso em $60 \%$ dos casos de CaP, ao contrário de outras neoplasias onde este gene tem sido descrito como superexpresso (Tang et al., 2005). Entretanto, o estudo imuno-histoquímico mostrou positividade de MMP-2 na maioria dos casos de CaP (77,7\%). Nossos resultados são semelhantes aqueles publicados na literatura que têm demonstrado uma discrepância entre os níveis de RNAm e proteína de MMP-2 no câncer de próstata (Lichtinghagen et al, 2002; Brehmer et al., 2003). Essa discrepância poderia ser explicada pelo controle pós transcripcional de MMP-2 exercido por RECK, o que não pode ser pensado avaliando os nossos achados desde que observamos subexpressão desse gene. Outra hipótese seria a ação de micro RNA, como por exemplo, o miR-129b que tem como possível alvo genes relacionados a produção de colágeno entre eles MMP2 (Liu Y, 2010). 
A subexpressão do gene MMP-2 pode estar associada ao processo de carcinogênese, pois tem-se demonstrado que a ausência de determinadas MMP pode promover tumorigênese, como foi mostrado por Balbín et al. (2003) em estudos experimentais em camundongos onde houve aumento da susceptibilidade ao câncer de pele naqueles que não expressavam MMP-8.

Quando analisamos a expressão de MMP-2 e os fatores prognósticos notamos que o gene da MMP-2, mesmo mantendo-se subexpresso, teve uma expressão maior entre os pacientes que apresentavam Gleason $\geq 7(p=0,04)$. A grande maioria dos pacientes apresentava uma subexpressão de MMP-2, entretanto $32(40,5 \%)$ pacientes apresentavam este gene superexpresso. Analisando individualmente esses pacientes encontramos que 21 (65,6\%) apresentavam Gleason $\geq 7,13(40,6 \%)$ apresentavam $P S A \geq 10 \mathrm{ng} / \mathrm{mL}, 13$ $(40,6 \%)$ foram estadiados pT3 e $12(37,5 \%)$ recidivaram. De todos os pacientes que apresentavam superexpressão desse gene apenas $6(18,7 \%)$ não possuíam um desses fatores de prognóstico ou evolução desfavoráveis. Portanto a superexpressão desse gene está relacionada a aspectos desfavoráveis do CaP e portanto pode também fazer parte dos marcadores de pior prognóstico. Outros estudos já associaram altos níveis protéicos de MMP-2 com pior prognóstico do $\mathrm{CaP}$, e a expressão do RNAm desse gene já foi associada com pior prognóstico de outras neoplasias como leucemia linfoblástica aguda (Scrideli et al., 2010). De acordo com a expressão proteica 
não encontramos diferenças estatística entre as variáveis clínico-patológicas estudadas.

As MMP são expressas de forma abundante em tumores malignos, independentemente de sua origem e uma correlação significativa entre a expressão aumentada de MMP e um pior prognóstico, em termo de sobrevida, pôde ser demonstrada em diversos casos. (Heppner et al., 1996; Basset et al., 1997; Johnsen et al., 1998). Em conseqüência disso, a possibilidade de serem empregadas como marcadores tumorais têm sido aventada.

A inibição das formas ativas das MMP pode se dar pela ação de seus inibidores teciduais (TIMP). São quatro TIMP descritos 1, 2, 3 e 4. Com exceção do TIMP-3 todos são secretados sob forma solúvel e são capazes de efetuar fortes ligações com membros da família das MMP, exercendo assim sua função inibitória. São importantes no estabelecimento do balanço entre síntese e degradação da MEC induzidas pelas MMP. Nós encontramos uma subexpressão dos genes TIMP-1 e TIMP-2 em 70,0\% e 72,2\% dos casos de CaP respectivamente, e também encontramos ausência destas proteínas no estudo imuno-histoquímico em $52,8 \%$ e $100,0 \%$ dos casos respectivamente. Em outras neoplasias esses genes também se encontram subexpressos.

Apesar de haver subexpressão do gene TIMP-2 na maioria dos nossos casos, observamos uma maior expressão desse gene em pacientes com tumores de alto grau de Gleason ( $p=0,02)$. O conceito original de que TIMP são 
responsáveis por efeitos contrários à progressão neoplásica nem sempre pode ser observado, uma vez que apresentam múltiplas funções biológicas, inclusive atividades promotoras de crescimento celular e ativação de pró-MMP-2 como foi demonstrado por Kraiem e Korem (2000). Em 22 pacientes encontramos superexpressão de TIMP-2. Fazendo uma análise particular desse grupo encontramos que destes, $15(68,1 \%)$ apresentavam Gleason $\geq 7,11(50 \%)$ apresentavam PSA $\geq 10 \mathrm{ng} / \mathrm{mL}, 9$ (40,9\%) foram estadiados pT3 e 12 (54,5\%) recidivaram. De todos os pacientes que apresentavam superexpressão deste gene apenas $3(13,6 \%)$ não possuíam um desses fatores de prognóstico desfavorável. A superexpressão desse gene pode também ser considerada um fator de pior prognóstico.

De modo interessante identificamos uma relação entre a expressão da proteína TIMP-1 e a não recidiva bioquímica. Quando TIMP-1 foi positiva $77,8 \%$ dos casos não apresentavam recidiva bioquímica $(p=0,042)$. Além disso, encontramos uma média de tempo médio de sobrevida de 105 meses nos pacientes que apresentavam TIMP-1 positiva e de apenas 62,8 meses naqueles onde não havia expressão de TIMP-1 $(p=0,054)$. Assim podemos aventar a hipótese de que a avaliação da expressão proteica de TIMP-1 pode se tornar uma ferramenta importante para identificar pacientes com maior chance de recidiva bioquímica. 
Em relação a expressão proteica de TIMP-1 e TIMP-2 e os fatores prognósticos clássicos do $\mathrm{CaP}$ não encontramos diferenças estatísticas significativas.

A MMP-14 ou MT1-MMP tem sido considerada a mais importante metaloproteinase da superfície celular envolvida na digestão da matriz pericelular e, direta ou indiretamente, está envolvida na via de ativação de proMMP-2. Atribui-se a ela numerosas funções incluindo a migração e invasão celular, e parece ter uma função na via intracelular de degradação do colágeno (Cao e cols, 2004). Em nosso trabalho, nós encontramos uma subexpressão do gene MMP-14 em 62,0\% dos casos de CaP, e ao contrário encontramos a proteína MMP14 presente na reação de imuno-histoquímica na maioria dos casos $(65,7 \%)$. Em outras neoplasias o gene e a proteína já foram identificados como superexpresso (Yoshida, Takahashi, 2009).

A subexpressão do gene MMP-14 em nossa amostra, talvez explique a subexpressão de MMP-2, já que a ativação da pro-MMP-2 ocorre na surperfície celular e requer a formação de um complexo único envolvendo a MMP-14 e a TIMP-2 (Sato e cols, 1996). Entretanto, a níveis proteicos encontramos ausência de TIMP-2 em 100\% dos casos, e uma positividade de MMP-2 e MMP-14 em 77,7\% e 66,7\% dos casos. Embora esperássemos uma concordância entre a expressão gênica e a proteica, devemos levar em consideração que a expressão gênica foi feita de modo quantitativo e não 
obtivemos expressão nula em nenhum dos casos, portanto realmente não esperávamos ausência total das respectivas proteínas.

De acordo com os fatores prognósticos a expressão de MMP-14 mostrou uma correlação marginal com o escore de Gleason. Embora a grande maioria dos pacientes apresentasse este gene subexpresso, a expressão foi maior entre aqueles que apresentavam Gleason $\geq 7 \quad(p=0,081)$. A análise final demonstrou que 30 pacientes apresentavam uma superexpressão deste gene, destes $18(60 \%)$ apresentavam Gleason $\geq 7,12$ (40\%) apresentavam PSA $\geq 10$ $\mathrm{ng} / \mathrm{ml}, 13(43,3 \%)$ foram estadiados pT3 e $14(46,6 \%)$ recidivaram, sendo que apenas $7(23,3 \%)$ desses pacientes não apresentavam uma característica desfavorável considerando os marcadores prognósticos clássicos do CaP. Com relação a expressão proteica não encontramos associação com os fatores prognósticos e recidiva bioquímica.

RECK é uma glicoproteína que regula a expressão de pelo menos três genes da família das metaloproteinases da matriz, MMP-2 MMP-9 e MMP-14. Nós encontramos no CaP uma subexpressão de RECK em 64,6\% dos casos. RECK está subexpressa na maioria das neoplasias (Dong et al., 2010). Não realizamos análise proteica para RECK, pois não encontramos anticorpos comercialmente disponíveis para a análise imuno-histoquímica em tecido parafinado desta proteína. 
Quando os pacientes foram subdivididos de acordo com os fatores prognósticos, uma maior expressão de RECK foi marginalmente associada com pacientes que apresentavam Gleason $\geq 7(p=0,06)$. Analisando individualmente os pacientes encontramos que 29 apresentavam superexpressão de RECK, mais uma vez esses apresentavam características patológicas desfavoráveis, apenas $5(17,2 \%)$ pacientes que apresentavam superexpressão de RECK, possuíam todas as características de prognóstico favoráveis, além disso 20 (68,9\%) apresentavam Gleason $\geq 7,14(48,2 \%)$ apresentavam PSA $\geq 10 \mathrm{ng} / \mathrm{ml}, 12$ $(41,3 \%)$ foram estadiados pT3 e $15(51,7 \%)$ recidivaram. Entretanto, o fato de RECK apresentar uma expressão maior em pacientes com características de pior prognóstico, pode não significar que este gene, considerado um supressor tumoral até então, seja um marcador de pior prognóstico, este aumento da expressão de RECK pode ser um evento secundário a doença, uma resposta em defesa ao crescimento tumoral.

Estudo in vitro feito em células de melanoma humano demonstrou que a interleucina-8 (IL-8) está envolvida em um aumento da transcrição da MMP-2 aumentando a invasão do estroma pelas células tumorais, facilitando a angiogênese e a metastatização (Luca et al., 1997). Em outras neoplasias este gene encontra-se superexpresso, como no câncer gástrico em pacientes infectados por $H$. pylori e no adenocarcinoma pancreático (Yuan et al., 2004). No CaP, ao contrário encontramos uma subexpressão de IL-8 em 65,8\% dos casos, mas de acordo com a expressão proteica encontramos uma positividade 
de IL-8 em 63,9\% dos casos. Outros trabalhos envolvendo a expressão protéica de IL-8 no câncer de próstata, demonstram que os níveis de IL-8 aumentam de acordo com os estágios avançados da neoplasia, em nosso trabalho nós não encontramos associação da expressão gênica e protéica de IL-8 com fatores prognósticos e recidiva do CaP.

TGF- $\beta$, é um fator de crescimento que controla proliferação e diferenciação celular. Em nosso trabalho nós encontramos uma subexpressão de TGF- $\beta$ em $67 \%$ dos casos de CaP. Já a proteína TGF- $\beta$ esteve presente em $78,3 \%$ dos casos analisados. Quando a reação com o anticorpo anti-TGF- $\beta$ foi negativa no estudo IHQ a média de expressão do RNAm foi de 0,79 , e quando foi positiva à média de expressão do RNA foi de 3,31.

Quando os pacientes foram subdivididos de acordo com os fatores prognósticos, uma maior expressão de TGF- $\beta$ foi associada com aqueles que apresentavam Gleason $\geq 7 \quad(p=0,002)$, portanto tumores com maior potencial de agressividade. A superexpressão de TGF- $\beta$ foi encontrada em 26 pacientes, destes $21(80,7 \%)$ apresentavam Gleason $\geq 7,13$ (50\%) apresentavam PSA $\geq 10$ $\mathrm{ng} / \mathrm{ml}, 12(46 \%)$ foram estadiados pT3 e $9(34,6 \%)$ recidivaram. Apenas 2 $(7,7 \%)$ pacientes que apresentavam superexpressão deste gene não apresentaram nenhum fator prognóstico desfavorável. Na expressão proteica não encontramos diferenças estatística em nenhuma variável analisada. 
A superexpressão de TGF- $\beta$ já foi descrita em muitos tumores incluindo o câncer de próstata onde foi associada a fenótipos mais agressivos e a progressão e desenvolvimento de metástases (Soulitizis e cols, 2006, Yang, Moses, 1990). MMP-9 induz ativação de TGF- $\beta$ na superfície de queratinócitos normais, sendo um fator importante no remodelamento tecidual em situações fisiológicas. No nosso estudo com câncer de próstata a superexpressão que identificamos de MMP-9 pode ter induzido a ativação de TGF- $\beta$ que teria uma ação no remodelamento da matriz facilitando invasão tumoral e promovendo a angiogênese, fundamentais na progressão de neoplasias (Yu, Stamenkovic, 2000). Este evento foi considerado um paradoxo, desde que TGF- $\beta$ é inibitório ao crescimento das células do câncer de próstata. Entretanto, a superexpressão de TGF- $\beta$ pelas células do câncer já foi demonstrada alterando interações entre as células tumorais e o hospedeiro facilitando o crescimento tumoral através da estimulação da produção de matriz extracelular, promoção da angiogênese e inibição do sistema imune (Yang, Moses, 1990).

De acordo com as vias representadas no início do trabalho, nós concluímos que provavelmente o gene MMP-2 não está sendo regulado por TIMP-2 no CaP, pois ambas encontram-se subexpressas. A subexpressão de MMP-2, talvez seja explicada pela também subexpressão de seus reguladores positivos MMP-14 e IL-8, já que de acordo com a expressão proteica a presença de MMP-2 é acompanhada pela também presença de MMP-14 e IL-8. A superexpressão de MMP-9 pode ser explicada pela subexpressão de TIMP-1 
e RECK, que são seus inibidores, o que acontece também avaliando expressão proteica, já que MMP-9 é presente na maioria dos casos e TIMP-1 ausente.

Identificamos também que altos níveis de expressão do gene MMP-9 foram associados com níveis elevados de PSA pré-operatório e com pacientes que tiveram recidiva bioquímica. Esses achados são de grande relevância clínica, pois vislumbram um potencial marcador prognóstico para essa neoplasia de alta prevalência.

Os genes MMP-2, TIMP-2, MMP-14, RECK e TGF- $\beta$ apresentaram-se subexpressos no CaP na maioria dos casos. Entretanto quando os mesmos foram superexpressos os pacientes apresentavam características clinicopatológicas desfavoráveis.

Além disso, identificamos associação da proteína supressora tumoral TIMP-1 com recidiva bioquímica, sendo que a ausência desta proteína pode ser uma importante ferramenta na discriminação de indivíduos que possam apresentar recidiva após prostatectomia radical. 
6. Conclusões 


\section{Conclusões}

De acordo com análise gênica encontramos uma superexpressão de MMP-9 e uma subexpressão de MMP-2, TIMP-1, TIMP-2, MMP-14, RECK, IL-8 e TGF- $\beta$, em espécimes de pacientes com CaP localizado submetidos a prostatectomia radical.

Considerando os fatores prognósticos encontramos que a aumentada expressão do gene da MMP-9 está associada com PSA pré-cirúrgico maior que $10 \mathrm{ng} / \mathrm{mL}$ com tendência de associação entre a superexpressão de MMP-9 com recidiva bioquímica do $\mathrm{CaP}$.

Com relação à análise de expressão proteica com uso de imunohistoquímica e TMA encontramos positividade de MMP-9, MMP-2, MMP-14 e TGF- $\beta$ na maioria dos casos, e ausência de expressão de TIMP-1 e TIMP-2. Encontramos também uma associação entre a ausência de expressão da proteína TIMP-1 com recidiva bioquímica pós prostatectomia radical. 


\section{Perspectivas}




\section{Perspectivas}

Nossa proposta é explorarmos os papeis de prováveis micro RNAs que estejam controlando a expressão dos genes estudados, e comprovar a ação dos mesmos com ensaios in vitro.

Um estudo preliminar realizado para testar essa hipótese foi realizado e encontramos, em um grupo de pacientes, superexpressão de miR-21 e subexpressão de RECK, havendo uma relação desse perfil com tumores nãoórgão confinados. O próximo passo é ampliarmos esse estudo, analisando um número maior de micro RNA que tenham como possíveis alvos MMP e seus reguladores e em estudos in vitro verificar se realmente essas moléculas têm papel no controle da expressão desses genes. 
8. Anexo 
Tabela demonstrando características de todos os casos analisados, bem como a expressão dos genes para cada paciente

\begin{tabular}{|c|c|c|c|c|c|c|c|c|c|c|c|c|c|}
\hline Caso & idade & Gleason & Psa-pré & Est Pat & Recidiva & MMP-2 & MMP-9 & TIMP-1 & TIMP-2 & MMP-14 & RECK & IL-8 & TGF $\beta$ \\
\hline 15 & 69 & 5 & 4 & $\mathrm{~T} 2$ & 0 & 1,386 & 1,360 & 1,969 & 0,167 & 2,318 & 1,924 & 0,494 & 1,407 \\
\hline 296 & 56 & 6 & 9 & T2 & 0 & 1,027 & 4,183 & 0,864 & 0,626 & 0,153 & 0,802 & 0,538 & 0,767 \\
\hline 35 & 63 & 4 & 11 & T2 & 0 & 0,224 & 0,612 & 0,314 & 0,360 & 0,575 & 0,448 & 1,061 & 0,671 \\
\hline 73 & 61 & 5 & 6 & T2 & 0 & 0,469 & 12,984 & 0,811 & 0,196 & 1,117 & 0,489 & 2,574 & 0,425 \\
\hline 47 & 56 & 5 & 19 & T2 & - & 0,354 & 4,537 & 3,008 & 0,482 & 2,492 & 0,560 & 19,091 & 6,205 \\
\hline 61 & 64 & 5 & 6 & T2 & 0 & 0,307 & 0,851 & 0,309 & 0,254 & 0,527 & 0,801 & 0,256 & 0,471 \\
\hline 317 & 71 & 7 & 7 & T2 & 0 & 1,086 & 8,280 & 0,921 & 0,757 & 0,832 & 1,179 & 0,696 & 0,425 \\
\hline 26 & 61 & 5 & 7 & T2 & 1 & 0,786 & 19,049 & 2,063 & 2,109 & 1,762 & 1,185 & 1,148 & 0,590 \\
\hline 44 & 59 & 4 & 9 & T2 & 0 & 9,421 & 68,958 & 62,458 & 3,994 & 60,555 & 0,771 & 54,411 & 17,771 \\
\hline 232 & 68 & 8 & 8 & T2 & 0 & 1,102 & 3,799 & 0,614 & 0,870 & 0,780 & 1,429 & 5,000 & 1,623 \\
\hline 310 & 76 & 7 & 6 & T2 & 1 & 1,118 & 3,557 & 0,668 & 0,493 & 0,771 & 0,889 & 0,219 & 0,954 \\
\hline 121 & 52 & 6 & 8 & T2 & 1 & 0,633 & 0,435 & 0,227 & 0,179 & 0,724 & 0,676 & 0,821 & 0,671 \\
\hline 49 & 48 & 4 & 9 & T2 & 0 & 0,157 & 0,111 & 0,170 & 0,162 & 0,325 & 0,354 & 0,087 & 0,353 \\
\hline 293 & 65 & 9 & 10 & T2 & 0 & 2,242 & 21,461 & 1,669 & 1,831 & 2,014 & 2,745 & 0,767 & 6,103 \\
\hline 491 & 61 & 6 & 8 & T2 & 0 & 0,457 & 0,704 & 0,249 & 0,240 & 0,140 & 0,228 & 0,919 & 0,092 \\
\hline 222 & 64 & 7 & 9 & T2 & 0 & 0,087 & 1,772 & 0,237 & 0,117 & 0,463 & 0,231 & 0,120 & 0,121 \\
\hline 478 & 68 & 6 & 9 & T2 & 1 & 1,546 & 15,451 & 1,064 & 1,239 & 0,631 & 1,115 & 1,338 & 0,346 \\
\hline 297 & 49 & 7 & 10 & T2 & 0 & 0,689 & 8,240 & 0,604 & 0,504 & 0,886 & 0,629 & 0,467 & 0,657 \\
\hline 187 & 71 & 8 & 15 & T2 & 0 & 0,416 & 0,945 & 0,402 & 0,428 & 0,478 & 0,805 & 0,737 & 0,436 \\
\hline 499 & 63 & 6 & 8 & T2 & 0 & 1,243 & 1,247 & 0,893 & 1,596 & 1,743 & 0,967 & 0,528 & 0,552 \\
\hline 342 & 65 & 5 & 5 & T2 & 1 & 0,109 & 0,019 & 0,198 & 0,105 & 0,255 & 0,312 & 0,016 & 0,452 \\
\hline
\end{tabular}




\begin{tabular}{|c|c|c|c|c|c|c|c|c|c|c|c|c|c|}
\hline 754 & 59 & 8 & 7 & T2 & 0 & 0,655 & 31,727 & 1,169 & 1,066 & 0,894 & 1,418 & 0,873 & 33,346 \\
\hline 63 & 56 & 5 & 4 & T2 & 0 & 0,291 & 3,022 & 0,316 & 0,392 & 0,603 & 0,682 & 0,577 & 0,607 \\
\hline 1700 & 66 & 8 & 8 & T2 & - & 0,357 & 0,350 & 0,471 & 0,265 & 0,436 & 0,563 & 0,062 & 2,640 \\
\hline 492 & 71 & 5 & 8 & T2 & 0 & 0,735 & 6,429 & 0,906 & 0,471 & 1,107 & 0,277 & 0,491 & 0,316 \\
\hline 109 & 68 & 5 & 6 & T2 & 0 & 0,447 & 3,157 & 0,633 & 0,297 & 0,316 & 1,185 & 1,010 & 0,453 \\
\hline 321 & 58 & 7 & 4 & T2 & 1 & 7,017 & 8,229 & 4,169 & 4,352 & 6,347 & 5,385 & 0,398 & 18,551 \\
\hline 148 & 65 & 9 & 37 & T2 & 0 & 2,738 & 6,992 & 0,228 & 1,235 & 0,903 & 3,253 & 1,677 & 2,640 \\
\hline 54 & 65 & 5 & 14 & T2 & 0 & 1,013 & 4,940 & 9,665 & 0,715 & 2,432 & 2,386 & 2,291 & 3,963 \\
\hline 115 & 50 & 5 & 10 & T2 & 0 & 0,309 & 27,620 & 0,907 & 0,224 & 0,960 & 0,645 & 7,663 & 0,026 \\
\hline 315 & 70 & 7 & 4 & T2 & 1 & 3,585 & 47,067 & 5,799 & 1,610 & 4,056 & 2,291 & 0,934 & 0,841 \\
\hline 125 & 70 & 5 & 5 & T2 & 0 & 1,058 & 7,478 & 0,497 & 0,900 & 1,293 & 1,342 & 1,240 & 0,540 \\
\hline 477 & 63 & 5 & 9 & T2 & 0 & 1,299 & 5,616 & 2,292 & 1,704 & 1,936 & 0,970 & 0,309 & 0,831 \\
\hline 102 & 60 & 5 & 25 & T2 & 1 & 0,258 & 12,620 & 0,838 & 0,264 & 0,481 & 0,280 & 1,230 & 0,128 \\
\hline 336 & 65 & 7 & 7 & T2 & 0 & 1,590 & 3,248 & 2,270 & 0,600 & 1,176 & 1,729 & 0,370 & 0,485 \\
\hline 118 & 65 & 8 & 18 & T2 & 1 & 1,367 & 27,410 & 3,151 & 1,986 & 7,276 & 2,393 & 1,917 & 8,159 \\
\hline 334 & 73 & 5 & 6 & T2 & 0 & 2,425 & 42,478 & 2,467 & 1,444 & 1,234 & 1,693 & 2,014 & 3,289 \\
\hline 1727 & 54 & 8 & 11 & T2 & 0 & 0,737 & 5,531 & 0,633 & 0,411 & 0,961 & 0,484 & 0,471 & 5,674 \\
\hline 217 & 73 & 8 & 5 & T3 & 1 & 0,451 & 2,758 & 0,797 & 0,407 & 0,976 & 1,171 & 0,502 & 1,242 \\
\hline 421 & 68 & 8 & 31 & T3 & 1 & 0,008 & 24,128 & 0,968 & 0,158 & 4,554 & 2,003 & 2,151 & 1,011 \\
\hline 672 & 58 & 8 & 11 & T3 & 0 & 2,028 & 0,061 & 2,898 & 1,926 & 2,071 & 2,151 & 0,485 & 0,845 \\
\hline 303 & & 8 & 12 & T3 & - & 0,292 & 5,493 & 0,451 & 0,257 & 0,295 & 0,639 & 0,833 & 0,954 \\
\hline 560 & 41 & 5 & 6 & T3 & 0 & 0,295 & 0,148 & 0,541 & 0,390 & 0,683 & 0,453 & 0,155 & 0,156 \\
\hline 327 & 60 & 6 & 10 & T3 & 0 & 1,079 & 0,003 & 0,646 & 1,169 & 0,985 & 0,994 & 0,577 & 0,568 \\
\hline 708 & 75 & 8 & 14 & T3 & 0 & \begin{tabular}{|l}
0,631 \\
\end{tabular} & 0,198 & 0,707 & 1,206 & 1,210 & 1,237 & 0,110 & 0,485 \\
\hline
\end{tabular}




\begin{tabular}{|c|c|c|c|c|c|c|c|c|c|c|c|c|c|}
\hline 1707 & 77 & 8 & 9 & T3 & 0 & 0,924 & 1,091 & 0,749 & 0,752 & 0,740 & 0,603 & 0,267 & 7,128 \\
\hline 320 & 51 & 5 & 8 & T3 & 1 & 1,602 & 5,624 & 2,579 & 0,460 & 1,216 & 0,407 & 1,718 & 0,411 \\
\hline 182 & 64 & 9 & 21 & T3 & 1 & 0,583 & 6,924 & 0,550 & 0,378 & 0,597 & 0,916 & 0,459 & 0,370 \\
\hline 216 & 60 & 8 & 10 & T3 & - & 0,116 & 1,977 & 0,246 & 0,332 & 0,354 & 0,411 & 0,102 & 0,246 \\
\hline 79 & 64 & 6 & 15 & T3 & 1 & 0,208 & 4,123 & 0,222 & 0,280 & 0,390 & 0,554 & 1,352 & 0,489 \\
\hline 76 & 58 & 8 & 8 & T3 & 1 & 0,326 & 1,584 & 0,348 & 0,469 & 0,425 & 0,444 & 1,527 & 0,095 \\
\hline 183 & 66 & 9 & 7 & T3 & 0 & 1,420 & 1,109 & 2,124 & 0,673 & 1,338 & 1,589 & 2,460 & 0,424 \\
\hline 295 & 66 & 7 & 13 & T3 & 1 & 0,189 & 1,150 & 0,429 & 0,086 & 0,374 & 0,250 & 0,523 & 0,084 \\
\hline 746 & 66 & 7 & 13 & T3 & 1 & 1,330 & 17,480 & 2,641 & 1,968 & 2,104 & 1,309 & 0,699 & 0,305 \\
\hline 325 & 51 & 5 & 9 & T3 & 0 & 0,633 & 8,578 & 0,577 & 0,479 & 0,514 & 0,638 & 0,858 & 0,374 \\
\hline 829 & 64 & 7 & 15 & T3 & 1 & 1,512 & 1,879 & 1,032 & 0,705 & 0,451 & 0,629 & 0,896 & 0,221 \\
\hline 501 & 59 & 8 & 13 & T3 & 1 & 1,385 & 28,298 & 1,483 & 1,811 & 3,425 & 1,080 & 0,427 & 0,418 \\
\hline 201 & 60 & 8 & 11 & T3 & 1 & 3,740 & 94,264 & 7,289 & 7,360 & 7,761 & 5,633 & 0,682 & 14,315 \\
\hline 481 & 51 & 5 & 4 & T3 & 0 & 0,571 & 1,345 & 0,300 & 0,721 & 0,382 & 0,526 & 0,792 & 0,163 \\
\hline 243 & 65 & 8 & 6 & T3 & 0 & 0,267 & 0,366 & 0,403 & 0,227 & 1,365 & 0,532 & 0,714 & 0,444 \\
\hline 459 & 50 & 8 & 7 & T3 & 0 & 0,868 & 13,696 & 0,782 & 0,479 & 0,589 & 0,360 & 0,235 & 1,001 \\
\hline 122 & 74 & 6 & 19 & T3 & 1 & 0,467 & 12,249 & 0,896 & 0,368 & 0,127 & 2,038 & 0,577 & 0,375 \\
\hline 1710 & 74 & 9 & 9 & T3 & 1 & 1,488 & 6,610 & 0,757 & 1,452 & 1,316 & 0,873 & 3,412 & 6,419 \\
\hline 463 & 79 & 8 & 15 & T3 & 0 & 0,689 & 3,031 & 0,984 & 0,522 & 0,436 & 0,192 & 0,152 & 0,707 \\
\hline 167 & 66 & 8 & 12 & T3 & 0 & 0,214 & 5,616 & 0,633 & 0,313 & 0,676 & 0,305 & 1,403 & 1,930 \\
\hline 551 & 68 & 6 & 8 & T3 & 1 & 0,412 & 1,767 & 0,139 & 0,101 & 0,135 & 0,119 & 0,384 & 0,049 \\
\hline 87 & 65 & 8 & 9 & T3 & 1 & 0,566 & 0,352 & 1,439 & 0,742 & 1,344 & 0,923 & 0,240 & 0,754 \\
\hline 741 & 60 & 8 & 25 & T3 & 1 & 0,572 & 2,575 & 0,557 & 0,288 & 0,574 & 0,293 & 0,417 & 0,126 \\
\hline 206 & 62 & 8 & 6 & T3 & 0 & 0,310 & 2,534 & 0,772 & 0,597 & 0,940 & 0,993 & 0,534 & 1,526 \\
\hline
\end{tabular}




\begin{tabular}{|c|c|c|c|c|c|c|c|c|c|c|c|c|c|}
\hline 83 & 61 & 8 & 16 & T3 & 1 & 1,858 & 5,961 & 0,449 & 1,193 & 2,333 & 2,563 & 1,263 & 1,912 \\
\hline 1724 & 70 & 9 & 13 & T3 & - & 0,768 & 4,606 & 1,120 & 0,563 & 0,572 & 0,634 & 0,909 & 4,177 \\
\hline 1693 & 59 & 8 & 10 & T3 & - & 0,820 & 7,334 & 0,532 & 0,447 & 0,446 & 0,439 & 1,799 & 6,809 \\
\hline 108 & 76 & 5 & 9 & T3 & 1 & 0,629 & 2,217 & 0,333 & 0,321 & 0,406 & 0,447 & 1,348 & 0,321 \\
\hline 260 & 62 & 8 & 5 & T3 & 0 & 1,246 & 2,781 & 0,927 & 0,668 & 0,882 & 0,691 & 2,057 & 0,922 \\
\hline 280 & 68 & 8 & 4 & T3 & 0 & 0,362 & 0,307 & 0,732 & 0,325 & 0,454 & 0,332 & 0,300 & 0,205 \\
\hline 31 & 68 & 8 & 17 & T3 & 1 & 1,228 & 13,686 & 1,530 & 0,413 & 0,755 & 23,196 & 0,466 & 0,232 \\
\hline 55 & 72 & 8 & 8 & T3 & 1 & 2,133 & 0,083 & 0,510 & 2,253 & 2,296 & 3,632 & 0,928 & 18,967 \\
\hline 88 & 60 & 5 & 2 & T3 & 0 & 0,284 & 1,254 & 0,509 & 0,445 & 0,697 & 0,687 & 0,404 & 0,627 \\
\hline 186 & 51 & 9 & 10 & - & 1 & 1,199 & 11,573 & 0,377 & 1,002 & 1,097 & 1,462 & 1,892 & 1,719 \\
\hline
\end{tabular}




\section{Referências Bibliográficas}




\section{Referências Bibliográficas}

Antunes AA, Leite KR, Sousa-Canavez JM, Camara-Lopes LH, Srougi M. The role of prostate specific membrane antigen and pepsinogen $C$ tissue expression as an adjunctive method to prostate cancer diagnosis. J Urol 181: 594-600, 2009

Baker, A.H., Edwards D.R., Murphy G.: Metalloproteinase inhibitors: Biological actions and therapeutic opportunities. J Cell Science 115: 3719-27, 2002.

Balbín M, Fueyo A, Tester AM, Pendás AM, Pitiot AS, Astudillo A, Overall CM, Shapiro SD, López-Otín C. Loss of collagenase-2 confers increased skin tumor susceptibility to male mice. Nat Genet. 35: 252-7, 2003

Basset P, Bellocq JP, Wolf C, Stoll I, Hutin P, Limacher JM et al. A novel metalloproteinase gene specifically expressed in stromal cells of breast carcinomas. Nature 348: 699-704, 1997

Brawer M.K., Stamey T.A., Fowler J., Droller M., Messing E., Fair W.R.: Perspective on prostate cancer diagnosis and tratament: a roundtable. Urology 58: 135-40, 2001

Brehmer B, Biesterfeld S, Jakse G. Expression of matrix metalloproteinases (MMP-2 and -9) and their inhibitors (TIMP-1 and -2) in prostate cancer tissue. Prostate Cancer Prostatic Dis. 6: 217-22, 2003

Brew K., Dinakarpandian D., Nagase H.: Tissue inhibitors of metalloproteinases: Evolution, structure and function. Biochim Biophys Acta 1477: 267-83, 2000 
Cao J, Kozarekar P, Pavlaki M, Chiarelli C, Bahou WF, Zucker S. Distinct roles for the catalytic and hemopexin domains of membrane type 1-matrix metalloproteinase in substrate degradation and cell migration. J Biol Chem. 279: 14129-39, 2004

Carter H.B., Pearson J.D.: Prostate-specific antigen testing for early diagnosis cancer: formulation of guidelines. Urology 54: 780-6, 1999

Catalona W.J., Smith D.S., Ratliff T.L. et al. Measurement of prostate specific antigen in serum as a screening test for prostate cancer. N Engl J Med 324: 1156-61, 1991

Caterina J.J., Skobe Z., Shi J., Ding Y., Simmer J.P., Birkedal-Hansen H., Bartlett J.D.: Enamelysin (matrix metalloproteinase-20)- deficient mice display an amelogenesis imperfecta phenotype. J Biol Chem 277: 49598-604, 2002.

Chambers A. F., Matrisian L.M.: Changing views of the role of matrix metalloproteinases in metastasis. J Natl Cancer Inst 89: 1260-70, 1997

Chang CK, Hung WC, Chang HC. The Kazal motifs of RECK protein inhibit MMP-9 secretion and activity and reduce metastasis of lung cancer cells in vitro and in vivo. J Cell Mol Med 2008; ahead of print

Crawford E.D. Epidemiology of prostate cancer. Urology 62: 3-12, 2003

Coussens L.M., Fingleton B., Matrisian L.M.: Matrix metalloproteinase inhibitors and cancer: trials and tribulations. Science 295: 2387-92, 2002 
Curran, S., Murray, G.I.: Matrix metaloproteinases in tumor invasion and metastasis. J Pathol 189: 300-8, 1999

Diamandis EP, Nadkarni S, Bhaumik B, Abdelrahman A, Melegos DN, Borchert G, Black MH, Alonso M, Salas A, de los Toyos JR, Sampedro A, López-Otín C. Immunofluorometric assay of pepsinogen $\mathrm{C}$ and preliminary clinical applications. Clin Chem. 43: 1365-71, 1997

Djavan B, Zlotta A, Remzi M, Ghawidel K, Basharkhah A, Schulman CC, Marberger M. Optimal predictors of prostate cancer on repeat prostate biopsy: a prospective study of 1,051 men. J Urol. 163: 1144-8, 2000

Dong $Q$, Yu D, Yang CM, Jiang B, Zhang H. Expression of the reversioninducing cysteine-rich protein with Kazal motifs and matrix metalloproteinase-14 in neuroblastoma and the role in tumour metastasis. Int $J$ Exp Pathol 91: 368-73, 2010

Dos Reis ST, Pontes J Jr, Villanova FE, Andrade PM, Antunes AA, Dall'Oglio MF, Srougi M, Moreira Leite KR. Genetic Polymorphisms of Matrix Metalloproteinases: Susceptibility and Prognostic Implications for Prostate Cancer. J Urol 2009 [In press]

Dos Reis ST, Villanova FE, Andrade PM, Pontes J Jr, de Sousa-Canavez JM, Sañudo A, Antunes AA, Dall'Oglio MF, Srougi M, Moreira Leite KR. Matrix metalloproteinase-2 polymorphism is associated with prognosis in prostate cancer. Urol Oncol 2008 [Epub ahead of print]

Egeblad M., Werb Z.: New functions for the matrix metalloproteinases in cancer progression. Nat Rev Cancer 2: 161-74, 2002 
Epstein J.I., Allsbrook W.C. Jr. Amin M.B. et al. The 2005 International Society of Urological Pathology (ISUP) consensus conference on Gleason grading of prostatic carcinoma. Am J Surg Pathol 29: 1228-42, 2005

Fong Y.C., Dutton C.M., Cha S.S., Garamszegi N., Sim F.H., Scully S.P.: Absence of a correlation between presence of single nucleotide polymorphism in the matrix metalloproteinase 1 promoter and outcome in patients of chondrosarcoma. Clin Cancer Res 10: 7329-34, 2004

Gann S.I., Hennekens C.H., Stampfer M.J.: A prospective evaluation of plasma prostate specific antigen for detection of prostate cancer. JAMA 273: 289-94, 1995

Gleason D.F.: Histologic grading of prostate cancer: A perspective. Hum Pathol 23: 273-9, 1992

Greene F.L., Page D., Morrow M., Balch C., Haller D., Fritz A., Fleming I., eds. AJCC Cancer Staging Manual 6th ed. New York: Springer; 2010

Hamdy FC, Fadlon EJ, Cottam D, Lawry J, Thurrell W, Silcocks PB, Anderson $\mathrm{JB}$, Williams JL, Rees RC. Matrix metalloproteinase 9 expression in primary human prostatic adenocarcinoma and benign prostatic hyperplasia. $\mathrm{Br} \mathrm{J}$ Cancer 69: 177-82, 1994

Heppner KJ, Matrisian LM, Jensen RA, Rodgers WH. Expression of most matrix metalloproteinase family members in breast cancer represents a tumor-induced host response. Am J Pathol 149: 273-282, 1996 
INCA (Instituto Nacional do Câncer). Ministério da Saúde, Brasil. Disponível em: http://www.inca.gov.br. Dados de 2010

Johnsen M, Lund LR, Remer J, Almholt K, Dano K. Cancer invasion and tissue remodeling: common themes in proteolytic matrix degradation. Curr Opin Cell Biol 10: 667-671, 1998

Kang GH, Lee S, Lee HJ, Hwang KS. Aberrant CpG island hypermethylation of multiple genes in prostate cancer and prostatic intraepithelial neoplasia. J Pathol 202: 233-240, 2004

Kleiner, D.E., Stetler-Stevenson, W.G.: Matrix metalloproteinases and metastasis. Cancer Chemother Pharmacol 43: S42, 1999

Konish N., Hiasa Y., Hayashi I., Tao M., Matsuda H., Tsuzuki T., Kitahori Y., Shiraishi T., Yatani R., Shimazaki J., Lin J.C.: Intratumor cellular heterogeneity and alterations in ras oncogene and p53 tumor supressor gene in human prostate carcinoma. Am J Pathol 147: 1112-22, 1995

Kraiem Z, Korem S. Matrix Metalloproteinases and the thyroid. Thyroid 10: 1061-69, 2000

Lafleur MA, Handsley MM, Edwards DR. Metalloproteinases and their inhibitors in angiogenesis. Expert Rev Mol Med. 5: 1-39, 2003

Lauer-Fields J.L., Juska D., Fields G.B.: Matrix metalloproteinases and collagen catabolism. Biopolymers 66: 19-32, 2002

Lee M.H., Murphy G.: Matrix metalloproteinases at a glance. J Cell Science 117: 4015, 2004 
Leite K.R., Srougi M., Kauffmann J.R., Bevilacqua R.G., Nesrallah L.J., CamaraLopes L.H.: Well differentiated localized prostate carcinoma: prognostic relevance of tertiary Gleason pattern 4 and tumor volume. Rev Assoc Med Bras 51: 329-33, 2005

Leite KR, Sousa-Canavez JM, Reis ST, Tomiyama AH, Camara-Lopes LH, Sañudo A, Antunes AA, Srougi M. Change in expression. Of miR-let7c, miR100 , and miR-218 from high grade localized prostate cancer to metastasis. Urol Oncol 29: 265-9, 2011

Li y., Jin X., Kang S., Wang Y., Du H., Zhang J., Guo W., Wang N., Fang S.: Polymorphisms in the promoter regions of the matrix metalloproteinases-1, - 3 , 7 , and -9 and the risk of epithelial ovarian cancer in china. Gynecol oncol 101: 92-6, 2006

Lichtinghagen R, Musholt PB, Lein M, Römer A, Rudolph B, Kristiansen G, Hauptmann S, Schnorr D, Loening SA, Jung K. Different mRNA and protein expression of matrix metalloproteinases 2 and 9 and tissue inhibitor of metalloproteinases 1 in benign and malignant prostate tissue. Eur Urol. 42: 398406, 2002

Liotta L.A., Tumor invasion and metastases - Role of extracellular matrix. Cancer Res. 46: 1-7, 1986

Liu Y, Taylor NE, Lu L, Usa K, Cowley AW Jr, Ferreri NR, Yeo NC, Liang M. Renal medullary microRNAs in Dahl salt-sensitive rats: miR-29b regulates several collagens and related genes. Hypertension. 55: 974-82, 2010 
Livak KJ, Schmittgen TD. Analysis of relative gene expression data using realtime quantitative PCR and the 2(-Delta Delta C(T)) Method. Methods. 25: 402-8, 2001

Luca M, Huang S, Gershenwald JE, Singh RK, Reich R and Bar-Eli M. Expression of interleukin-8 by human melanoma cells up-regulates MMP-2 activity and increases tumor growth and metastasis. American Journal of Pathology 151: 1105-13, 1997

Lynch C.C., Matrisian L.M., Matrix metalloproteinases: in tumor-host cell comunication. Diferentiation 70: 561-73, 2002

McCawley L.J., Matrisian L.M.: Matrix metalloproteinases: They're not just for matrix anymore!: Curr Opin Cell Biol 13: 534-40, 2001

Nagase H., Woessner J.F.Jr.: Matrix metalloproteinases. J Biol Chem 274: 21491-4, 1999

Nam RK, Sugar L, Yan W et al. Expression of the TMPRSS2: ERG fusion gene predicts cancer occurrence after surgery for localized prostate cancer. $\mathrm{Br} \mathrm{J}$ Cancer 97: 1690-95, 2007

Nelson W.G., De Marzo A.M., Isaacs W.B.: Prostate cancer. NEJM 349: 366-81, 2003

O-Charoenrat P., Leksrisakul P., Saugruchi S.: A functional polymorphism in the matrix metalloproteinase-1 gene promotor is associated with susceptibility and aggressiveness of head and neck cancer. Int J Cancer 118: 2548-53, 2006 
Opdenakker G., Van Den Steen P.E., Van Damme J.: Gelatinase B: A tuner and amplifier of immune functions. Trends immuno I22: 571-9, 2001

Perrer S.I., et al. Cancer Statistics, 1996. Cancer J Clin 46: 5-27, 1996

Pontes-Junior J, Reis ST, de Oliveira LC, Sant'Anna AC, Dall'Oglio MF, Antunes AA, Ribeiro-Filho LA, Carvalho PA, Cury J, Srougi M, Leite KR. Association between integrin expression and prognosis in localized prostate cancer. Prostate 70: 1189-95, 2010

Pupa SM, Ménard S, Forti S, Tagliabue E. New insights into the role of extracellular matrix during tumor onset and progression. J Cell Physiol 192: 25967,2002

Sato H, Takano T, Kinoshita T, Imai K, Okada Y, Steler-Stevenson WG et al., Cell surface biding and activation of gelatinase $A$ induced by expression of membrane -type-1-matrix metalloproteinase (MT1-MMP). FEBS Lett 385: 23840, 1996

Schulman C.C., Ekane S., Zlotta R.A.: Nutrition and cancer prostate: Evidence or Suspicion? Urology 58: 318-34, 2001

Scrideli CA, Cortez MA, Yunes JA, Queiróz RG, Valera ET, da Mata JF, Toledo SR, Pavoni-Ferreira P, Lee ML, Petrilli AS, Brandalise SR, Tone LG. mRNA expression of matrix metalloproteinases (MMPs) 2 and 9 and tissue inhibitor of matrix metalloproteinases (TIMPs) 1 and 2 in childhood acute lymphoblastic leukemia: potential role of TIMP-1 as an adverse prognostic factor. Leuk Res. 34: 32-7, 2010 
Seiki M.: Membrane-type matrix metalloproteinases. APMIS 107:137-143, 1999 Shou Y., Hirano T., Gong Y., et al.: Influence of angiogenetic factors and matrix metalloproteinases upon tumor progression in non-small-cell lung cancer. $\mathrm{Br} \mathrm{J}$ cancer 85: 1706-12, 2001

Simi L, Andreani M, Davini F, Janni A, Pazzagli M, Serio M, Orlando C Simultaneous measurement of MMP-9 and TIMP-1 mRNA in human non small cell lung cancers by multiplex real time RT-PCR. Lung Cancer 45: 171-9, 2004

Soulitzis N, Karyotis I, Delakas D, Spandidos D. Expression analysis of peptides growth factors VEGF, FGF2, TGF $\beta 1$, EGF and IGF1 in prostate cancer and benign prostatic hyperplasia. Int. Journal of Oncology 29: 305-14, 2006

Stamenkovic I.: Extracellular matrix remodelling: The role of matrix metalloproteinases. J Pathol 200: 448-64, 2003

Steller-Stevenson W.G., Krutzsch H.C., Liota L.A.: Tissue inhibitor of metalloproteinase (TIMP-2). A new member of the metalloproteinase inhibitor family. J Biol Chem 264: 17374-8, 1989

Su L., Zhou W., Asomaning K., Lin X., Wain J.C., Lynch T.J., Liu G., Christiani D.C.: Genotypes and haplotypes of matrix metalloproteinase 1, 3 and 12 genes and risk of lung cancer. Carcinogenesis 27: 1024-29, 2005

Tang ZG, Li JM, Hong ZZ, Yu ZW, Liu CH. Expression of matrix metalloproteinase 2 in oral verruvous carcinoma and squamous cell carcinoma. Zhong Nan Da Xue Xue Bao Yi Xue Ban. 30: 650-2, 2005 
van Kempen L.C., Rhee J.S., Dehne K., Lee J., Edwards D.R., Coussens L.M.: Epethelial carcinogenesis: dynamic interplay between neoplastic cells and their microenvironment. Diferentiation 70: 610-23, 2002

Vlermincvkx, K., Vakaet, L., JR Mareel, M., Fier, W., Van Roy, R.: Genetic Manipulation of E-cadherin expression by epithelial tumor cells reveals an invasion suppressor role. Cell 66: 108, 1991

Welch HG, Fisher ES, Gottlieb DJ, Barry MJ. Detection of prostate cancer via biopsy in the Medicare-SEER population during the PSA era. J Natl Cancer Inst. 99: 1395-400, 2007

Westermarck J., Kähäri V-M.: Regulation of matrix metalloproteinase expression in tumor invasion. FASEB 13: 781-92, 1999

Yang EY, Moses HL. Transforming growth factor b1-induced changes in cell migration, proliferation, and angiogenesis in the chicken chorioallantoic membrane. J Cell Biol 111: 731-741, 1990

Yoshida S, Takahashi H. Expression of extracellular matrix molecules in brain metastasis. J Surg Oncol. 100:65-8, 2009

Yu Q, Stamenkovic I. Cell surface-localized matrix metalloproteinase-9 proteolytically activates TGF- $\beta$ and promotes tumor invasion and angiogenesis. Genes and Development 14: 163-176, 2000

Yu C., Zhou Y., Miao X., Xiong P., Tan W., Lin D.: Functional haplotypes in the promoter of matrix metalloproteinase-2 predict risk of the occurrence and metastasis of esophageal cancer. Cancer Res 64: 7622-8, 2004 
Yuan JP, Li T, Chen HB, Li ZH, Yang GZ, Hu BY, Shi XD, Tong SQ, Li YX, Guo $\mathrm{XK}$. Analysis of gene expression profile in gastric cancer cells stimulated with Helicobacter pylori isogenic strains. J Med Microbiol. 53: 965-74, 2004

Xiang ZL, Zeng ZC, Fan J, Tang ZY, Zeng HY, Gao DM. Gene expression. Profililing of fixed tissues identified HIF-1alpha, VEGF, and MMP-2 as biomarkers of Lymph Node Metastasis in Hepatocellular carcinoma. Clin Cancer Res 2011 [Epub ahead of print].

Zhong WD, Han ZD, He HC, Bi XC, Dai QS, Zhu G, Ye YK, Liang YX, Qin WJ, Zhang Z, Zeng GH, Chen ZN. CD147, MMP-1, MMP-2 and MMP-9 protein expression as significant prognostic factors in human prostate cancer. Oncology 75: $230-236,2008$

Zinzindohoue F., Lecomte T., Ferraz J.M., Houllier A.M., Cugnene P.H., Berger A., Blons H., Laurent-Puig P.: Prognostic significance of MMP-1 and MMP-3 functional promoter polymorfisms in colorectal cancer. Cin Cancer Res 15: 5949, 2005 
10. Apêndices 


\section{Artigos científicos publicados}

1. Clinics

TGF- $\beta$ expression, a biomarker of poor prognosis in prostate cancer

\section{Artigos Científicos submetidos}

2. International Journal of Biological Markers

MMP-9, TIMP-1 and RECK profiles are altered in prostate cancer

3. International Brazilian Journal of Urology

Underexpression of MMP-2 and its Regulators, TIMP2, MT1-MMP and IL-8, are Associated with Prostate Cancer

4. Urology

Negative regulation of RECK by microRNA21 is related to higher stage prostate cancer

\section{Congressos}

1. XXVII Congresso Brasileiro de Patologia

2. $56^{\circ}$ Congresso Brasileiro de Genética

3. International Congress of the International Academy of Pathology

\section{Prêmio}

1. XXVII Congresso Brasileiro de Patologia

$4^{\circ}$ lugar - Apresentação oral

Ética

1. Aprovação no comité de ética $0453 / 08$ 
TGF- $\beta 1$ expression, a biomarker of poor prognosis in prostate cancer

Sabrina Thalita dos Reis ${ }^{1,2}$ PhD., José Pontes-Júnior ${ }^{1,2}$ M.D. PhD., Alberto Azoubel Antunes ${ }^{1,2}$ M.D. PhD., Juliana Moreira de Sousa-Canavez $z^{3}$ PhD., Daniel Kanda $\mathrm{Abe}^{2}$ M. D., José Arnaldo Shiomi da Cruz 1, Marcos Francisco Dall'Oglio $^{2}$ M.D. PhD., Nayara Izabel Vianaํ, Miguel Srougi¹ M.D. PhD. , Kátia Ramos Moreira Leite ${ }^{1}$ M.D. PhD.

1- Laboratory of Medical Investigation (LIM55), Urology Department, University of Sao Paulo Medical School, Sao Paulo, Brazil

2- Uro-Oncology Group, Urology Department, University of Sao Paulo Medical School, Sao Paulo, Brazil

3- Genoa Biotechnology SA, Sao Paulo, Brazil

Running Title: TGF- $\beta$ in prostate cancer

\section{Correspondence:}

Sabrina Thalita dos Reis

Av. Dr. Arnaldo 455, $2^{\text {nd }}$ floor, room 2145

01246-903, Sao Paulo, Brazil

sasareis@gmail.com 


\section{Abstract}

objective: To evaluate the correlation between TGF- $\beta$ expression and prognosis in prostate cancer.

Patients and Methods: TGF- $\beta$ expression levels were analyzed by quantitative real-time polymerase chain reactions (qRT-PCR) in fresh-frozen malignant and benign tissue specimens collected from 89 patients with clinically localized $\mathrm{PCa}$ who were treated with radical prostatectomy. The control group consisted of 11 patients with benign prostate hyperplasia (BPH). TGF- $\beta$ expression levels were compared with Gleason scores, staging and PSA serum levels.

Results: In the majority of tumor samples, TGF- $\beta$ was underexpressed (6.07 x $\left.10^{-1}\right)$. The same profile was identified in benign tissues of patients with PCa. Although most cases showed underexpression of TGF- $\beta$, a higher expression was found in patients with Gleason scores $\geq 7$, when compared with those patients with Gleason scores $<7(p=0.002)$. Among 26 cases of TGF- $\beta$ overexpression, $92.3 \%$ had poor prognosis characteristics.

Conclusion: TGF- $\beta$ is underexpressed in $\mathrm{PCa}$, however, higher expression was observed in tumors with higher Gleason scores, suggesting this gene may be a useful prognostic marker. Further studies in clinical specimens should be done in order to clarify the role of TGF- $\beta$ in prostate carcinogenesis.

Keywords: Prostate cancer, prognosis, molecular markers 


\section{Introduction}

Prostate cancer $(\mathrm{PCa})$ is the most common male malignancy and the second leading cause of death in many countries, including Brazil [1]. Staging, Gleason scores and PSA serum levels are the most important prognostic factors, but even together they do not perfectly identify those patients at risk for progression [2]. Therefore, research has been aimed toward the identification of molecular markers that can predict PCa predisposition and progression.

TGF- $\beta$ is the prototypic member of a superfamily that consists of more than 25 members. Some of the members include inhibin, bone morphogenic protein, and Mullerian inhibiting substance. The TGF- $\beta$ sub-family contains five members: TGF- $\beta 1,-\beta 2,-\beta 3,-\beta 4$ and $\beta 5$. TGF- $\beta 1,-\beta 2$, and $-\beta 3$ have been identified in mammals [3,4]. Although TGF- $\beta$ is a pleiotropic growth factor, it inhibits growth in most cell types, especially to those of epithelial lineage. It also inhibits prostatic epithelial cell proliferation and induces apoptosis [5, 6]. TGF- $\beta$ is an important transcriptional regulator of extracellular matrix components, apart from its numerous effects on cell proliferation, phenotype and differentiation [7].

The process of malignant transformation is characterized by multiple genetic mutations leading to an additional growth advantage when compared with benign cells. The development of prostate cancer is not an exception. Regarding TGF- $\beta$, two important events always appear to be associated with the conversion from a benign state to a malignant state. They are 1) a loss of or 
reduction in the sensitivity to the inhibitory effect of TGF- $\beta$, and 2) an increase in ability to elevate TGF- $\beta$ expression levels, which assists the carcinogenesis process by stimulating extracellular matrix production, promoting angiogenesis, and inhibiting the host immune system [8].

To evaluate whether the expression levels of TGF- $\beta 1$ in prostate cancer cells are associated with prognosis as postulated by the second event of carcinogenesis, we investigated a possible correlation between TGF- $\beta$ gene expression and Gleason scores, pathological stages and PSA serum levels. 


\section{Patients and Methods}

\section{Patients}

The study was conducted using surgical specimens from 79 patients with clinically localized PCa who underwent radical prostatectomy in our institution between 1993 and 2007; patients with a minimum follow up of 5 years were randomly selected in a frozen tumor tissue database (table 1). Additionally, we analyzed benign tissue samples from 10 patients with $\mathrm{PCa}$ who also underwent radical prostatectomy. Patients who had undergone other treatments for $\mathrm{PCa}$ were excluded. All subjects provided informed consent to participate in the study and to allow their biological samples to be genetically analyzed. Approval for the study was given by the Institutional Board of Ethics ( $\mathrm{n}^{0} 0453 / 08$ ).

We correlated the expression levels of the TGF- $\beta$ genes with Gleason scores, pathological TNM 2002 stage and serum PSA levels $(\mathrm{ng} / \mathrm{mL})$. For analysis, pathological stage was considered as organ-confined (pT2) or nonorgan-confined (pT3) disease. Gleason scores were classified as low grade (Gleason score $<7$ ) and high grade (Gleason score $\geq 7$ ), and preoperative PSA was also used to identify patients at high risk $(\geq 10 \mathrm{ng} / \mathrm{mL})$ and low risk $(<10$ $\mathrm{ng} / \mathrm{mL}$ ) for disease recurrence. In addition, in a mean follow-up time of 60 months, we analyzed the gene expression levels in cases of biochemical recurrence, which was defined as PSA levels $>0.4 \mathrm{ng} / \mathrm{mL}$. 
The control group consisted of tissue specimens from 11 patients with $\mathrm{BPH}$ who presented with lower urinary tract symptoms and an indication to undergo surgery (mean age $64 \pm 6.0$ years).

\section{RNA Isolation and cDNA Synthesis}

All tumor samples were obtained from surgical specimens and immediately frozen at $-170^{\circ} \mathrm{C}$ in liquid nitrogen. A slide with a mirror of the frozen fragment was stained with hematoxylin and eosin for verification that the tumor represented at least $75 \%$ of the fragment in patients with cancer and that no tumors were present in those with $\mathrm{BPH}$.

Total RNA was isolated with the RNAaqueous Kit (Applied Biosystems, CA, USA), according to the manufacturer's instructions. The RNA concentration was determined by $260 / 280 \mathrm{nM}$ absorbance with a Nanodrop® ND-1000 spectrophotometer (Thermo Scientific, DE, EUA). cDNA was generated using the High Capacity cDNA Reverse Transcription Kit (Applied Biosystems, CA, USA). The reactions were incubated at $25^{\circ} \mathrm{C}$ for $10 \mathrm{~min}$ followed by $37^{\circ} \mathrm{C}$ for 120 $\min$ and $85^{\circ} \mathrm{C}$ for $5 \mathrm{~min}$. The cDNA was stored at $-20^{\circ} \mathrm{C}$ until further use.

\section{Quantitative Real-Time PCR and Gene Expression}

The expression level of the TGF- $\beta 1$ gene was analyzed by qRT-PCR using the $\mathrm{ABI} 7500$ fast system (Applied Biosystems, CA, USA). The target 
sequences were amplified in a $10 \mu$ reaction volume containing $5 \mu$ of TaqMan® Universal PCR Master Mix, $0.5 \mu \mathrm{l}$ of TaqMan® Gene Expression Assays (TGF- $\beta$ Hs00852894_m1; and B2M Hs99999907_m1), $1 \mu$ l of cDNA, and 3.5 $\mu$ l of DNase-free water. The PCR cycling conditions were 2 minutes at $50^{\circ} \mathrm{C}$ and 10 minutes at $95^{\circ} \mathrm{C}$ followed by 40 cycles of 15 seconds at $95^{\circ} \mathrm{C}$ and $1 \mathrm{~min}$ at $60^{\circ} \mathrm{C}$. The TaqMan endogenous control assay utilized was $\mathrm{B} 2 \mathrm{M}$.

We used the $\triangle \Delta C T$ method to calculate the relative expression of the three target genes using the formula $\Delta \Delta C T=(C T$ target gene, PCa sample $-\mathrm{CT}$ endogenous control, PCa sample) - (CT target gene, BPH sample - CT endogenous control, BPH sample). The fold change in gene expression was calculated as $2^{-\Delta \Lambda C T}$.

\section{Statistical Analysis}

The quantitative variables were expressed through median value, interquartile range (Q1-Q3), and minimum and maximum values. Qualitative variables were expressed as number and percentage. For descriptive analysis of TGF- $\beta$ expression according to pathological stages, Gleason scores and PSA levels, we constructed a box plot. For comparison between categories, we used the Mann-Whitney test. Statistical analysis was performed using GraphPad Prism 3, and significance was set at $p \leq 0.05$. 


\section{Results}

As shown in Figure 1, analysis of the 79 patients with PCa showed that TGF- $\beta 1$ was underexpressed (median $6.07 \times 10^{-1}$ times) in malignant prostatic tissue as compared to BPH samples.

TGF- $\beta 1$ expression level according to Gleason scores are shown in Table 2. The median expression levels of TGF- $\beta 1$ were significantly higher $(p=0.0065)$ among patients with Gleason scores $\geq 7\left(9.4 \times 10^{-1}\right.$ times) when compared with those with Gleason scores $<7\left(4.6 \times 10^{-1}\right.$ times $)$. Regarding the pathological stage, expression of TGF- $\beta 1$ was statistically similar $(p=0.2514)$ between patients staged pT3 (median $4.9 \times 10^{-1}$ times) and pT2 (median $6.6 \times 10^{-1}$ times). When the results were evaluated according to preoperative PSA values, median TGF- $\beta 1$ expression levels were also statistically similar $(p=0.5110)$ among patients with PSA levels $\geq 10 \mathrm{ng} / \mathrm{mL}\left(6.7 \times 10^{-1}\right.$ times $)$ compared to patients with PSA levels $<10\left(5.5 \times 10^{-1}\right.$ times $)$.

We found overexpression of TGF- $\beta 1$ in 26 cases. Of these, 21 (80.7\%) had Gleason scores $\geq 7,13(50 \%)$ had PSA levels $\geq 10 \mathrm{ng} / \mathrm{ml}, 12(46 \%)$ were staged pT3 and $9(6 \%)$ showed biochemical recurrence. Only $2(7.7 \%)$ patients with overexpression of this gene showed no unfavorable prognostic factor.

We also evaluated the expression levels of TGF- $\beta 1$ with biochemical recurrence defined as a PSA level above $0.4 \mathrm{ng} / \mathrm{ml}$ in a mean follow up period of 60 months. Median TGF- $\beta 1$ expression levels were statistically similar $(p=0.528)$ among patients with or without recurrence $\left(5.4 \times 10^{-1}\right.$ and $6.1 \times 10^{-1}$ respectively). 
We performed the multivariate analysis and the Gleason score was the unique independent prognostic factor in our series $(p=0.022)$.

Additionally, testing the expression of TGF- $\beta 1$ in the benign prostatic tissue from 10 patients with $\mathrm{PCa}$, we observed the same profile of expression as observed in malignant tissue (median $\left.1.7 \times 10^{-1}\right)(p=0.05)$. 


\section{Discussion}

In this study we demonstrated that TGF- $\beta 1$ was underexpressed in malignant prostatic tissue as compared to BPH samples (median $7 \times 10^{-1}$ times). Thus we may assume that TGF- $\beta$ contributes to the development of prostate cancer by acting as an inhibitor of cell proliferation and inductor of apoptosis $[8,9]$. Furthermore, we identified a higher TGF- $\beta$ expression in tumors with higher Gleason scores, suggesting that this gene may have a role in $\mathrm{PCa}$ progression and prognosis.

Soulitzis et al.[10] also has shown decreases in TGF- $\beta$ expression in PCa. TGF- $\beta$ is generally a growth-inhibitor to both benign prostatic epithelial cells [11] and prostate cancer cells in vitro [12]. It has been shown to inhibit proliferation and induce apoptosis in prostatic epithelial cells $[8,13]$.

Moreover, TGF- $\beta$ stimulates the synthesis of collagens, fibronectin, and integrins, and inhibits matrix degradation through the down-regulation of proteinases, such as collagenases, stromelysins, and plasminogen activators [14]. Paired with its down-regulation of proteinases, TGF- $\beta$ upregulates proteinase inhibitors, such as the endogenous MMP-inhibitors, tissue inhibitor of metalloproteinase-1 (TIMP-1) [15] and the plasminogen activator inhibitor-1 [16]. It also exerts its action as a repressor of matrix metalloproteinase expression through the TGF- $\beta$ inhibitory element (TIE) found in the 5 '-flanking region of 
several genes of the MMP-family, namely the interstitial collagenase (MMP-1), and 92-KDa type IV collagenase (MMP-9) [17].

Interestingly, quantitative analysis showed a positive association between increased TGF- $\beta 1$ mRNA levels and higher Gleason scores $(p=0.002)$. Although controversial, this finding is similar to a previous study in which TGF- $\beta$ plasma levels were seen to be elevated in men with PCa metastases compared with healthy men [18]. Shariat et al.[19] also found a strong correlation between elevated plasma TGF- $\beta$ and prostate cancer progression and development of metastases in patients with locally advanced disease. Faria et al.[20] demonstrated that among patients with $\mathrm{PCa}$, the relative levels of TGF- $\beta 1$ mRNA increased during the late stages of the disease.

Some authors have suggested that decreased expression of TGF- $\beta$ is not completely necessary as some tumor cells could escape the inhibitory effect of TGF- $\beta$ through mutations that would provide a growth advantage over their benign counterparts. It is also known that both TGF- $\beta$ receptors, T $\beta R$-I and T $\beta R$ II, are required for proper transduction of TGF- $\beta$ signaling [21] and prostate

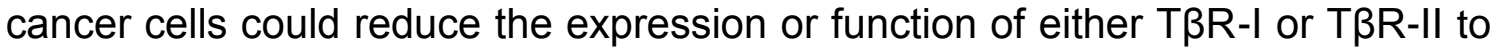
escape the growth-inhibitory effect of TGF- $\beta$. This loss of sensitivity to TGF- $\beta$ by the receptors, could induce a compensatory overexpression of TGF- $\beta$, leading to more aggressive phenotypes [22]. 
Studies have suggested that the tumor suppression versus oncogenic effects of TGF- $\beta$ are contextual and/or dependent upon the temporal stage of cellular transformation [23]. A recent report identified activation of TGF- $\beta$ pathways that would be responsible for mediating the epithelial-mesenchymal transition (EMT), enhancing invasiveness and survival of transformed cells [24]. Also TGF- $\beta$ can alter the host-tumor interaction, facilitating tumor growth, promoting angiogenesis, and inhibiting the host immune system $[9,25]$.

Examining benign prostate tissue from patients with $\mathrm{PCa}$ treated by radical prostatectomy, we observed the same profile of TGF- $\beta$ expression as in malignant tissue. This is interesting because we could propose the use of TGF- $\beta$ as a tumor marker, overcoming the sampling error that is commonly seen in conventional prostate biopsies; larger studies should validate our findings, however.

In conclusion, we showed for the first time in clinical specimens that decreased expression of TGF- $\beta$ is a characteristic of prostate cancer and should be related to cancer initiation and promotion; its role as a regulator of cell growth and apoptosis should be confirmed in larger series. On the other hand, TGF- $\beta$ superexpression should be related to tumor progression, since it is more highly expressed by more aggressive tumors and this aspect could be explained by mutations conferring resistance to TGF- $\beta$ receptors. This hypothesis also deserves further experimental studies in order to indicate TGF- $\beta$ as a diagnostic or prognostic marker. 
Grant sponsors: This study was supported by FAPESP (Fundação de Amparo à Pesquisa do Estado de Sao Paulo) under protocol number 2009/50368-9. 


\section{References}

1. Jemal A, Siegel R, Ward E, et al. Cancer statistics, 2009. CA Cancer J Clin 59: 1-25, 2009

2. Partin AW, Kattan MW, Subong EN, Walsh PC, Wojno KJ, Oesterling JE, et al. Combination of prostate-specific antigen, clinical stage, and Gleason score to predict pathological stage of localized prostate cancer. A multiinstitutional update. JAMA 277: 1445-1451, 1997.

3. Derynck R, Jarret JA, Chen EY, Eaton DH, Bell JR, Assoian RK, Roberts AB, Sporn MB, Geoddel DV. Human transforming growth factor-b complementary DNA sequences and expression in normal and transformed cells. Nature 316:701-705, 1985.

4. Madison L, Webb NR, Rose TM, Marquardt H, Ikeda T, Twardzik D, Seyedin S, Purchio AF. Transforming growth factor-beta 2: cDNA cloning and sequence analysis. DNA 7:1-8, 1988.

5. Sutkowski DM, Fong C-J, Sensibar JA, Rademaker AW, Sherwood ER, Kozlowski JM, Lee C. Interaction of epidermal growth factor and transforming growth factor-b1 in human prostatic epithelial cells in culture. Prostate 21:133-143, 1992.

6. Wilding G. Response of prostate cancer cells to peptide growth factor: transforming growth factor-b. Cancer Surv 11:147-163, 1991.

7. Alexandrow MG, Moses HL. Transforming growth factor $\beta$ and cell cycle regulation. Cancer Res 55: 1452-1457, 1995

8. Lee C, Sintich SM, Mathews EP, Shah AH, Kundu SD, Perry KT, Cho JS et al. Transforming Growth Factor- $\beta$ in Benign and Malignant Prostate. The Prostate 39: 285-290, 1999 
9. Yang EY, Moses HL. Transforming growth factor b1-induced changes in cell migration, proliferation, and angiogenesis in the chicken chorioallantoic membrane. J Cell Biol 111:731-741, 1990.

10. Soulitzis N, Karyotis I, Delakas D, Spandidos D. Expression analysis of peptides growth factors VEGF, FGF2, TGF $\beta 1$, EGF and IGF1 in prostate cancer and benign prostatic hyperplasia. Int. Journal of Oncology 29: 305314, 2006

11. Sutkowski DM, Fong C-J, Sensibar JA, Rademaker AW, Sherwood ER, Kozlowski JM, Lee C. Interaction of epidermal growth factor and transforming growth factor-b1 in human prostatic epithelial cells in culture. Prostate 21:133-143, 1992.

12. Wilding G. Response of prostate cancer cells to peptide growth factor: transforming growth factor-b. Cancer Surv 11:147-63, 1991.

13. Martikainen P, Kyprianou N, Isaacs JT. Effect of transforming growth factorb1 on proliferation and death of rat prostatic cells. Endocrinology 127:29632968, 1990

14. Franzèn $P$, Ichijo $H$, Miyazono $K$. Different signals mediate transforming growth factor_1-induced growth inhibition and extracellular matrix production in prostatic carcinoma cells. Exp Cell Res 207: 1-7, 1993.

15. Edwards DR, Leco KJ, Beaudry PP et al. Differential effects of transforming growth factor-beta1 on the expression of matrix metalloproteinases and tissue inhibitors of metalloproteinases in young and old human fibroblasts. Exp Gerontol 31: 207-223, 1996.

16. Arnoletti JP, Albo D, Granick MS et al. Thrombospondin and transforming growth factor-beta 1 increase expression of urokinase-type plasminogen 
activator and plasminogen activator inhibitor-1 in human MDA-MB-231 breast cancer cells. Cancer 76: 998-1005, 1995.

17. Matrisian LM. Matrix metalloproteinase gene expression. Ann NY Acad Sci 732: 42-50, 1994.

18.Shariat, S.F.; Menesses-Diaz, A.; Kim, I.Y.; Muramoto, M.; Wheeler, T.M.; Slawin, K.M. Tissue expression of transforming growth factor-eta1 and its receptors: correlation with pathologic features and biochemical progression in patients undergoing radical prostatectomy. Urology 63(6), 1191-7, 2004.

19.Shariat, S.F.; Kattan, M.W.; Traxel, E.; Andrews, B.; Zhu, K.; Wheeler, T.M.; et al. Association of pre and postoperative plasma levels of transforming growth factor beta(1) and interleukin 6 and its soluble receptor with prostate cancer progression. Clin Cancer Res. 10(6), 1992-1999.

20. Faria PC, Saba K, Neves AF, Cordeiro ER, Marangoni K, Freitas DG, Goulart LR. Transforming Growth Factor-Beta1 gene polymorphisms and expression in the blood of Prostate Cancer patients. Cancer investigation 25:726-732, 2007

21. Wrana JL, Attisano L, Wieser R, Ventura F, Massague J. Mechanism of activation of the TGF-b receptor. Nature 370:341-347, 1994.

22. Barrack ER. TGF-b on prostate cancer: a growth inhibitor that can enhance tumorigenicity. Prostate 31:61-70, 1997.

23.Bello-DeOcampo, D.; Tindall, D.J. TGF-betal/Smad signaling in prostate cancer. Curr. Drug Targets 4(3), 197-207, 2003.

24.Prindull, G.; Zipori,D. Environmental guidance of normal and tumor cell plasticity: epithelial mesenchymal transitions as a paradigm. Blood. 103(8), 2892-2899, 2004 
25. Letterio JJ, Roberts AB. Regulation of immune responses by TGF-b. Annu Rev Immunol 16:137-161, 1998. 
Table 1. Relative expression of the TGF- $\beta 1$ gene in the malignant prostatic tissue according to Gleason score, Pathological stage, PSA value and Recidive biochemical. Fold change in gene expression was calculated using the $\triangle \Delta C T$ method $\left(\mathrm{QRel}=2^{-\Delta \Lambda \mathrm{CT}}\right)$.

\begin{tabular}{ll} 
& TGF- $\boldsymbol{\beta}$ \\
Gleason Score & \\
$<7(n=32)$ & $0.46(0.02-6.20)$ \\
$\geq 7(n=36)$ & $0.93(0.02-33.3)$ \\
p-value & $\mathbf{0 . 0 0 6}$ \\
\hline Pathological & \\
Stage & \\
pT2 $(n=37)$ & $0.65(0.02-33.3)$ \\
pT3 $(n=40)$ & $0.48(0.04-18.9)$ \\
p-value & 0.249 \\
\hline PSA value & \\
$<10(n=45)$ & $0.55(0.04-33.3)$ \\
$\geq 10(n=33)$ & $0.67(0.02-14.3)$ \\
$p-v a l u e$ & 0.508 \\
\hline Recidive & \\
Biochemical & \\
W/n $(n=29)$ & $0.60(1.12-33.3)$ \\
With $(n=28)$ & $0.54(0.04-18.9)$ \\
$p-v a l u e$ & 0.523 \\
\hline
\end{tabular}


Table 2. Primers utilized

\begin{tabular}{ll}
\hline Gene symbol & Assays ID \\
\hline TGF- $\boldsymbol{\beta}$ & Hs00852894_m1 \\
B2M & Hs99999907_m1 \\
\hline
\end{tabular}

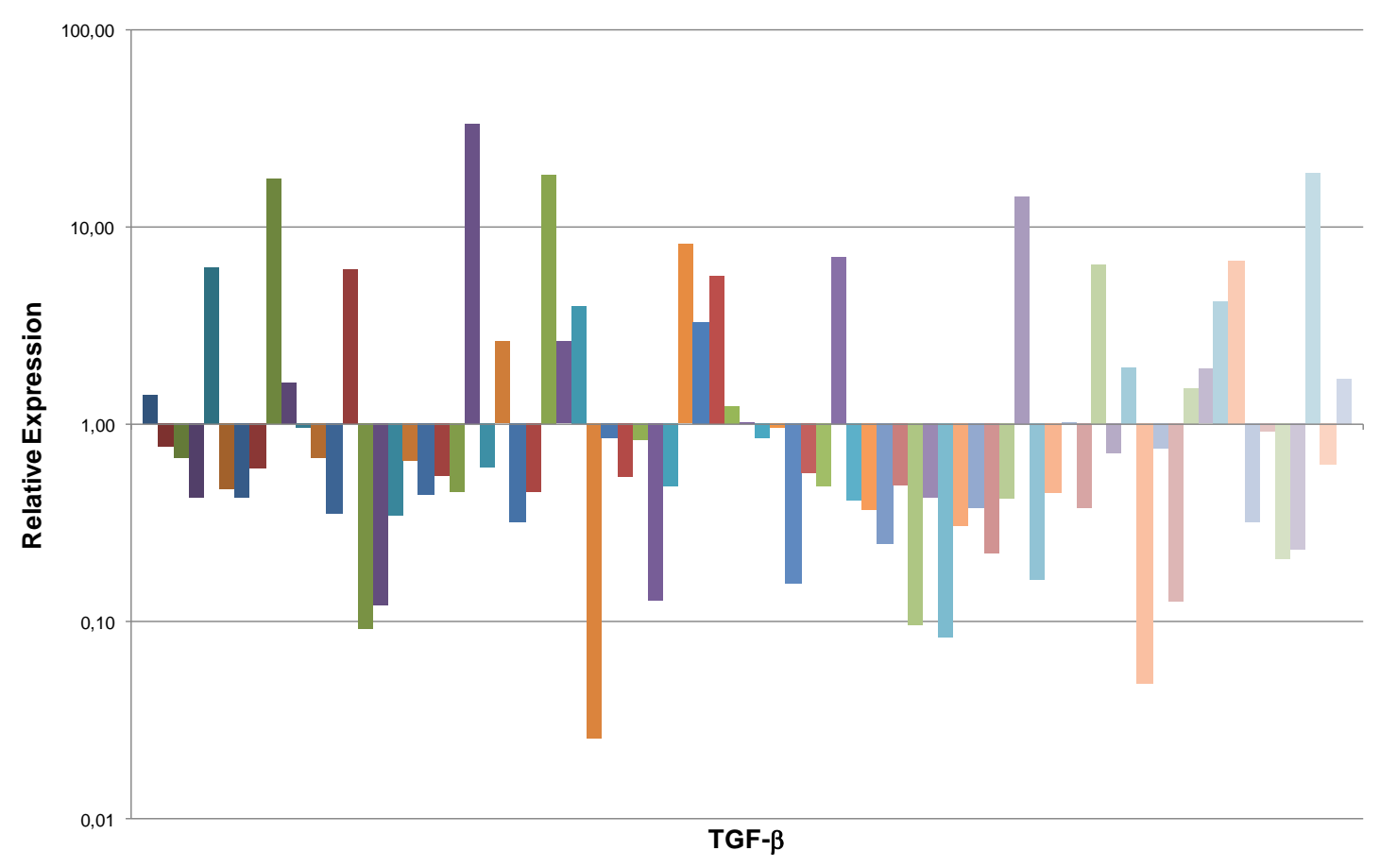

Figure 1. Quantitative expression of TGF- $\beta 1$ in malignant prostatic tissue 


\section{MMP-9, TIMP-1 and RECK profiles are altered in prostate cancer}

Sabrina Thalita Reis ${ }^{1,2}$ PhD., José Pontes-Junior ${ }^{1},{ }^{2}$ M.D. PhD., Alberto Azoubel Antunes $^{1,2}$ M.D. PhD., Juliana Moreira de Sousa-Canavez ${ }^{3}$ PhD., Marcos Francisco Dall'Oglio $^{1,2}$ M.D. PhD., Carlo C. Passerotti' M.D. PhD., Daniel Kanda Abe M.D.1,2, Alexandre Crippa ${ }^{2}$ M.D. PhD., Jose Arnaldo Shiomi da Cruz', Luciana M. S. Timoszczuk1, Miguel Srougi ${ }^{1,2}$ M.D. PhD., Kátia R. M. Leite ${ }^{1,2}$ M.D. PhD.

1 - Laboratory of Medical Investigation (LIM55), Urology Department, University of Sao Paulo Medical School, Sao Paulo, Brazil

2 - Uro-Oncology Group, Urology Department, University of Sao Paulo Medical School, Sao Paulo, Brazil

3 - Genoa Biotechnology SA, Sao Paulo, Brazil.

\section{Corresponding author:}

Sabrina Thalita Reis

Av. Dr. Arnaldo 455, $2^{\circ}$ floor, room 2145

01246-903, Sao Paulo, Brazil

sasareis@gmail.com

Running Title: Metalloproteinases in prostate cancer 


\section{Abstract}

Objective: Extracellular matrix homeostasis is strictly maintained by a coordinated balance between the expression of metalloproteinases (MMPs) and their inhibitors. The purpose of this study was to investigate whether the expression of MMP-9 and its specific inhibitors, TIMP-1 and RECK, are expressed in a reproducible, specific pattern and if the profiles are related to prognosis and clinical outcome in prostate cancer (PC).

Materials and Methods: MMP-9, TIMP-1 and RECK expression levels were analyzed by quantitative real-time polymerase chain reaction (qRT-PCR) in fresh-frozen malignant tissue specimens collected from 69 patients with clinically localized PC submitted to radical prostatectomy (RP). Frozen benign prostatic tissue from another 10 men with prostate cancer, also submitted to RP, was analyzed to determine if the profile of gene expression were maintained. The control group consisted of 11 patients with benign prostate hyperplasia (BPH).

Results: In the tumor samples, MMP-9 was overexpressed $\left(4.1 \times 10^{\circ}\right)$, and TIMP-1 and RECK were underexpressed $\left(7.5 \times 10^{-1}\right.$ and $8.0 \times 10^{-1}$, respectively). Overexpression of MMP-9 was significantly related to PSA levels above $10 \mathrm{ng} / \mathrm{mL}(\mathrm{p}=0.033)$. In addition, MMP-9 overexpression was related to biochemical recurrence, with a marginal statistical significance $(p=0.089)$. MMP9 was also overexpressed in benign tissues of patients with PC, as were TIMP-1 and RECK, in contrast to their underexpression in tumor samples.

Conclusion: Our results show that MMP-9 is overexpressed and its negative regulators are underexpressed in PC tissue, emphasizing a possible role of 
MMP-9 in the carcinogenesis process. Additionally, we noticed a relationship between MMP-9 overexpression and increased levels of PSA, an important prognostic factor. In benign tissue adjacent to tumors, the MMP-9 equilibrium is likely maintained because the expression of its negative regulators is preserved. Key words: Prostate cancer; Matrix Metalloproteinase; Prognosis; Diagnosis; Gene expression 


\section{Abbreviations:}

Benign prostatic hyperplasia - BPH

Complementary deoxyribonucleic acid - cDNA

Extracellular matrix - ECM

Matrix metalloproteinase - MMP

Prostate cancer - PC

Prostate-specific antigen - PSA

Quantitative real-time polymerase chain reaction - qRT-PCR

Reversion-inducing cysteine-rich protein with Kazal motif - RECK

Ribonucleic acid - RNA

Tissue inhibitor of metalloproteinases 1 - TIMP-1 


\section{Introduction}

Prostate cancer $(\mathrm{PC})$ is a common disease with a multifactorial and complex etiology. It is the most common male malignancy and the second leading cause of death among men in many countries, including Brazil. In the United States, 217,730 new cases and 32,060 deaths related to PC are estimated for the year $2010^{[1]}$.

The widespread use of prostate-specific antigen (PSA) has increased prostate cancer the detection rates at earlier stages. However, up to $20 \%$ of clinically localized cases present disease recurrence after local radical treatment in a 10-year follow-up period ${ }^{[2]}$. In addition, current clinical and pathological parameters fail to determine an accurate prognosis in many cases ${ }^{[3]}$. Therefore, research has been directed at the identification of molecular markers that can predict PC outcome.

Degradation of basal membranes and the extracellular matrix (ECM) is essential for tumor invasion and development of metastases, and matrix metalloproteinases (MMPs) are potent proteolytic enzymes that are known to play a key role in these processes. Within the MMP family, Matrix Metallproteinase 2 (MMP-2) (gelatinase A, $72 \mathrm{kDa}$ ) and Matrix Metalloproteinase 9 (MMP-9) (gelatinase B, $92 \mathrm{kDa}$ ) cleave type IV collagen and gelatin, which are the main structural components of the basal membrane ${ }^{[4]}$. Expression of MMP-9 has been implicated in the development and progression of many neoplasias, such as bladder ${ }^{[5]}$, colorectal ${ }^{[6]}$, skin ${ }^{[7]}$ and lung cancer ${ }^{[8]}$. The balance 
between secreted MMPs and their specific inhibitors plays an important role in maintaining connective tissue homeostasis in normal tissue ${ }^{[9]}$. In neoplastic diseases, an imbalance between MMPs and their inhibitors, leading to an excess of degradative activity, is assumed to be linked to the invasive character of tumor cells ${ }^{[10,11,12]}$.

The aim of the present study was to investigate whether MMP-9 and its specific inhibitors, Tissue inhibitors of metalloproteinases 1 (TIMP-1) and Reversion-inducing cysteine-rich protein with Kazal motifs (RECK), are expressed in a reproducible, specific pattern in PC. Additionally, we evaluated the correlation between the expression of these genes and three important prognostic parameters (Gleason score, pathological stage and PSA serum levels) and outcome in patients with localized PC submitted to radical prostatectomy. 


\section{Patients and Methods}

\section{Patients}

The study was conducted using surgical specimens from 79 patients with clinically localized PC who underwent radical prostatectomy in our institution between 1993 and 2007. Additionally, we analyzed benign tissue samples from 10 patients with PC who also underwent radical prostatectomy. These cases were randomly selected from our database. The patients belong to a private clinic, all patients underwent surgery by the same surgeon, and they were followed by measuring the PSA in the first 5 years each 6 months and then annually. We excluded from the study patients who undergone adjuvant or neoadjuvant treatment. All subjects provided informed consent to participate in the study and to allow their biological samples to be genetically analyzed. Approval for the study was given by the Institutional Board of Ethics (no. 0453/08).

We first analyzed MMP-9, TIMP-1 and RECK expression levels in fresh tumor specimens from the 79 PC patients using quantitative real-time polymerase chain reaction (qRT-PCR). The clinical and pathological characteristics of these specimens are listed in Table 1. The control group consisted of tissue specimens from 11 patients with benign prostatic hyperplasia (BPH) who presented with lower urinary tract symptoms and were submitted to retropubic prostatic resection (mean age $64 \pm 6.0$ years). 
We then correlated the expression levels of the genes with Gleason score, pathological stage (TNM 2010) and pre-operative serum PSA levels $(\mathrm{ng} / \mathrm{mL})$. For analysis, pathological stage was considered as organ-confined (pT2) or non-organ-confined (pT3) disease, Gleason score was classified as low grade (Gleason score $\leq 6$ ) or high grade (Gleason score $\geq 7$ ), and preoperative PSA was also used to identify patients at high risk $(\geq 10 \mathrm{ng} / \mathrm{mL})$ and low risk $(<10$ $\mathrm{ng} / \mathrm{mL}$ ) for disease recurrence. In addition, in a mean follow-up time of 60 months, we analyzed the gene expression levels in cases of biochemical recurrence, wich was defined as PSA levels $>0.4 \mathrm{ng} / \mathrm{mL}$.

Finally, we evaluated the expression levels of MMP and its negative regulators in benign prostatic tissue from 10 other patients with PC submitted to radical prostatectomy. 


\section{RNA Isolation and cDNA Synthesis}

All tumor samples were obtained from surgical specimens and immediately frozen at $-170^{\circ} \mathrm{C}$ in liquid nitrogen. A slide with a mirror of the frozen fragment was stained with hematoxylin and eosin to verify that the tumor represented at least $75 \%$ of the fragment in patients with cancer and to demonstrate the absence of tumor in those with $\mathrm{BPH}$.

Total RNA was isolated with an RNAaqueous Kit (Applied Biosystems, CA, USA) according to the manufacturer's instructions. RNA concentration was determined by 260/280 nM absorbance using a Nanodrop ND-1000 spectrophotometer (Thermo Scientific). cDNA was generated using a High Capacity cDNA Reverse Transcription Kit (Applied Biosystems, CA, USA). The reactions were incubated at $25^{\circ} \mathrm{C}$ for $10 \mathrm{~min}$, followed by $37^{\circ} \mathrm{C}$ for $120 \mathrm{~min}$ and $85^{\circ} \mathrm{C}$ for $5 \mathrm{~min}$. The $\mathrm{CDNA}$ was stored at $-20^{\circ} \mathrm{C}$ until further use.

\section{Quantitative Real-Time PCR and Gene Expression}

Expression levels of the three genes were analyzed by qRT-PCR using an ABI 7500 Fast Real-Time PCR System (Applied Biosystems). Target sequences were amplified in a $10-\mu \mathrm{l}$ reaction containing $5 \mu \mathrm{l}$ of TaqMan Universal PCR Master Mix, $0.5 \mu$ l of TaqMan Gene Expression Assays (primers and probes; see Table 2), $1 \mu \mathrm{l}$ of cDNA and $3.5 \mu \mathrm{l}$ of DNase-free water. The 
PCR cycling conditions were 2 minutes at $50^{\circ} \mathrm{C}, 10$ minutes at $95^{\circ} \mathrm{C}$, and then 40 cycles of 15 seconds at $95^{\circ} \mathrm{C}$ and 1 min at $60^{\circ} \mathrm{C}$. A TaqMan B2M assay was utilized as the endogenous control (Table 1).

We used the $\triangle \Delta C T$ method to calculate the relative expression of the three target genes using the formula $\Delta \Delta \mathrm{CT}=(\mathrm{CT}$ target gene, $\mathrm{PC}$ sample $-\mathrm{CT}$

endogenous control, PC sample) - (CT target gene, BPH sample - CT endogenous control, BPH sample). The fold change in gene expression was calculated as $2^{-\Delta \Delta C T}$.

\section{Statistical Analysis}

Quantitative variables were expressed as median values, interquartile range (Q1-Q3), and minimum and maximum values. Qualitative variables were expressed as number and percentage. To compare the clinical characteristics of patients with PC, we used the Mann-Whitney, chi-squared and Fisher exact tests. For descriptive analysis of MMP-9, TIMP-1 and RECK expression according to pathological stage, Gleason score and PSA, we constructed a box plot, and for comparison between categories, we used the Mann-Whitney test. Statistical analysis was performed using SPSS 15.0 for Windows, and significance was set at $p \leq 0.05$. 


\section{Results}

As shown in Figure 1, the analysis of 79 patients with PC showed that MMP-9 was overexpressed (median 9.2 times) and TIMP-1 and RECK were underexpressed (median $7.5 \times 10^{-1}$ and $8.0 \times 10^{-1}$ times, respectively) in malignant prostatic tissue relative to $\mathrm{BPH}$ samples. When the results were evaluated according to preoperative PSA value, we found that patients with PSA $\geq 10 \mathrm{ng} / \mathrm{mL}$ had higher MMP-9 expression levels (median 5.61 times) than patients with PSA $<10 \mathrm{ng} / \mathrm{mL}$ (median 2.75 times; $\mathrm{p}=0.033$ ). The median expression levels of RECK and TIMP-1 were statistically similar (Table 3).

Our analysis of MMP-9, TIMP-1 and RECK expression levels according to biochemical recurrence is shown in Table 3. Overexpression of MMP-9 was higher among patients with biochemical recurrence (median 6.28 times) compared to those without recurrence (median 3.24 times; $p=0.09$ ).

When MMP-9, TIMP-1 and RECK expression levels were analyzed according to pathological stage, we found that the median expression levels of MMP-9 (4.94 and 2.66 times), TIMP-1 (8.38 $\times 10^{-1}$ and $7.19 \times 10^{-1}$ times) and $\operatorname{RECK}\left(8.89 \times 10^{-1}\right.$ and $6.38 \times 10^{-1}$ times $)$ were statistically similar between patients staged $\mathrm{pT} 2$ and those staged $\mathrm{pT} 3$, respectively (MMP-9, $\mathrm{p}=0.134$; TIMP-1, $p=0.585 ;$ RECK, $p=0.262$ ). With regard to Gleason score, expression of RECK (6.6 $\times 10^{-1}$ and $9.19 \times 10^{-1}$ times), MMP-9 $\left(3.64 \times 10^{0}\right.$ and $4.2 \times 10^{0}$ times $)$ and TIMP-1 $\left(6.39 \times 10^{-1}\right.$ and $7.53 \times 10^{-1}$ times $)$ did not significantly differ 
between patients with a Gleason score $\geq 7$ and those with a Gleason score $<7$, respectively (Table 3).

In the third part of the study, MMP-9, TIMP-1 and RECK expression levels were determined in benign prostatic tissue from patients with PC to test whether the expression pattern observed in tumor tissues would be maintained. While the expression pattern of MMP-9 was similar to that found in malignant prostatic tissue, TIMP-1 and RECK were overexpressed in benign tissue from patients with PC compared to those with BPH in most cases. However, statistical analysis revealed that these differences were not significant. 


\section{Discussion}

The present study demonstrates that MMP-9 is overexpressed and TIMP1 and RECK are underexpressed in malignant prostatic tissues compared with $\mathrm{BPH}$ tissues. Additionally, with regard to standard prognostic factors, we found an association between MMP-9 and a PSA $\geq 10 \mathrm{ng} / \mathrm{mL}$. Another important finding was the connection between increased MMP-9 expression and biochemical recurrence, although this association only reached marginal significance $(p=0.089)$. Finally, our analysis of benign prostatic tissue from patients with PC showed that the pattern of MMP-9 expression was similar to that found in malignant prostatic tissue. However, TIMP-1 and RECK, which are negative regulators of MMP-9, were overexpressed in most benign tissues from patients with PC compared to those with $\mathrm{BPH}$.

Prostate cancer is the most common cancer in men, and the advanced metastatic disease is currently incurable. Due to the lack of efficient parameters to identify potentially aggressive tumors in many cases, clinicians are frequently unable to identify patients at greater risk of disease progression. Therefore, novel molecular makers that can more precisely indicate the biological behavior and prognosis of PC are urgently needed. Extensive studies have revealed that malignant invasion and metastasis require ECM degradation, mainly by MMPs [13]. Excessive or inappropriate MMP expression may contribute to the pathogenesis of cancer in a wide variety of diseases by facilitating tissue 
degradation. Currently, there are more than 20 identified MMPs that can be categorized by substrate specificity.

Despite the clinical significance of the pathogenetic impact of MMPs in human cancer, including prostate cancer, only a few studies of MMPs are available in the literature, and those are mainly analyses of protein expression ${ }^{[14]}$. Gelatin zymograms have revealed higher MMP-9 levels in cancerous versus non-cancerous parts of the prostate ${ }^{[15]}$. Increased MMP-9 expression has also been described in studies analyzing human prostatic cell cultures and a few tissue samples [16, 17]; however, large clinical studies have not been performed. Our detailed evaluation of surgical specimens and long follow-up period permit us to make important conclusions regarding the potential utility of MMPs and their regulators as prognosis determinants for PC. Similar studies focused on other tumor types have been published; for example, Simi et al. ${ }^{[14]}$ found that MMP-9 mRNA levels were upregulated in lung cancer tissue compared with control tissues.

In the present study, we have shown not only that MMP-9 is overexpressed in cancer tissue, but also that MMP-9 levels are significantly higher in patients with PSA $\geq 10 \mathrm{ng} / \mathrm{mL}$, an important prognostic factor. MMP-9 expression levels increase together with serum PSA levels, suggesting that it is probably associated with a worse outcome in PC. This is the first time that a study has shown a correlation between PSA levels and MMP-9 RNAm expression in PC. Increased MMP-9 expression has also been shown to have 
an independent prognostic impact on operable human non-small cell lung cancer ${ }^{[18]}$ and renal cell carcinoma ${ }^{[19]}$.

Another important result was our demonstration of a relationship between MMP-9 and biochemical recurrence during a long follow-up period with a mean of 60 months. Although the significant difference was only marginal $(p=0.089)$, the mean expression of MMP-9 in patients with recurrence was 12.6, which is more than double that observed in patients without recurrence (mean=5.6). This result might reflect an important biological phenomenon that could be confirmed in larger studies and that could become a tool to identify patients likely to progress. MMPs are abundantly expressed in malignant tumors regardless of their origin, and a significant correlation between increased MMP expression and a poor prognosis in terms of survival has been demonstrated in several cases ${ }^{[20,21]}$. As a result, the possibility of MMPs being used as tumor markers has been suggested.

At the post-translational level, all MMPs are under the control of specific tissue inhibitors (TIMPs) that bind proximal to the catalytic domain of MMPs, preventing substrate attachment. TIMPs are not simply regulators of MMP activity; they also have multifunctional roles that include cell growth promotion ${ }^{10}$ and inhibition of angiogenesis ${ }^{[22]}$. Thus, overexpression of these inhibitors may be indicative of a stromal cell response to the malignant expansion, but it is also probable that tumor cells themselves directly secrete TIMPs to control their own growth ${ }^{[10]}$. Four TIMPs have been identified. They inhibit all MMPs, forming noncovalent complexes with the active forms. Among them, TIMP-1 selectively 
binds pro-MMP-9 and is considered the main inhibitor of MMP-9 ${ }^{[10,11]}$. The reversion-inducing cysteine-rich protein with Kazal motifs (RECK) gene was identified as an inducer of a flat morphology in v-Ki ras-transformed NIH3T3 cells ${ }^{[23]}$. RECK expression is observed in normal human organs; however, several oncogenic factors, such as activated Ras ${ }^{[24]}$, EBV latent membrane protein $1^{[25]}$, and HER-2/neu ${ }^{[26]}$ suppress the expression of RECK. Additionally, it has been reported that RECK overexpression decreases the amount of active MMP-2 and MMP-9 in conditioned medium and inhibits metastatic activity in vitro ${ }^{[27]}$ and in vivo ${ }^{[28]}$. Interestingly, our results demonstrate that MMP-9 is overexpressed and TIMP-1 and RECK are underexpressed in PC compared with $\mathrm{BPH}$.

Due to the influence of TIMPs and RECK, an increase in MMP-9 mRNA expression may not necessarily be associated with an increase in enzymatic activity. Here we have shown that in PC tissue, there is an altered balance in the control of ECM due to the overexpression of MMP-9 and underexpression of its negative regulators, TIMP and RECK. This phenomenon has been described as a characteristic of malignant disease ${ }^{[29]}$. In addition, the relationship between MMP-9 and PSA serum levels and between RECK and Gleason score make these proteins good candidates for prognostic biomarkers that could be part of the parameters used to select the best therapy to treat PC.

When examining benign prostate tissue from patients with PC treated by radical prostatectomy, we also observed MMP-9 overexpression. This finding is interesting and suggests that MMP-9 could be used as a tissue marker to 
overcome the sampling error that is commonly seen in conventional prostate biopsies. However, TIMP-1 and RECK did not show the same patterns in the normal and cancer tissues. They were overexpressed in most cases, indicating that their underexpression is a specific characteristic of the tumor.

In conclusion, by evaluating the expression of MMP-9, TIMP-1 and RECK, we have shown that there is an upregulation of MMP-9 and a downregulation of its specific inhibitors, TIMP-1 and RECK, in PC. In addition, this is the first study to indicate the prognostic relevance of MMP-9 mRNA expression in PC, as demonstrated by the significant correlation between MMP9 expression and higher PSA levels and marginal significance between MMP-9 expression and biochemical recurrence of localized PC in patients treated with radical prostatectomy. These findings suggest the possibility of using the profiles of MMP-9 as prognostic marker and, in the future, might inspire the development of targeted drugs.

Grant sponsors: This study was supported by FAPESP (Fundação de Amparo à Pesquisa do Estado de Sao Paulo) under protocol number 2009/50368-9. 


\section{References}

1. Jemal A, Siegel R, Ward E, et al. Cancer statistics, 2010. CA Cancer J Clin 2010; [Epub ahead of print]

2. Zerbib M, Zelefsky MJ, Higano CS, Carroll PR. Conventional treatments of localized prostate cancer. Urology 72:S25-35, 2008

3. Berger AP, Spranger R, Kofler K, Steiner H, Bartsch G, Horninger W. Early detection of prostate cancer with low PSA cut-off values leads to significant stage migration in radical prostatectomy specimens. Prostate 57:93-98, 2003

4. Toi M, Ishigaki S, Tominaga T. Metalloproteinases and tissue inhibitors of metalloproteinases. Breast Cancer Res Treat 52:113-124, 1998

5. Eissa S, Ali-Labib R, Swellam M, Bassiony M, Tash F, El-Zayat TM. Noninvasive diagnosis of bladder cancer by detection of matrix metalloproteinases (MMP-2 and MMP-9) and their inhibitor (TIMP-2) in urine. Eur Urol 52:1388-1396, 2007

6. Liabakk NB, Talbot I, Smith RA, Wilkinson K, Ballewill F. Matrix metalloproteinase 2 (MMP-2) and matrix metalloproteinase 9 (MMP-9) type IV collagenase in colorectal cancer. Cancer Res 56:190-196, 1996

7. Pyke C, Ralfkier E, Huhtala P, Hurskainen T, Dano K, Tryggvason K. Localization of messenger RNA for Mr 72,000 and 92,000 type IV collagenase in human skin cancers by in situ hybridization. Cancer Res 52:1336-1341, 1992

8. Kodate $\mathrm{M}$, Kasai $\mathrm{T}$, Hashimoto $\mathrm{H}$, Yabumoto $\mathrm{K}$, Iwata $\mathrm{Y}$, Manobe $\mathrm{H}$. Expression of matrix metalloproteinase (gelatinase) in T1 adenocarcinoma of the lung. Pathol Int 47:461-469, 1997

9. Chen WT: Membrane proteases: roles in tissue remodeling and tumour invasion. Curr Opin Cell Biol 4:802-809, 1992 
10. Henriet P, Blavier L, Declerck YA. Tissue inhibitors of metalloproteinases (TIMP) in invasion and proliferation. APMIS 107:111-119, 1999

11. Nawrocki B, Polette M, Marchand V, Monteau M, Gillery P, Tournier JM. Expression of matrix metalloproteinases and their inhibitors in human bronchopulmonary carcinomas: quantificative and morphological analyses. Int J Cancer 72:556-564, 1997

12. Polette M, Nawrocki-Raby B, Gilles C, Clavel C and Birembaut P: Tumour invasion and matrix metalloproteinases. Crit Rev Oncol Hematol 49:179176,2004

13.Zhong WD, Han ZD, He HC, Bi XC, Dai QS, Zhu G, Ye YK, Liang YX, Qin WJ, Zhang Z, Zeng GH, Chen ZN. CD147, MMP-1, MMP-2 and MMP-9 protein expression as significant prognostic factors in human prostate cancer. Oncology 75:230-236, 2008

14. Simi L, Andreani M, Davini F, Janni A, Pazzagli M, Serio M, Orlando C Simultaneous measurement of MMP-9 and TIMP-1 mRNA in human non small cell lung cancers by multiplex real time RT-PCR. Lung Cancer 45:171179,2004

15. Lichtinghagen R, Musholt PB, Lein M, Römer A, Rudolph B, Kristiansen G, Hauptmann S, Schnorr D, Loening SA, Jung K. Different mRNA and protein expression of matrix metalloproteinases 2 and 9 and tissue inhibitor of metalloproteinases 1 in benign and malignant prostate tissue. Eur Urol 42: 398-406, 2002

16. Festuccia C, Angelucci A, Gravina GL, Villanova I I, Teti A, Albini A, Bologna M. Osteoblast-derived TGFbeta-1 modulates matrix degrading protease expression and activity in prostate cancer cells. Int J Cancer 86:888, 2000

17. Hamdy FC, Fadlon EJ, Cottam D, Lawry J, Thurrell W, Silcocks PB, Anderson JB, Williams JL, Rees RC. Matrix metalloproteinase 9 expression in primary human prostatic adenocarcinoma and benign prostatic hyperplasia. Br J Cancer 69:177-182, 1994 
18. Simi L, Andreani M, Davini F, Janni A, Pazzagli M, Serio M, Orlando C Simultaneous measurement of MMP-9 and TIMP-1 mRNA in human non small cell lung cancers by multiplex real time RT-PCR. Lung Cancer 45:171179, 2004

19. Cho NH, Shim HS, Rha SY, Kang SH, Hong SH, Choi YD, Hong SJ, Cho $\mathrm{SH}$. Increased expression of matrix metalloproteinase 9 correlates with poor prognostic variables in renal cell carcinoma. Eur Urol 44:560-566, 2003

20. Takeuchi T, Hisanaga M, Nagao M, et al. The membrane-anchored matrix metalloproteinase (MMP) regulator RECK in combination with MMP-9 serves as an information prognostic indicator for colorectal cancer. Clin Cancer Res 10: 5572-5579, 2004

21. Heppner KJ, Matrisian LM, Jensen RA, , Rodgers WH. Expression of most matrix metalloproteinase family members in breast cancer represents a tumor-induced host response. Am J Pathol 149:273-282, 1996

22. Cox G, Jones JL, Walker RA, Steward WP, O'Byrne KJ. Angiogenesis and non-small cell lung cancer. Lung Cancer 27:81-100, 2000

23. Takahashi C, Sheng Z, Horan TP, et al. Regulation of matrix metalloproteinase-9 and inhibition of tumor invasion by the membraneanchored glycoprotein RECK. Proc Natl Acad Sci U S A 95:13221-13226, 1998

24. Sasahara RM, Takahashi C, Noda M. Involvement of the Sp1 site in rasmediated down-regul ation of the RECK metastasis suppressor gene. Biochem Biophys Res Commun 264:668-675, 1999

25. Chang HC, Liu LT, Hung WC. Involvement of histone deacetylation in rasinduced down regulation of metastasis suppressor RECK. Cell Signal 16:675-679, 2004

26. Hsu MC, Chang HC, Hung WC. HER-2/neu represses the metastasis suppressor RECK via ERK and $S p$ transcription factor to promote cell invasion. J Biol Chem 281:4718-4725, 2006 
27. Oh J, Takahashi R, Kondo S, et al. The membrane anchored MMP inhibitor RECK is a key regulator of extracellular matrix integrity and angiogenesis. Cell 107: 789-800, 2001

28. Chang CK, Hung WC, Chang HC. The Kazal motifs of RECK protein inhibit MMP-9 secretion and activity and reduce metastasis of lung cancer cells in vitro and in vivo. J Cell Mol Med 2008; ahead of print

29. Nelson AR, Fingleton B, Rothenberg ML, Matrisian LM. Matrix metalloproteinases: biologic activity and clinical implications. J Clin Oncol 18:1135-1149, 2000 
Table 1. Demographic characteristics of 79 men submitted to radical prostatectomy to treat prostate cancer

\begin{tabular}{ll} 
Age (years) & 63 \\
Mean & $41-79$ \\
Min - Max & \\
\hline PSA (ng/ml) & 10.8 \\
Mean & $2.0-37.0$ \\
Min - Max & $47(59.5)$ \\
$<10$ n (\%) & $32(40.5)$ \\
$\geq 10$ n (\%) & $46(58.3)$ \\
\hline Stage & $38(48)$ \\
pT2 n (\%) & $41(52)$ \\
\hline GT3 n (\%) & \\
\hline
\end{tabular}


Table 2. Primers utilized

\begin{tabular}{ll}
\hline Gene symbol & Assays ID \\
\hline MMP-9 & Hs00957562_m1 \\
TIMP-1 & Hs00212624_m1 \\
RECK & Hs01019179_m1 \\
B2M & Hs99999907_m1 \\
\hline
\end{tabular}




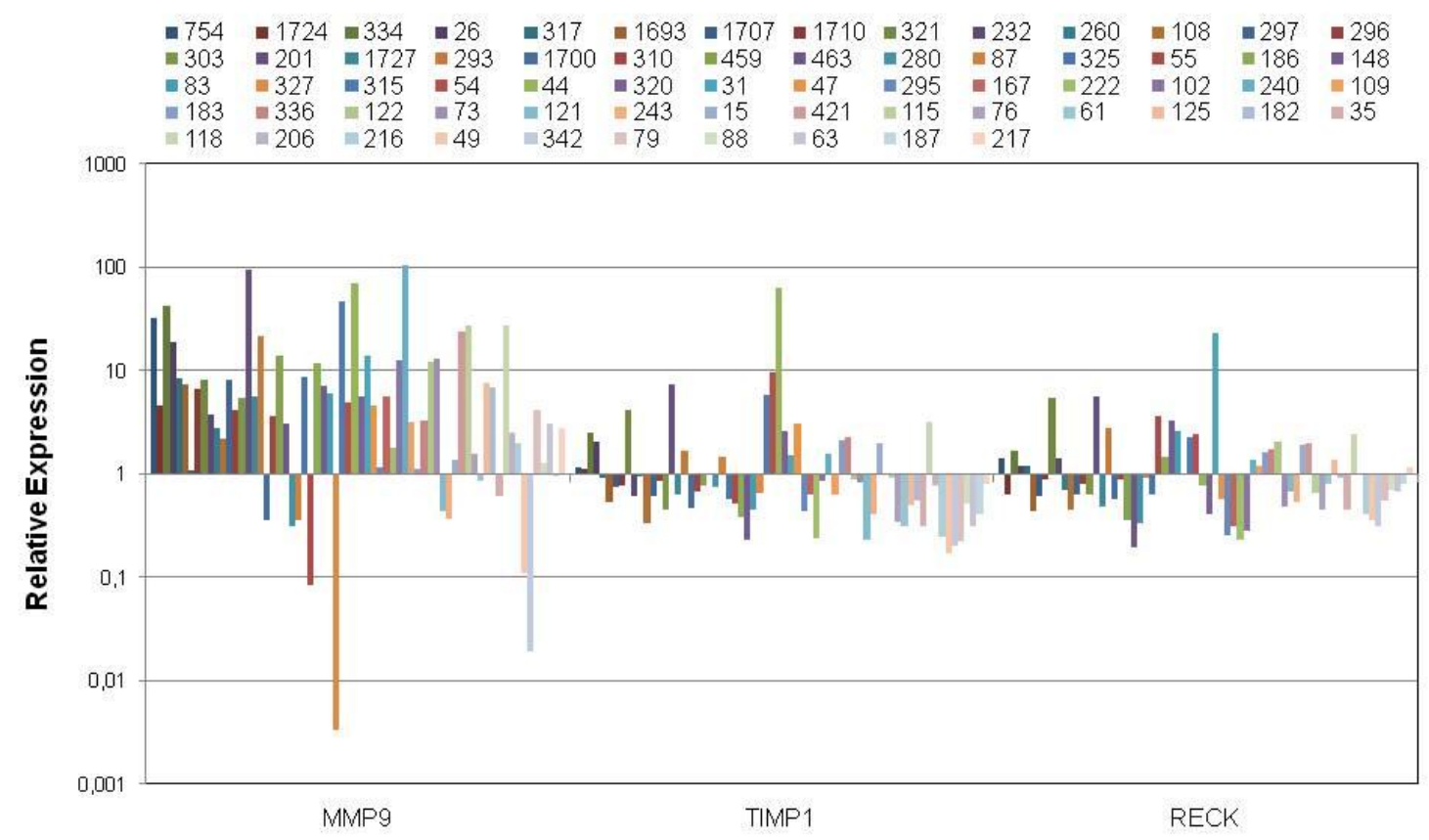

Figure 1. Expression level of the three genes in the PCa tissue compared with $\mathrm{BPH}$. Fold change in expression was calculated using the $2^{-\Delta \Delta \mathrm{CT}}$ method. 
Underexpression of MMP-2 and its Regulators, TIMP2, MT1-MMP and IL-8, are Associated with Prostate Cancer

Sabrina Thalita Reis ${ }^{1,2}$ PhD., Alberto Azoubel Antunes ${ }^{1,2}$ M.D. PhD., José Pontes-Junior ${ }^{1},{ }^{2}$ M.D. PhD., Juliana Moreira de Sousa-Canavez ${ }^{3}$ PhD., Marcos Francisco Dall'Oglio ${ }^{1,2}$ M.D. PhD., Camila Belfort Piantino ${ }^{1}$ Msc., Jose Arnaldo Shiomi da Cruz ${ }^{1}$, Denis Reis Morais ${ }^{1}$, Miguel Srougi ${ }^{1,2}$ M.D. PhD., Kátia R. M. Leite $^{1,2}$ M.D. PhD.

1 - Laboratory of Medical Investigation (LIM55), Urology Department, University of Sao Paulo Medical School, Sao Paulo, Brazil

2 - Uro-Oncology Group, Urology Department, Instituto do Cancer do Estado de Sao Paulo (ICESP), University of Sao Paulo Medical School, Sao Paulo, Brazil

3 - Genoa Biotechnology SA, Sao Paulo, Brazil.

Running Title: Metalloproteinases in prostate cancer

\section{Corresponding author:}

Katia Ramos Moreira Leite

Av. Dr. Arnaldo 455, $2^{\circ}$ floor, room 2145

01246-903, Sao Paulo, Brazil

katiaramos@uol.com.br 


\section{Abstract}

Objective: Extracellular matrix homeostasis is strictly maintained by a coordinated balance between the expression of metalloproteinases (MMPs) and their regulators. The purpose of this study was to investigate whether the expression of MMP-2 and its specific regulators, TIMP-2, MT1-MMP and IL-8, are expressed in a reproducible, specific pattern and if the profiles are related to prognosis and clinical outcome in prostate cancer $(\mathrm{PCa})$.

Materials and Methods: MMP-2, TIMP-2, MT1-MMP and IL-8 expression levels were analyzed by quantitative real-time polymerase chain reaction (qRT-PCR) in freshly frozen malignant and benign tissue specimens collected from 79 patients with clinically localized PCa who underwent radical prostatectomies. The control group consisted of 11 patients with benign prostate hyperplasia (BPH). The expression profile of the MMP-2 and its regulators were compared using Gleason scores, pathological stage, pre-operative PSA levels and the final outcome of the PCa.

Results: The analysis of 79 specimens of PCa revealed that MMP-2, TIMP-2, MT1-MMP and IL-8 were underexpressed at $60.0 \%, 72.2 \%, 62.0 \%$ and $65.8 \%$, respectively, in malignant prostatic tissue relative to $\mathrm{BPH}$ samples. Considering the prognostic parameters, we demonstrated that high Gleason score tumors $(\geq 7)$ overexpressed MMP-2 $(p=0.048)$ and TIMP-2 $(p=0.021)$, compared to low Gleason score tumors $(<7)$.

Conclusion: We have shown that MMP-2 and its regulators are underexpressed in PCa. Alternatively, overexpression of MMP-2 and TIMP-2 
was related to higher Gleason score tumors. We postulate that alterations in metalloproteinase expression may be important in the control of tissue homeostasis related to prostate carcinogenesis and tumor behavior.

Key words: Prostate cancer, Matrix Metalloproteinase, Prognosis, Diagnosis, Gene expression 


\section{Introduction}

Prostate cancer $(\mathrm{PCa})$ is a common disease with a multifactorial and complex etiology. It is the most common male malignancy and the second leading cause of death in many countries, including Brazil. Estimates for 2011 indicate that 903,500 new cases and 258,400 deaths related to PCa will occur worldwide [1]. Tumor staging, Gleason scores and PSA serum values are the most important prognostic factors, but even when used together, they cannot be used to perfectly diagnose patients at risk for progression [2]. Therefore, research has been aimed at the identification of molecular markers that can contribute to diagnosis and predict PCa progression.

Degradation of basal membranes and extracellular matrix (ECM) is essential for tumor invasion and development of metastases, and matrix metalloproteinases (MMPs) are potent proteolytic enzymes that are known to play a key role in these processes. Within the MMP family, MMP2 (gelatinase A, $72 \mathrm{kDa}$ ) cleaves type IV collagen and gelatin, which are the main structural components of the basal membrane [3]. Expression of MMP2 has been implicated in the development and progression of many neoplasias, such as bladder [4] and colon cancer [5].

MMPs are transcriptionally regulated. MMP2 is mainly regulated by its zymogen inhibitor, tissue inhibitor of metalloproteinase 2 (TIMP2), and by its major activator, membrane type-1 MMP (MT1-MMP), also known as MMP14. 
MT1-MMP specifically activates the pro-gelatinase, MMP2, on the tumor cell surface in vitro through the formation of a complex with TIMP2 [6]. IL8 upregulates MMP2 in tumor cells, which is thought to be responsible for its angiogenic activity [7].

Neoplasias, an imbalance between MMPs and their regulators, leads to excess degradation, which may be linked to the invasive character of tumor cells $[8,9,10]$. The aim of the present study was to investigate the expression profile of MMP2 and it specific regulators, TIMP2, MT1-MMP and IL8 in prostate cancer, associating them with the three most important prognostic parameters: Gleason score, pathological stage and pre-operatory PSA serum levels. Also, we aimed to relate these profiles to the outcome of patients with localized $\mathrm{PCa}$ who underwent radical prostatectomies. 


\section{Patients and Methods}

\section{Patients}

The study was conducted using surgical specimens from 79 patients with clinically localized PCa who underwent radical prostatectomy in our institution between 1993 and 2007. These cases were randomly selected from our database. Patients who had undergone other adjuvant and neoadjuvant treatments for PCa were excluded from the study. All subjects provided informed consent to participate in the study and to allow their biological samples to be genetically analyzed. The Institutional Board of Ethics approved this study (\#0453/08).

We first analyzed MMP-2, TIMP-2, MT1-MMP and IL-8 expression levels in fresh tumor specimens from the 79 PCa patients using quantitative real-time polymerase chain reaction (qRT-PCR). The clinical and pathological characteristics of these specimens are listed in Table 1. The control group consisted of tissue specimens from 11 patients with benign prostatic hyperplasia $(\mathrm{BPH})$, who had lower urinary tract symptoms and had undergone retropubic prostatic resection (mean age $64 \pm 6.0$ years).

We then correlated the expression levels of the genes with Gleason scores, pathological stage (TNM 2010) and pre-operative serum PSA levels $(\mathrm{ng} / \mathrm{mL})$. For analytical purposes, the pathological stages were described as organ-confined (pT2) or non-organ-confined (pT3) diseases; Gleason scores 
were classified as low grade (Gleason score $<7$ ) or high grade (Gleason score $\geq 7$ ). Preoperative PSA levels were also used to identify patients at high risk ( $\geq 10$ $\mathrm{ng} / \mathrm{mL}$ ) and low risk ( $<10 \mathrm{ng} / \mathrm{mL})$ for disease recurrence. Additionally, we related the gene expression with the biochemical recurrence free survival rate in a mean follow-up time of 60 months, considering PSA levels $>0.4 \mathrm{ng} / \mathrm{mL}$.

\section{RNA Isolation and cDNA Synthesis}

All tumor samples were obtained from surgical specimens and immediately frozen at $-170{ }^{\circ} \mathrm{C}$ in liquid nitrogen. A slide with a mirror of the frozen fragment was stained with hematoxylin and eosin to verify that the tumor represented at least $75 \%$ of the fragment in patients with cancer and to demonstrate the absence of tumor in those with $\mathrm{BPH}$.

Total RNA was isolated with an RNAaqueous Kit (Applied Biosystems, CA, USA) according to the manufacturer's instructions. RNA concentration was determined by measuring absorbance at 260/280 nM using a Nanodrop ND1000 spectrophotometer (Thermo Scientific). cDNA was generated using a High Capacity cDNA Reverse Transcription Kit (Applied Biosystems, CA, USA). The reactions were incubated at $25{ }^{\circ} \mathrm{C}$ for $10 \mathrm{~min}$, followed by $37 \stackrel{\circ}{\circ} \mathrm{C}$ for $120 \mathrm{~min}$ and $85^{\circ} \mathrm{C}$ for $5 \mathrm{~min}$. The cDNA was stored at $-20^{\circ} \mathrm{C}$ until further use.

\section{Quantitative Real-Time PCR and Gene Expression}


Expression levels of the four genes were analyzed by qRT-PCR using an ABI 7500 Fast Real-Time PCR System (Applied Biosystems). Target sequences were amplified in a $10 \mu \mathrm{l}$ reaction containing $5 \mu \mathrm{l}$ of TaqMan Universal PCR Master Mix, $0.5 \mu \mathrm{l}$ of TaqMan Gene Expression Assays (primers and probes, see Table 2), $1 \mu \mathrm{l}$ of cDNA and $3.5 \mu \mathrm{l}$ of DNase-free water. The PCR cycling conditions were 2 minutes at $50 \stackrel{\circ}{\circ}, 10$ minutes at $95 \stackrel{\circ}{\circ}$, and then 40 cycles of 15 seconds at $95^{\circ} \mathrm{C}$ and $1 \mathrm{~min}$ at $60^{\circ} \mathrm{C}$. A TaqMan B2M assay was used as the endogenous control (Table 2).

We used the $\triangle \triangle C T$ method to calculate the relative expression of the three target genes using the formula $\Delta \Delta C T=(C T$ target gene, PCa sample $-\mathrm{CT}$ endogenous control, PCa sample) - (CT target gene, BPH sample - CT endogenous control, BPH sample). The fold change in gene expression was calculated as $2^{-\Delta \Delta \mathrm{CT}}$.

\section{Statistical Analysis}

Quantitative variables were expressed as median values, interquartile range (Q1-Q3), and minimum and maximum values. Qualitative variables were expressed as numbers and percentages. To compare the clinical characteristics of patients with $\mathrm{PCa}$, we used the Mann-Whitney, chi-squared and Fisher exact tests. For descriptive analysis of MMP-2, TIMP-2, MT1-MMP and IL-8 expression according to pathological stage, Gleason scores and PSA levels, we 
constructed a box plot, and for comparison between categories, we used the Mann-Whitney test. Statistical analysis was performed using SPSS 15.0 for Windows, and significance was set at $p \leq 0.05$. 


\section{Results}

As shown in Figure 1, the analysis of 79 specimens of PCa revealed that MMP-2, TIMP-2, MT1-MMP and IL-8 were underexpressed in malignant prostatic tissue, relative to BPH samples. MMP-2, TIMP-2, MT1-MMP and IL-8 were underexpressed at levels of $60.0 \%, 72.2 \%, 62.0 \%$ and $65.8 \%$, respectively, in prostate cancer tissue, compared to benign prostate tissue.

We found differences in MMP-2 and TIMP-2 expression between highgrade PCa (Gleason $\geq 7$ ) versus low-grade PCa (Gleason <7). The median expression of MMP-2 was 0.84 for high-grade PCa vs. 0.52 for low-grade tumors $(p=0.048)$. The median expression of TIMP-2 was 0.59 vs. 0.39 for highgrade and low-grade $\mathrm{PCa}$, respectively $(\mathrm{p}=0.021)$. Only a marginal statistical difference for MT1-MMP was observed between the two tumor groups: the median was 0.89 for high-grade vs. 0.65 for low-grade PCa $(p=0.08)$. There were no differences in the expression levels of IL-8 when considering Gleason scores (Table 3).

There were no differences in the expression levels of the four genes according to the pathological stage, PSA pre-operatory serum levels or biochemical recurrence. 


\section{Discussion}

In the present study we demonstrated that MMP-2 and its regulators are underexpressed in PCa compared to BPH tissue. Others, studying different types of cancer, have found overexpression of these genes $(11,12)$. However, there are reports showing that the absence of some MMP can be related to the promotion of tumors. For instance, Balbin et al., has described an increased susceptibility to skin cancer in mice that didn't express MMP-8 (13). Our results are similar to those published by Lichtinghagen et al. (2002) (14), who showed MMP-2 underexpression in prostate cancer tissue using RT-PCR. Conversely, they observed higher expression of MMP-2 at the protein level using immunohistochemistry, a result later confirmed by Brehmer et al. (15), indicating that there is a discrepancy between the levels of MMP-2 mRNA and protein in prostate cancer.

Interestingly, we found an association between elevated expression of MMP-2 and TIMP-2 and Gleason scores $\geq 7$, while MT1-MMP, which was also expressed at a higher level in Gleason scores $\geq 7$, only reached a level of marginal statistical significance $(p=0.08)$. The Gleason score is the main prognostic parameter for $\mathrm{PCa}$, and it dictates the therapeutics in the majority of cases, although there are many pitfalls to using it as a determining factor. Because treatment options range from watchful waiting to palliative androgen deprivation, the correct characterization of histological differentiation is 
especially valuable for the correct treatment of the neoplasia. We have previously shown that it is possible to downgrade and upgrade PCa Gleason scores in radical prostatectomies to values of $14 \%$ and $29 \%$, respectively, showing the weakness of using it as a prognostic factor, even when utilized by an experienced uropathologist (16). This confirms the necessity for additional biological information regarding PCa behavior. This is the first time that a study has shown a correlation between Gleason scores and MMP-2/TIMP-2 mRNA expression in $\mathrm{PCa}$.

Extensive studies have revealed that malignant invasion and metastasis require ECM degradation, mainly by MMPs [17]. Excessive or inappropriate expression of MMPs may contribute to the pathogenesis of cancer in a wide variety of cases by facilitating tissue degradation. Currently, there are more than 20 identified MMPs that can be categorized by substrate specificity. Despite the clinical significance of the pathogenetic impact of MMPs in human cancer, including PCa, only a few studies of MMPs are available in the literature, and those mainly analyze protein expression [18].

Among the identified MMPs, MMP2 cleaves type IV collagen and gelatin, which are the main structural components of the basal membrane in the ECM, and the ECM is the first vital barrier on the course of tumor metastasis. Based on these findings, MMP-2 is thought to contribute to matrix breakdown. Todayit is clear that MMP-2 participates in many deregulated signaling pathways that are used by the tumor to promote cancer cell growth and angiogenesis. The fact 
that we are already aware of these attributes makes MMP-2 a promising prognostic marker [19].

Interestingly, we found that MMP2 is underexpressed in prostate cancer, indicating that this MMP is not related to the promotion of PCA. However after the establishment of the tumor, an increase in expression of MMP2 may be involved in tumor differentiation, which explains the association of elevated MMP2 expression in high-grade tumors.

At the post-translational level, MMPs are under the control of specific tissue inhibitors (TIMPs) that bind proximal to the catalytic domain of the MMPs, preventing substrate binding. TIMPs are not simply regulators of MMP activity; they also have multifunctional roles that include cell growth promotion [20] and inhibition of angiogenesis [21]. At the time of their discovery, TIMPs were considered to be tumor suppressor proteins. Increased TIMP expression is currently associated with decreased tumor growth, invasiveness and metastasis in prostate cancer and other cancer cell lines [22]. However, the results of the current study demonstrate a poor prognostic significance of increased TIMP-2 expression, which is contrary to the original tumor-suppressor role that TIMPs were hypothesized to play. These results, however, are in line with recent evidence that supports a multifunctional and complex role for TIMPs. Nemith et al. [23] described the growth-promoting abilities of TIMP-2 in several human cell types, including fibroblasts, keratocytes, lymphocytes and stem cells. Increased TIMP1 and TIMP2 mRNA levels have been correlated with higher tumor stages, 
lymph node metastasis and shortened survival in patients with carcinoma of the colon [24], breast [25], or bladder [26].

Although the paradoxical positive effects of TIMPs on tumor progression are not completely understood, the tumor promoting activity may be due either to proteolytic degradation of ECM or a direct influence on cell survival and growth. Stimulation of cell growth by TIMPs is thought to be mediated by cAMPdependent activation of protein Kinase A and increased tyrosine phosphorylation [26].

TIMP-2 is reported to regulate matrix degradation, acting through a membrane type MMP (MT1-MMP). MT1-MMP is a key enzyme in tumor angiogenesis and metastasis: it hydrolyzes a variety of ECM components, and is a physiological activator of pro-MMP2 [27]. TIMP-2 forms a complex with MT1MMP on the cell surface promoting hydrolysis of pro-MMP2 to its active form resulting in degradation of ECM.

We have shown that even with decreased MMP-2, TIMP-2 and MT1MMP gene expression in cancer tissue, there was an increased expression in patients with Gleason scores $\geq 7$, an important prognostic factor of this disease. But we were not able to show a correlation between MMP-2, TIMP-2, MT1-MMP and IL-8, and the outcome of the disease in a 60-month follow-up period. This lack of supporting evidence in this regard can be attributed to the small number of cases in each group. 
We can postulate that the low expression of TIMP-2, MT1-MMP and IL-8 may be responsible for the decreased MMP-2 expression in PCa tissue, and this profile might be a characteristic of prostate cancer that can be utilized for tumor diagnosis in the future. Also, the fact that MMP-2 and TIMP-2 expression levels increase with tumor grade suggests that these genes might be involved in the differentiation of prostate cancer.

Grant sponsors: This study was supported by FAPESP (Fundação de Amparo à Pesquisa do Estado de Sao Paulo) under protocol number 2009/50368-9. 


\section{References}

1. Jemal A, Siegel R, Ward E, et al. Cancer statistics, 2011. CA Cancer J Clin 2011; [Epub ahead of print]

2. Berger AP, Spranger R, Kofler K, Steiner H, Bartsch G, Horninger W. Early detection of prostate cancer with low PSA cut-off values leads to significant stage migration in radical prostatectomy specimens. Prostate 2003, 57:93-8

3. Toi M, Ishigaki S, Tominaga T. Metalloproteinases and tissue inhibitors of metalloproteinases. Breast Cancer Res Treat 1998, 52:113-24

4. Eissa S, Ali-Labib R, Swellam M, Bassiony M, Tash F, El-Zayat TM. Noninvasive diagnosis of bladder cancer by detection of matrix metalloproteinases (MMP-2 and MMP-9) and their inhibitor (TIMP-2) in urine. Eur Urol 2007, 52:1388-96

5. Liabakk NB, Talbot I, Smith RA, Wilkinson K, Ballewill F. Matrix metalloproteinase 2 (MMP-2) and matrix metalloproteinase 9 (MMP-9) type IV collagenase in colorectal cancer. Cancer Res 1996, 56:190-6

6. Sato H, Takano T, Kinoshita T, Imai K, Okada Y, Steler-Stevenson WG et al., Cell surface biding and activation of gelatinase $A$ induced by expression of membrane -type-1-matrix metalloproteinase (MT1-MMP). FEBS Lett 1996; 385:238-40

7. Jovanovic M, Stefanoska I, Radojcic L, Vicovac L. Interleukin-8 (CXCL8) stimulates trophoblast cell migration and invasion by increasing levels of matrix metalloproteinase (MMP)2 and MMP9 and integrins $\alpha 5$ and $\beta 1$. Reprod. Research 2010, 139:789-8

8. Henriet P, Blavier L, Declerck YA. Tissue inhibitors of metalloproteinases (TIMP) in invasion and proliferation. APMIS 1999, 107:111-9 
9. Nawrocki B, Polette M, Marchand V, Monteau M, Gillery P, Tournier JM. Expression of matrix metalloproteinases and their inhibitors in human bronchopulmonary carcinomas: quantificative and morphological analyses. Int J Cancer 1997, 72:556-64

10. Polette M, Nawrocki-Raby B, Gilles C, Clavel C and Birembaut P: Tumour invasion and matrix metalloproteinases. Crit Rev Oncol Hematol 2004, 49:179-6

11. Tang ZG, Li JM, Hong ZZ, Yu ZW, Liu CH. Expression of matrix metalloproteinase 2 in oral verruvous carcinoma and squamous cell carcinoma. Zhong Nan Da Xue Xue Bao Yi Xue Ban. 2005; 30:650-2

12. Scrideli CA, Cortez MA, Yunes JA, Queiróz RG, Valera ET, da Mata JF, Toledo SR, Pavoni-Ferreira P, Lee ML, Petrilli AS, Brandalise SR, Tone LG. mRNA expression of matrix metalloproteinases (MMPs) 2 and 9 and tissue inhibitor of matrix metalloproteinases (TIMPs) 1 and 2 in childhood acute lymphoblastic leukemia: potential role of TIMP1 as an adverse prognostic factor. Leuk Res. 2010; 34:32-7

13. Balbín M, Fueyo A, Tester AM, Pendás AM, Pitiot AS, Astudillo A, Overall CM, Shapiro SD, López-Otín C. Loss of collagenase-2 confers increased skin tumor susceptibility to male mice. Nat Genet. 2003; 35: 252-7.

14. Lichtinghagen R, Musholt PB, Lein M, Römer A, Rudolph B, Kristiansen G, Hauptmann S, Schnorr D, Loening SA, Jung K. Different mRNA and protein expression of matrix metalloproteinases 2 and 9 and tissue inhibitor of metalloproteinases 1 in benign and malignant prostate tissue. Eur Urol. 2002; 42: 398-406

15. Brehmer B, Biesterfeld S, Jakse G. Expression of matrix metalloproteinases (MMP-2 and -9) and their inhibitors (TIMP-1 and -2) in prostate cancer tissue. Prostate Cancer Prostatic Dis. 2003; 6: 217-22 
16. Leite KR, Camara-Lopes LH, Dall1Oglio MF, Cury J, Antunes AA, Sañudo A, Srpugi M. Upgrading the Gleason Score in Extended Prostate Biopsy: Implications for Treatment Choice. International Journal of Radiation Oncology ${ }^{*}$ Biology ${ }^{*}$ Physics 2009; 73:353-56

17.Zhong WD, Han ZD, He HC, Bi XC, Dai QS, Zhu G, Ye YK, Liang YX, Qin WJ, Zhang Z, Zeng GH, Chen ZN. CD147, MMP-1, MMP-2 and MMP-9 protein expression as significant prognostic factors in human prostate cancer. Oncology 2008; 75:230-6

18. Simi L, Andreani M, Davini F, Janni A, Pazzagli M, Serio M, Orlando C Simultaneous measurement of MMP9 and TIMP1 mRNA in human non small cell lung cancers by multiplex real time RT-PCR. Lung Cancer 2004, 45:1719

19. Egeblad, M.; Werb, Z. New functions for the matrix metalloproteinases in cancer progression. Nat Rev Cancer 2002; 2:161-74

20. Henriet P, Blavier L, Declerck YA. Tissue inhibitors of metalloproteinases (TIMP) in invasion and proliferation. APMIS 1999; 107:111-9

21. Cox G, Jones JL, Walker RA, Steward WP, O'Byrne KJ. Angiogenesis and non-small cell lung cancer. Lung Cancer 2000; 27:81-100

22. Rabbani SA, Harakidas P, Guo Y, Steunman D, Davidsen SK, Morgan DW. Synthetic inhibitor of matrix metalloproteases decreases tumor growth and metastases in a syngeneic model of rat prostate cancer in vivo. Int $\mathrm{J}$ Cancer 2000; 87: 276-82

23. Nemeth JA, Rafe A, Steiner M, Goolsby CL. TIMP-2 growth stimulatory activity: a concentration and cell-type specific response in the presence of insulin. Exp Cell Res 1996; 224: 110-5. 
24. Murashige M, Miyahara M, Shiraishi N, Saito T, Kohno K, Kobayashi M. Enhanced expression of tissue inhibitors of metalloproteinases in human colorectal tumors. Jpn J Clin Oncol 1996; 26:303-09

25. Ree AH, Florenes VA, Berg JP, Malandsmo GM, Nesland JM, Fodstad O. High levels of messenger RNAs for tissue inhibitors of metalloproteinase (TIMP-1 and TIMP-2) in primary breast carcinomas are associated with development of distant metastasis. Clin Cancer Res 1997; 3:1623-8

26. Grignon DJ, Sakr W, Toth M, Ravery V, Angulo J, Shamsa F et al. High Levels of Tissue inhibithors metalloproteinase-2 (TIMP-2) expression are associated with poor outcome in invasive bladder cancer. Cancer Res 1996, 56: $1654-9$

27. Strongin Ay, Collier I, Bannikov G, Marmer BL, Grant GA, Goldberg GI. Mechanism of cell surface activation of 72-KDa type IV collagenase. Isolation of the activated form of the membrane metalloprotease. J Biol Chem 1995; 270: $5331-8$ 
Table 1. Demographic characteristics of 79 men who underwent a radical prostatectomy treatment for prostate cancer.

\begin{tabular}{ll} 
Age (years) & \\
Mean & 63 \\
Min - Max & $41-79$ \\
\hline PSA (ng/ml) & 10.8 \\
Mean & $2.0-37.0$ \\
Min - Max & $47(59.5)$ \\
$<10 \mathrm{n}(\%)$ & $32(40.5)$ \\
$\geq 10 \mathrm{n}(\%)$ & $38(48)$ \\
\hline Stage & $41(52)$ \\
pT2 n (\%) & \\
pT3 n (\%) & $33(41.7)$ \\
\hline Gleason Score & $46(58.3)$ \\
$<7 \mathrm{n}(\%)$ & \\
$\geq 7 \mathrm{n}(\%)$ & \\
\hline
\end{tabular}


Table 2. Primers used in this study.

\begin{tabular}{ll}
\hline Gene symbol & Assays ID \\
\hline MMP2 & Hs00234422_m1 \\
TIMP2 & Hs00234278_m1 \\
MMP14 & Hs00237119_m1 \\
IL-8 & Hs99999034_m1 \\
B2M & Hs99999907_m1 \\
\hline
\end{tabular}


Table 3. Relative expression of the four genes in malignant prostatic tissue according to Gleason scores, pathological stages, PSA values and biochemical recurrence. Fold changes in gene expression were calculated using the $\triangle \triangle C T$ method $\left(\mathrm{QRel}=2^{-\Delta \Lambda \mathrm{CT}}\right)$.

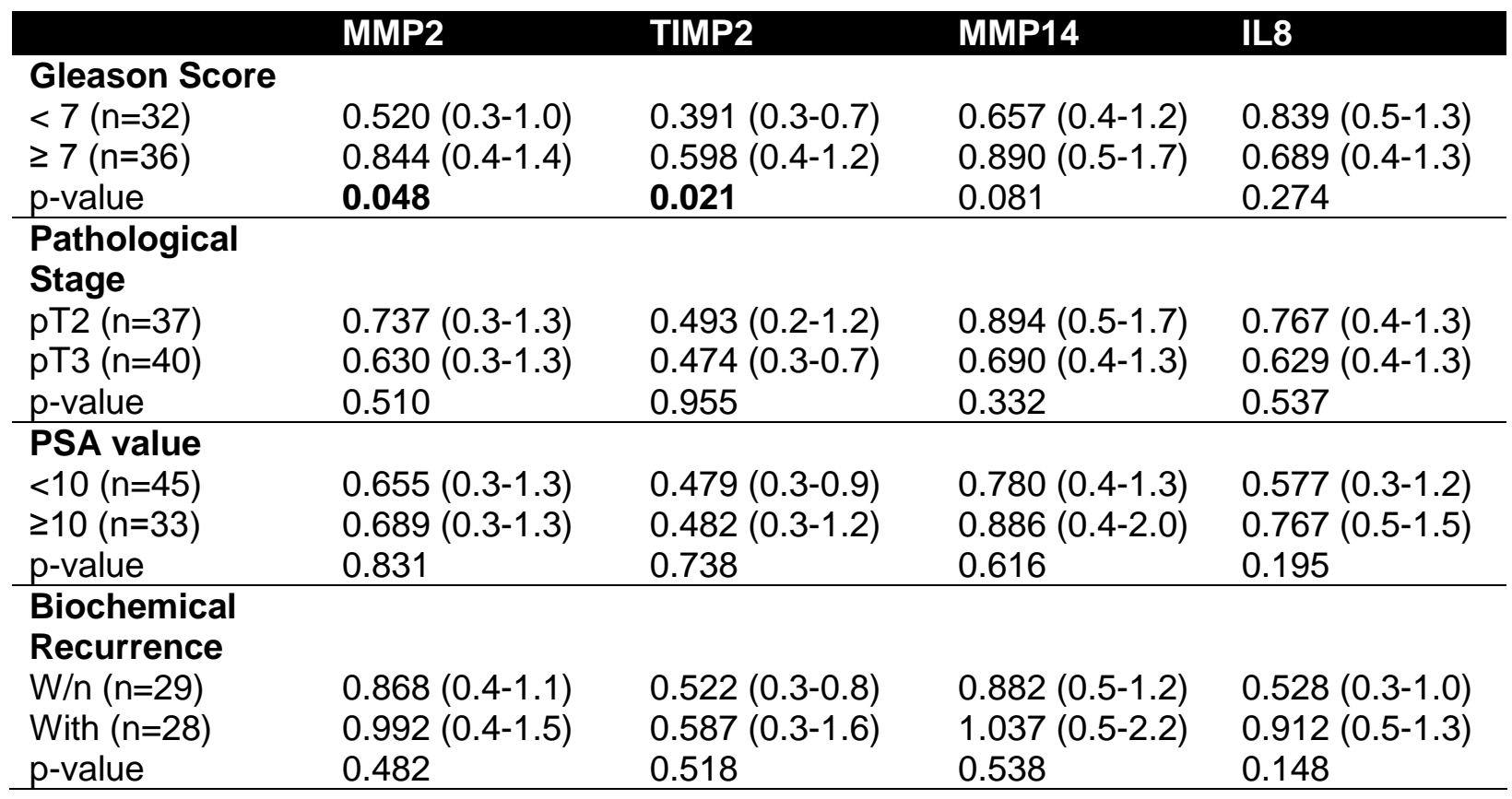




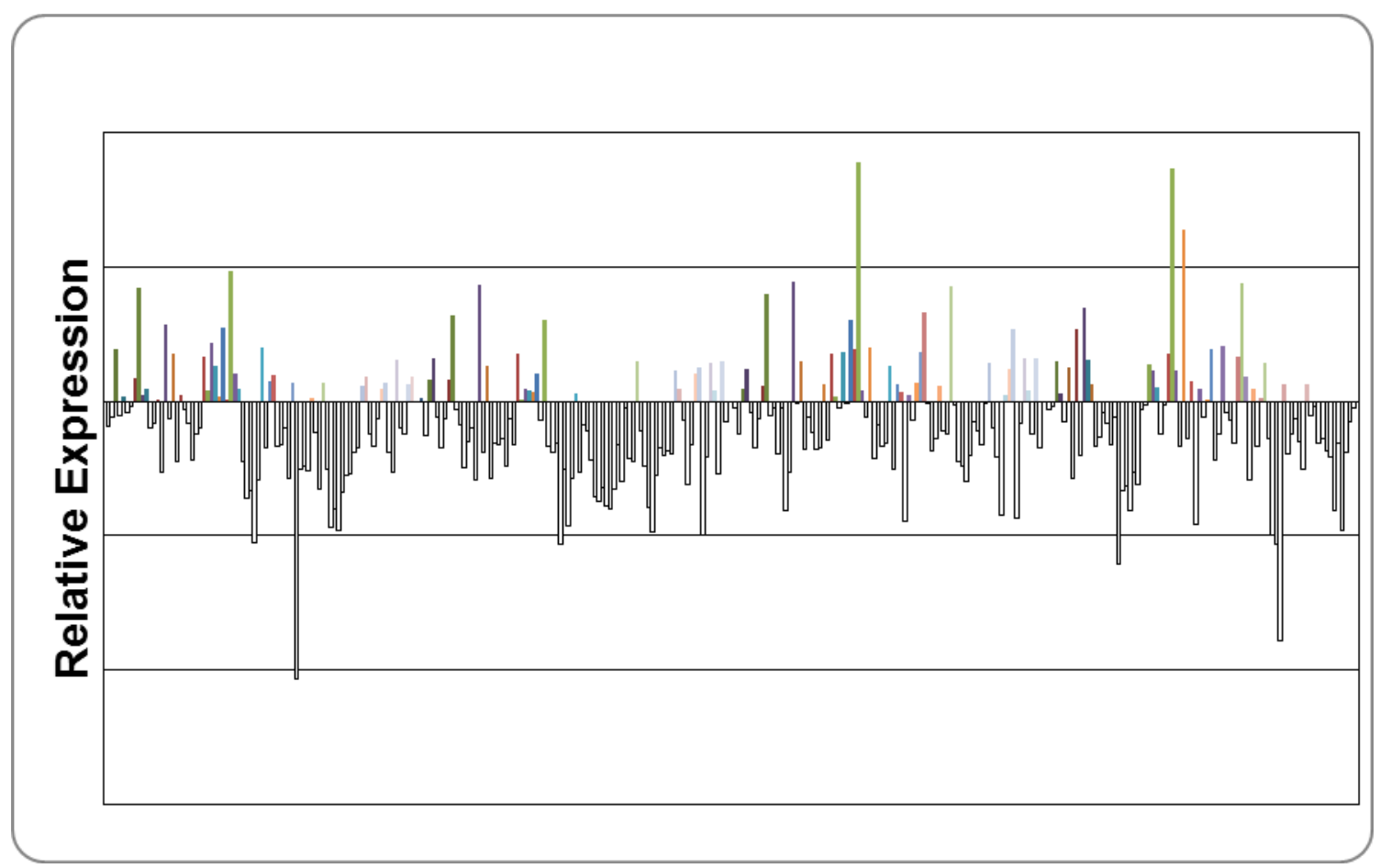

Figure 1. Expression levels of the four genes in PCa tissue compared to BPH. Fold change in expression was calculated using the $2^{-\Delta \Delta \mathrm{CT}}$ method. 
Negative regulation of RECK by microRNA21 is related to higher stage prostate cancer

Sabrina Thalita Reis ${ }^{1,2}$ PhD., José Pontes-Junior ${ }^{1}{ }^{2}$ M.D. PhD., Alberto Azoubel Antunes $^{1,2}$ M.D. PhD., Marcos Francisco Dall'Oglio ${ }^{1,2}$ M.D. PhD., Caio Martins Moura $^{1}$, Nelson Dip ${ }^{1}$ M.D., Miguel Srougi ${ }^{1,2}$ M.D. PhD., Kátia R. M. Leite ${ }^{1,2}$ M.D. PhD.

1 - Laboratory of Medical Investigation (LIM55), Urology Department, University of Sao Paulo Medical School, Sao Paulo, Brazil

2 - Uro-Oncology Group, Urology Department, University of Sao Paulo Medical School, Sao Paulo, Brazil

\section{Corresponding author:}

Sabrina Thalita Reis

Av. Dr. Arnaldo 455, $2^{\circ}$ floor, room 2145

01246-903, Sao Paulo, Brazil

sasareis@gmail.com

Running Title: miRNA 21 and RECK in prostate cancer

Key words: Prostate cancer; Prognosis; RECK; Micro RNA

Grant sponsors: This study was supported by FAPESP (Fundação de Amparo à Pesquisa do Estado de Sao Paulo) under protocol number 2009/50368-9. 
Abstract

Introduction: Prostate cancer $(\mathrm{PCa})$ is a common disease with a multifactorial and complex etiology. Here, we investigated the role of two known regulators of invasiveness in prostate cancer. The microRNA mir-21 has been shown to regulate invasiveness in other cancers through translational repression of the MMP inhibitor RECK. Our aim is to investigate the expression levels of RECK and miR-21 in prostate cancer and their association with important prognostic parameters and disease outcome.Materials and methods: To determine miR-21 and RECK expression levels in invasive $\mathrm{PCa}$, we performed quantitative realtime polymerase chain reaction (qRT-PCR) for both miR-21 and RECK on freshfrozen malignant tissue specimens collected from 53 patients with clinically localized PC that underwent radical prostatectomy (RP). As a control, we also assessed the expression level of miR-21 and RECK in frozen specimens of 11 patients that underwent retropubic prostatectomy to treat benign prostate hyperplasia $(\mathrm{BPH})$. Results: Our results are classified into three profiles. The first was characterized by miR-21 and RECK underexpression $(\mathrm{N}=25)$ the second was characterized by miR-21 overexpression and RECK underexpression $(\mathrm{N}=12)$, and the third was characterized by miR-21 underexpression and RECK overexpression $(\mathrm{N}=16)$. From men who presented the second profile (miR-21 overexpression and RECK underexpression) $91.7 \%$ were staged pT3. On the other hand only $48.0 \%$, and $46.7 \%$ of patients who followed the first and third profile were staged pT3 $(p=0.025)$. Conclusions: Our 
results demonstrate that miR-21 regulating $\mathrm{RECK}$, might be an important event in $\mathrm{PCa}$ progression, promoting tumor invasion. We may speculate that suppression of miR-21 may be a possible therapeutic approach to manage PCa. 


\section{Abbreviations:}

Benign prostatic hyperplasia - BPH

Complementary deoxyribonucleic acid - cDNA

Extracellular matrix - ECM

Matrix metalloproteinase - MMP

Prostate cancer - PCa

Prostate-specific antigen - PSA

Quantitative real-time polymerase chain reaction - qRT-PCR

Reversion-inducing cysteine-rich protein with Kazal motif - RECK

Ribonucleic acid - RNA

Tissue inhibitor of metalloproteinases 1 - TIMP-1 


\section{Introduction}

Prostate cancer $(\mathrm{PCa})$ is a common disease with a multifactorial and complex etiology. It is the most common cancer affecting males and the second leading cause of death in men in many countries, including Brazil. It is estimated that there will be 903,500 new cases of and 258,400 deaths related to $\mathrm{PCa}$ worldwide in 2011 [1]. Tumor staging, Gleason score and Prostatic specific antigen (PSA) serum levels are the most important prognostic factors; however, even taken together they cannot perfectly predict which patients are at risk for progression [2]. Therefore, identification of molecular markers that contribute to diagnosis and prediction of $\mathrm{PCa}$ progression has been an area of active research.

MicroRNAs (miRNAs) are a class of small noncoding RNA that regulate the expression of target genes by promoting translational repression or degradation of mRNAs $(3,4)$. In recent years, abnormalities in miRNA expression have been identified in the progression of various cancers and consequently have been proposed as potential targets for anticancer therapies (5). miRNAs have been shown to function as both tumor suppressors or oncogenes in various cancers $(6,7)$. Using high-throughput profiling of miRNA expression, miR-21 was identified as being strongly elevated in many tumors including breast, lung, ovarian and prostate $(8,9,10,11)$. However, our 
knowledge of the molecular mechanisms underlying the function of miR-21 in cancer generally, and prostate cancer specifically, is limited.

miR-21 regulates the expression of multiple mRNA targets associated with tumor invasiveness and microvascular proliferation. It has been shown that mir-21 regulates cell invasiveness by directly controlling the MMP inhibitor RECK (Reversion-inducing cysteine-rich protein with Kazal motifs), a key inhibitor of several MMPs. Indeed, RECK expression levels are predictive in determining prognoses in a number of common cancers; low levels of RECK are often associated with increased invasiveness and poor prognosis $(12,13)$. Additionally, it has been shown that inhibition of miR-21 results in reduced MMP activity leading to reduction of cell motility and invasiveness, through increased expression of RECK (14).

In this study, we will investigate the expression levels of RECK and miR21 in prostate cancer. We will then look for a correlation with their expression and important prognostic parameters such as Gleason score, pathological stage, pre-operatory PSA serum levels and the outcomes of patients with localized PCa treated with radical prostatectomy. 


\section{Patients and Methods}

\section{Patients}

The demographic and clinical characteristics of the 53 patients included in the study are exposed in table 1. After surgery, their PSA was measured every six months for the first five years and then once annually after that. Patients who underwent adjuvant or neoadjuvant treatment were excluded from this study. All subjects provided informed consent for study participation and to allow their biological samples to be analyzed genetically. The study was approved by the Institutional Board of Ethics (no. 0453/08).

We analyzed miR-21 and RECK expression levels in fresh-frozen tumor specimens randomly selected from our tumor bank from patients with clinically localized PCa who underwent radical prostatectomy by a single surgeon between 1993 and 2007 using quantitative real-time polymerase chain reaction (qRT-PCR). The control group consisted of tissue specimens from 11 patients with benign prostatic hyperplasia $(\mathrm{BPH})$ who presented lower urinary tract symptoms and underwent retropubic prostatic resection (mean age $64 \pm 6.0$ years).

We found three different profiles characterized as follows: (1) miR-21 and RECK underexpression ( $\mathrm{n}=25)$ (2) miR-21 overexpression and RECK underexpression or (3) miR-21 underexpression and RECK overexpression $(n=16)$. 
Then the three profile were correlated with Gleason score, pathological stage (TNM 2010) and pre-operative serum PSA levels $(\mathrm{ng} / \mathrm{mL})$. For this analysis, pathological stage was defined as organ-confined (pT2) or non-organconfined (pT3). Gleason score was classified as low grade (Gleason score $\leq 6$ ) or high grade (Gleason score $\geq 7$ ). Preoperative PSA was divided as $\geq 10 \mathrm{ng} / \mathrm{mL}$ or $<10 \mathrm{ng} / \mathrm{mL}$. Additionally, we analyzed miR-21 and RECK expression levels and their relation to biochemical recurrence, which was defined as PSA levels $>0.4 \mathrm{ng} / \mathrm{mL}$, in a mean follow-up time of 60 months.

\section{RNA and miRNA Isolation and cDNA Synthesis}

All tumor samples were obtained from surgical specimens and immediately frozen at $-170^{\circ} \mathrm{C}$ in liquid nitrogen. A section of the frozen fragment was stained with hematoxylin and eosin to verify that the tumor represented at least $75 \%$ of the fragment in PCa patients and that there was no tumor in control $\mathrm{BPH}$ patients. Total RNA was isolated from tissue samples using a RNAaqueous Kit (Applied Biosystems, CA, USA) and miRNA was isolated with a mirVANA Kit (Applied Biosystems, CA, USA) according to the manufacturer's instructions. RNA and miRNA concentration was determined by $260 / 280 \mathrm{nM}$ absorbance using a Nanodrop ND-1000 spectrophotometer (Thermo Scientific). cDNA from total RNA was generated using a High Capacity cDNA Reverse Transcription Kit (Applied Biosystems, CA, USA). Reactions were incubated at $25^{\circ} \mathrm{C}$ for $10 \mathrm{~min}$, followed by $37^{\circ} \mathrm{C}$ for $120 \mathrm{~min}$ and $85^{\circ} \mathrm{C}$ for $5 \mathrm{~min}$. cDNA from 
miRNAs was generated using a TaqMan ${ }^{\circledR}$ miRNA Reverse Transcription kit (Applied Biosystems, Foster City, CA). Reactions were incubated at $16^{\circ} \mathrm{C}$ for 30 $\min , 42^{\circ} \mathrm{C}$ for $30 \mathrm{~min}$ and $85^{\circ} \mathrm{C}$ for $30 \mathrm{~min}$. All cDNAs were stored at $-20^{\circ} \mathrm{C}$ until further use.

\section{Quantitative Real-Time PCR and Gene Expression analysis}

Expression levels of the miR-21 and RECK were analyzed by qRT-PCR using the ABI 7500 Fast Real-Time PCR System (Applied Biosystems). Target sequences were amplified in a $10-\mu \mathrm{l}$ reaction containing $5 \mu \mathrm{l}$ of TaqMan Universal PCR Master Mix, $0.5 \mu \mathrm{l}$ of TaqMan Gene Expression Assays for RECK and $0.5 \mu$ of TaqMan miRNA expression assays for miR-21, $1 \mu$ of cDNA and $3.5 \mu \mathrm{l}$ of DNase-free water. The PCR cycling conditions were 2 minutes at $50^{\circ} \mathrm{C}, 10$ minutes at $95^{\circ} \mathrm{C}$ and then 40 cycles of 15 seconds at $95^{\circ} \mathrm{C}$ and $1 \mathrm{~min}$ at $60^{\circ} \mathrm{C}$. Betha-2 microglobulin was used as the endogenous control in the analysis of RECK expression. RNU43 was used as the endogenous control for miR-21.

We used the $\Delta \triangle C T$ method to calculate the relative expression of the RECK and miR-21 using the formula $\Delta \Delta C T=(C T$ target gene, PC sample $-\mathrm{CT}$ endogenous control, PC sample) - (CT target gene, BPH sample - CT endogenous control, BPH sample). The fold change in gene expression was calculated as $2^{-\Delta \Delta C T}$. 


\section{Statistical Analysis}

Quantitative variables were expressed as median values, interquartile range (Q1-Q3), and minimum and maximum values. Qualitative variables were expressed as numbers and percentages. To compare the clinical characteristics of patients with PCa, we used the Mann-Whitney, Chi-squared and Fisher exact tests. For descriptive analysis of RECK and miR-21 expression according to pathological stage, Gleason score and PSA, we constructed a box plot. For comparison between all categories, we used the Mann-Whitney test. Statistical analysis was performed using SPSS 15.0 for Windows using a significance of $p$ $\leq 0.05$. 


\section{Results}

Analysis of 53 patients with PCa showed that miR-21 was overexpressed in $42.8 \%$ (median 1.64 ) and RECK in $57.2 \%$ (median 2.2 ) of malignant prostatic tissue samples, relative to control BPH samples (Figure 1). miR-21 and RECK expression data and their correlation with prognostic parameters are presented in Table 2. Since RECK is a target of miR-21, we defined three profiles for analysis. The first profile contained samples in which miR-21 and RECK were underexpressed $(25,47.1 \%)$. The second profile was composed of samples in which miR-21 was overexpressed and RECK underexpressed (12, 22.6\%), and the third profile was composed of samples in which miR-21 was underexpressed and RECK overexpressed $(16,30.2 \%)$. Comparison of pathological stage between the three groups showed that $91.7 \%$ of patients were staged pT3 when miR-21 was overexpressed and RECK underexpressed. On the contrary, when miR-21 was underexpressed and RECK overexpressed only $46.7 \%$ of patients were staged pT3, and when both were underexpressed only $48.0 \%$ of patients were staged pT3 $(p=0.025)$ (table 3$)$.

Additionally, there was a marginal statistical difference between the three profiles when we examined biochemical recurrence. From patients presenting miR-21 overexpression and RECK underexpression, $63.6 \%$ had biochemical recurrence compared with $50.0 \%$ and $25.0 \%$ of patients in the others profiles $(p=0.087)($ table 3$)$. 
There were no differences in the three groups considering Gleason score or PSA pre-operatory serum levels. 


\section{Discussion}

To understand the role of any miRNA in disease such as cancer, the mRNA targets of that miRNA must be identified. miR-21 plays a role in the regulation of cell proliferation, apoptosis and tumor invasiveness by targeting PTEN, PDCD4, and RECK (15). This is the first study to explore the role of miR21 controlling RECK in PCa. In 53 patient samples, 22.6\% exhibited miR-21 overexpression and RECK underexpression associated with non-organ confined tumors (pT3), and biochemical recurrence. We therefore believe that miR-21 may be playing a role in a subset of prostate cancers through regulation of RECK expression levels.

This same phenomenon has been observed in other types of human cancers. Liu et al. showed that inhibition of miR-21 lead to a decrease in invasiveness in hepatocellular carcinoma (15). Inhibition of miR-21 leads to increasing levels of RECK, a membrane-anchored glycoprotein that inhibits tumor cell invasion by regulating MMP-2, MMP-9 and MT1-MMP (16). In tumors in which RECK is absent or diminished, MMPs will be highly active, facilitating tumor promotion and progression. Recently, Zhang et al. have described the similar results in gastric cancer (17). Cancers which overexpressed miR-21 and had Helicobacter pylori infection had a higher capacity for invasion and migration of tumor cells. Here, we have demonstrated a similar association in PCa where $91.7 \%$ of tumors presenting overexpression of miR-21 were staged pT3. 
The miR-21 is one of the most commonly implicated miRNAs in cancer. Its expression is highly upregulated in a variety of solid tumors including gliomas, breast, lung and pancreas carcinomas (18, 19). Elevated miR-21 expression has been causally linked to proliferation, apoptosis, and migration of several cancer cell lines (20). However, the molecular mechanisms mediating miR-21 function in cancer generally, and PCa specifically, are poorly understood. MiR-21 regulates RECK, which we have observed can function as a tumor suppressor gene in PCa (unpublished data). RECK decreases the amount of active MMP-2 and MMP-9 in conditioned medium and inhibits metastatic activity in vitro (21) and in vivo (22) through modulation of these MMPs, which are known to be involved in cancer progression (23).

Our data show a tendency in association between miR-21 overexpression and biochemical recurrence. When miR-21 was overexpressed and RECK was underexpression $63.4 \%$ of patients suffered recurrence with a mean follow up of 60 months $(p=0.87)$. We may hypothesize that this specific profile is unfavorable for prostate adenocarcinoma.

In conclusion, we believe that miR-21 may be important in $\mathrm{PCa}$ progression through its regulation of RECK, a known regulator of tumor cell invasion. Experimental studies must be performed in order to show the precise role of miR-21 and mettaloproteinases, specially RECK in prostate carcinogenesis. Consequently, suppression of miR-21 would be considered as a potential therapeutic tool in the treatment of the neoplasia. 


\section{References}

26. Jemal A, Siegel R, Ward E, et al. Cancer statistics, 2011. CA Cancer J Clin 61: 212-236, 2011

27. Berger AP, Spranger R, Kofler K, et al. Early detection of prostate cancer with low PSA cut-off values leads to significant stage migration in radical prostatectomy specimens. Prostate 57:93-98, 2003

28. Peek Jr RM, Blaser MJ. Helicobacter pylori and gastrointestinal tract adenocarcinomas. Nat Rev Cancer 2:28-37, 2002

29. Pillai RS. MicroRNA function: multiple mechanisms for a tiny RNA? RNA 11:1753-176, 2005

30. Croce CM. Oncogenes and cancer. N Engl J Med 358:502-511, 2008

31. He L, He X, Lowe SW, et al. microRNAs join the p53 network-another piece in the tumour-supression puzzle. Nat Rev Cancer 7:819-822, 2007

32. Kent OA, Mendell JT. A small piece in the cancer puzzle: microRNAs as tumor suppressors and oncogenes. Onocogene 25:6188-6196, 2006

33. Asangani IA, Rasheed SA, Nikolova DA, et al. MicroRNA-21 (miR-21) posttranscriptionally downregulates tumor suppressor $\mathrm{Pdcd} 4$ and stimulates invasion, intravasation and metastasis in colorectal cancer. Oncogene 27:2128-2136, 2008 
34. Meng $F$, Henson $R$, Wehbe-Janek $H$, et al. MicroRNA-21 regulates expression of the PTEN tumor suppressor gene in human hepatocellular cancer. Gastroenterology 133:647-658, 2007

35. Si ML, Zhu S, Wu H, et al. miR-21-mediated tumor growth. Oncogene 26:2799-2803, 2007

36. Zhu S, Si ML, Wu H, et al. MicroRNA-21 targets the tumor suppressor genes tropomyosin 1 (TPM1). J Biol Chem 282:14328-14336, 2007

37. Kotzsch M, Farthmann J, Meye A, et al. Prognostic relevance of UPARdel4/5and TIMP-3 mRNA expression levels in breast cancer. Eur $\mathrm{J}$ Cancer 41:2760-2768, 2005

38. Takenaka $\mathrm{K}$, Ishikawa S, Kawano $\mathrm{Y}$, et al. Expression of a novel matrix metalloproteinase regulator, RECK, and its clinical significance in resected non-small cell lung cancer. Eur J Cancer 10:1617-1623, 2004

39. Gabriely G, Wurdinger T, Kesari S, et al. MicroRNA 21 promotes glioma invasion by targeting matrix metalloproteinase regulators. Molecular and Cellular Biology 28:5369-5380, 2008

40. Liu C, Yu J, Yu S, et al. MicroRNA-21 acts as an oncomir through multiple targets in human hepatocellular carcinoma. Journal of Hepatology 53:98107,2010

41. Takahashi C, Sheng Z, Horan TP, et al. Regulation of matrix metalloproteinase- 9 and inhibition of tumor invasion by the membraneanchored glycoprotein RECK. Proc Natl Acad Sci U S A 95:13221-13226, 1998

42. Zhang Z, Li Z, Gao C. miR-21 plays a pivotal role in gastric cancer pathogenesis and progression. Lab Invest 88:1358-1366, 2008 
43. Chan JA, Krichevsky AM, Kosik KS. MicroRNA-21 is an antiapoptotic factor in human glioblastoma cells. Cancer Res 65:6029-6033, 2005

44. Volinia S, Calin GA, Liu CG, et al. A microRNA expression signature of human solid tumors defines cancer gene targets. Procl. Natl. Acad. Sci. USA 103:2257-2261, 2006

45. Zhu S, Wu H, Wu G, et al. MicroRNA-21 targets tumor suppressor genes in invasion and metastasis. Cell Res. 18:350-359, 2008

46. Oh J, Takahashi R, Kondo S, et al. The membrane anchored MMP inhibitor RECK is a key regulator of extracellular matrix integrity and angiogenesis. Cell 107:789-800, 2001

47. Chang CK, Hung WC, Chang HC. The Kazal motifs of RECK protein inhibit MMP-9 secretion and activity and reduce metastasis of lung cancer cells in vitro and in vivo. J Cell Mol Med 12: 2781-2789, 2008

48. Oh J, Takahashi R, Kondo S. The membrane-anchored MMP inhibitor RECK is a key regulator of extracellular matrix integrity and angiogenesis. Cell 107:789-800, 2001 


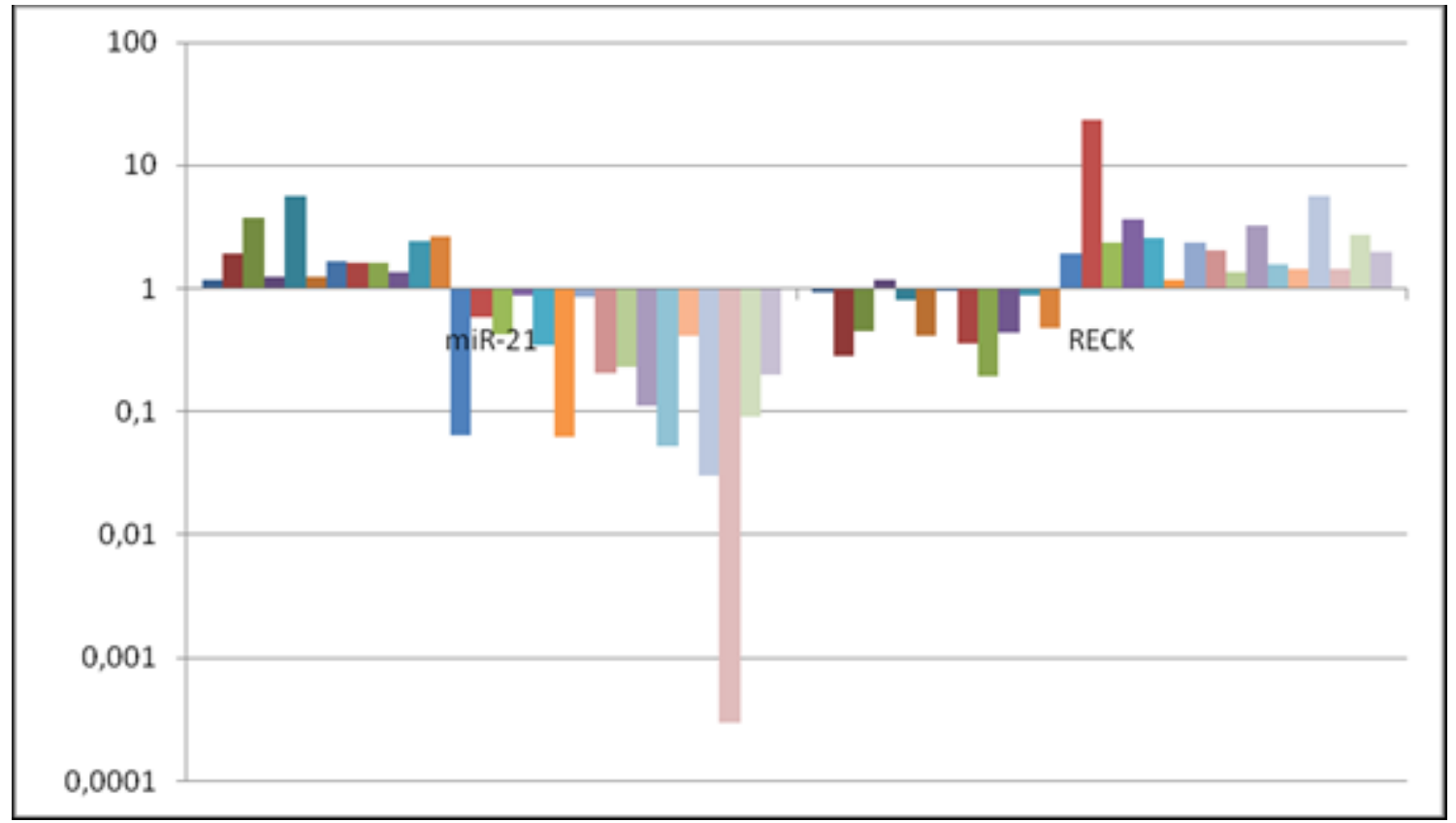

Figure 1. Graphical representation of the expression levels of miR-21 and $\mathrm{RECK}$ in $\mathrm{PCa}$ tissue compared with $\mathrm{BPH}$. Fold change in expression was calculated using the $2^{-\Delta \Delta C T}$ method. 
Table 1. Demographic and clinical characteristics of 53 men submitted to radical prostatectomy to treat prostate cancer

\begin{tabular}{ll} 
Age (years) & \\
Mean & 65.4 \\
Min - Max & $50-79$ \\
\hline PSA (ng/ml) & 11.0 \\
Mean & $2.0-37.0$ \\
Min - Max & $27(50.1)$ \\
$<10$ n (\%) & $26(49.9)$ \\
$\geq 10$ n (\%) & \\
\hline Stage & $31(58.5)$ \\
pT2 n (\%) & $22(42.3)$ \\
pT3 n (\%) & $30(57.7)$ \\
\hline Gleason Score & \\
\hline & \\
\hline
\end{tabular}


Table 2. Relative expression of the two genes in the malignant prostatic tissue according to Gleason score, Pathological stage, PSA value and Biochemical Recurrence. Fold change in gene expression was calculated using the $\triangle \Delta C T$ method $\left(\mathrm{QRel}=2^{-\triangle \Delta C \mathrm{~T}}\right)$.

$\begin{array}{lll} & \text { miR-21 } & \text { RECK } \\ \text { Gleason Score } & & \\ <7(n=22) & 0.63 & 0.88 \\ \geq 7(n=31) & 0.81 & 2.10 \\ p \text {-value } & 0.545 & 0.214\end{array}$

\section{Pathological}

Stage

$\begin{array}{lll}\text { pT2 }(n=22) & 0,36 & 1.18 \\ \text { pT3 }(n=30) & 1,01 & 1.85 \\ \text { p-value } & \mathbf{0 . 0 0 9} & 0.470\end{array}$

\section{PSA value}

$<10(n=27) \quad 0.68 \quad 0.94$

$\geq 10(n=26) \quad 0.80 \quad 2.18$

$\mathrm{p}$-value $\quad 0.701 \quad 0.390$

\section{Biochemical}

Recurrence

$\begin{array}{lll}\text { W/n }(\mathrm{n}=27) & 0.52 & 1.05 \\ \text { With }(\mathrm{n}=20) & 1.12 & 2.61 \\ \text { p-value } & \mathbf{0 . 0 5 1} & 0.366\end{array}$


Table 3. Relative expression of miR-21 and RECK in the malignant prostatic tissue correlated either with Gleason score, pathological stage, PSA serum value or biochemical recurrence. Fold change in gene expression was calculated using the $\Delta \Delta \mathrm{CT}$ method $\left(\mathrm{QRel}=2^{-\Delta \Delta \mathrm{CT}}\right)$.

\begin{tabular}{ccccc} 
& $\begin{array}{c}\downarrow m i R-21 \text { and } \\
\downarrow \text { RECK }\end{array}$ & $\begin{array}{c}\uparrow \text { miR-21 and } \\
\downarrow \text { RECK }\end{array}$ & $\begin{array}{c}\downarrow \text { miR-21 and } \\
\uparrow \text { RECK }\end{array}$ & P value \\
$\begin{array}{c}\text { Gleason } \\
\text { Score }\end{array}$ & & & & \\
$<7$ & $56.0 \%$ & $33.3 \%$ & $31.3 \%$ & 0.215 \\
$\geq 7$ & $44.0 \%$ & $67.7 \%$ & $68.7 \%$ & \\
\hline
\end{tabular}

\section{Pathological \\ Stage}

\begin{tabular}{lllll} 
pT2 & $52.0 \%$ & $8.3 \%$ & $53.3 \%$ & 0.025 \\
pT3 & $48.0 \%$ & $91.7 \%$ & $46.7 \%$ & \\
\hline
\end{tabular}

\section{PSA value}

$\begin{array}{lllll}<10 & 60.0 \% & 50.0 \% & 37.5 \% & 0.371 \\ \geq 10 & 40.0 \% & 50.0 \% & 62.5 \% & \end{array}$

\section{Biochemical}

Recurrence

$\begin{array}{lllll}\text { No } & 75.0 \% & 36.4 \% & 50.0 \% & \mathbf{0 . 0 8 7} \\ \text { Yes } & 25.0 \% & 63.6 \% & 50.0 \% & \end{array}$




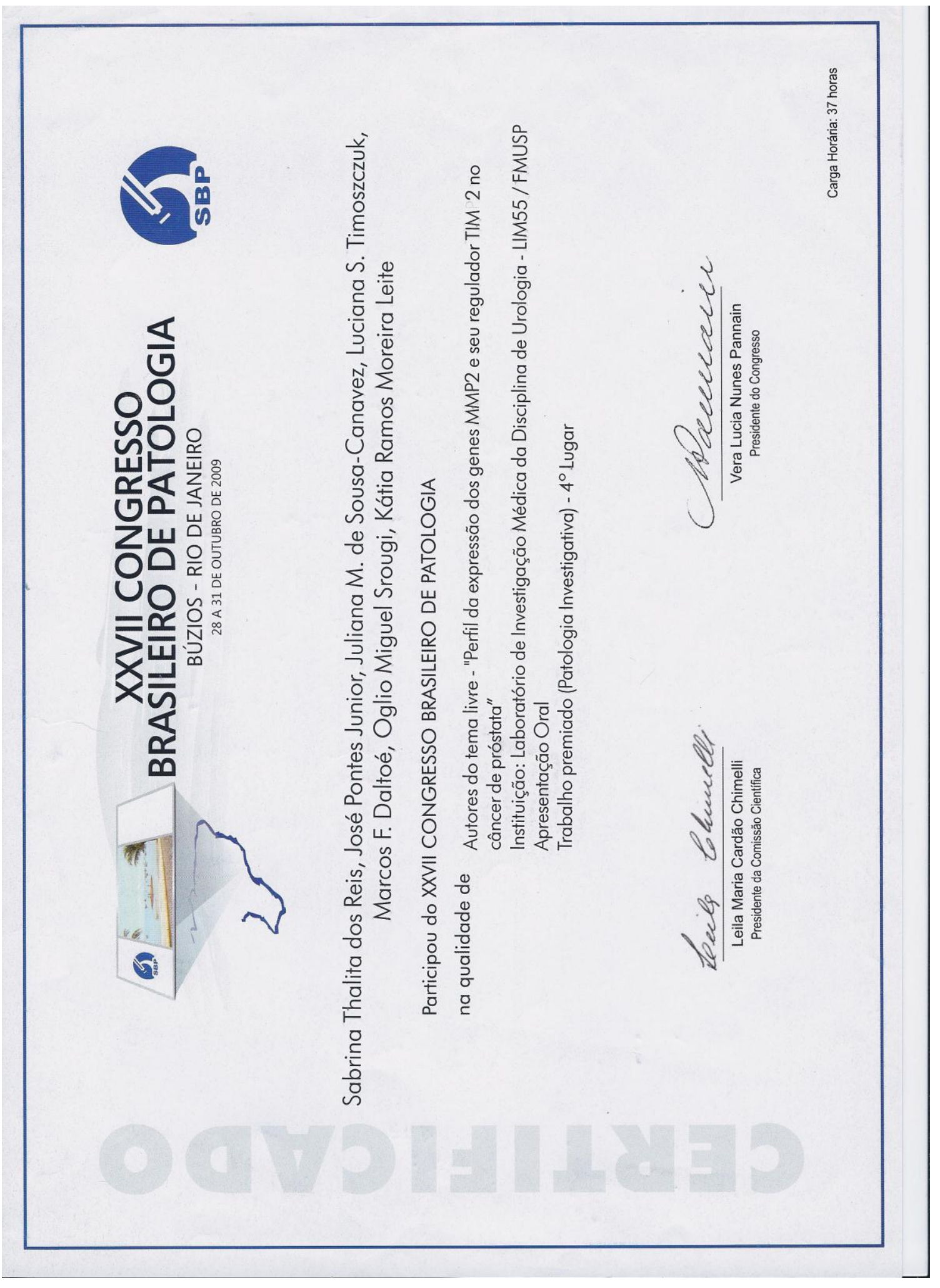




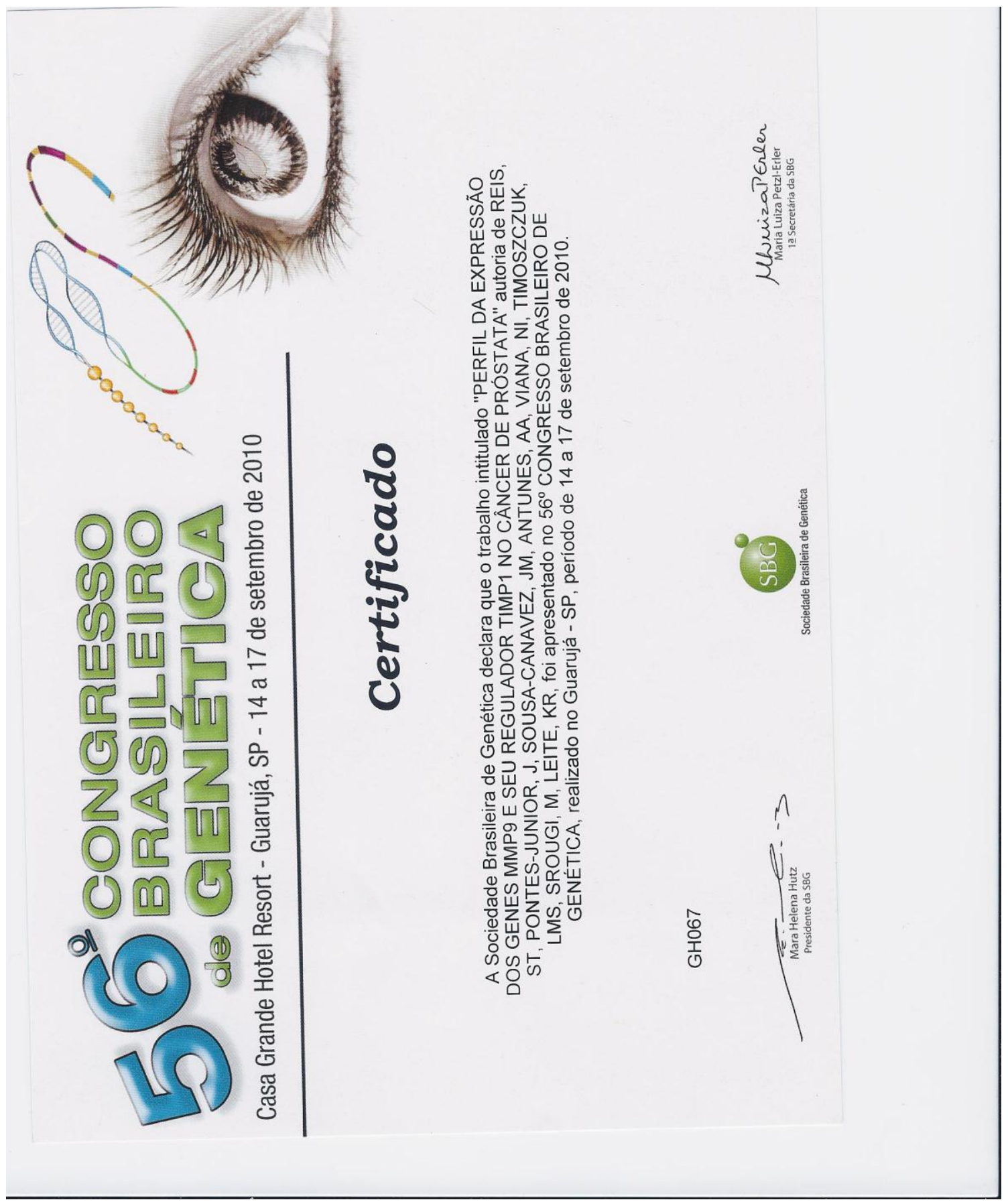




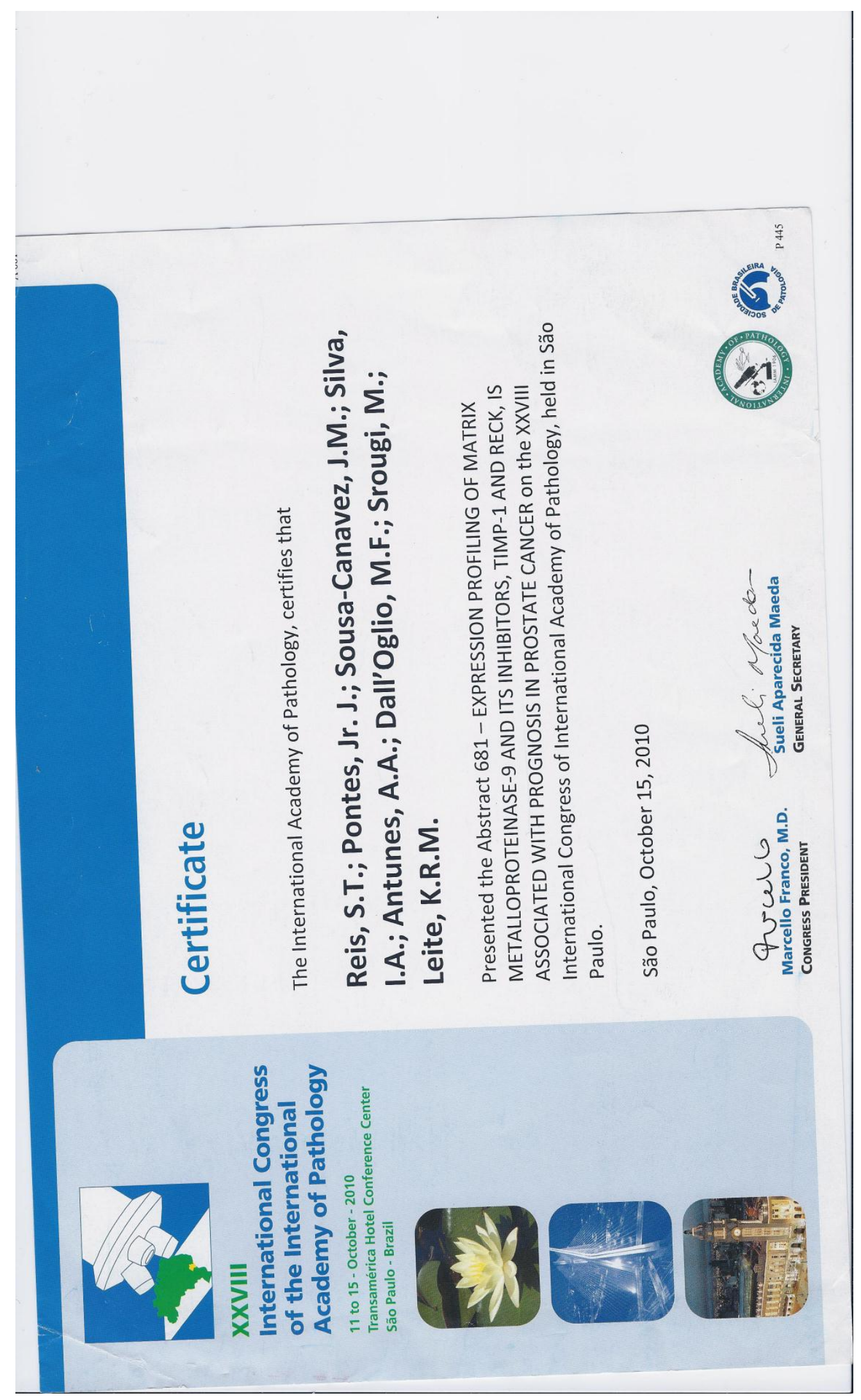




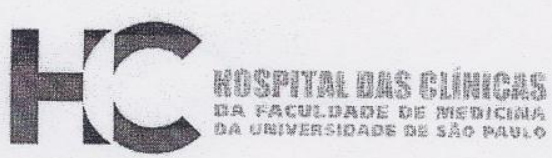

\section{APROVAÇÃO}

A Comissão de Ética para Análise de Projetos de Pesquisa CAPPesa da Diretoria Clínica do Hospital das Clínicas e da Faculdade de Medicina da Universidade de São Paulo, em sessão de 16/07/2008, APROVOU O Protocolo de Pesquisa $n^{\circ}$ 0453/08, intitulado: "ANÁLISE DA EXPRESSĀO DE MMP-2, MMP-9, MT1-MMP, TIMP-1, TIMP-2, RECK, TGF-BETA E INTERLEUCINA-8 EM CÂNCER DE PRÓSTATA" apresentado pelo Departamento de CIRURGIA, inclusive o Termo de Consentimento Livre e Esclarecido.

Cabe ao pesquisador elaborar e apresentar à CAPPesq, os relatórios parciais e final sobre a pesquisa (Resolução do Conselho Nacional de Saúde n० 196, de 10/10/1996, inciso IX.2, letra "c").

Pesquisador (a) Responsável: Kátia Ramos Moreira Leite

Pesquisador (a) Executante: Sabrina Thalita dos Reis

CAPPesq, 18 de Julho de 2008
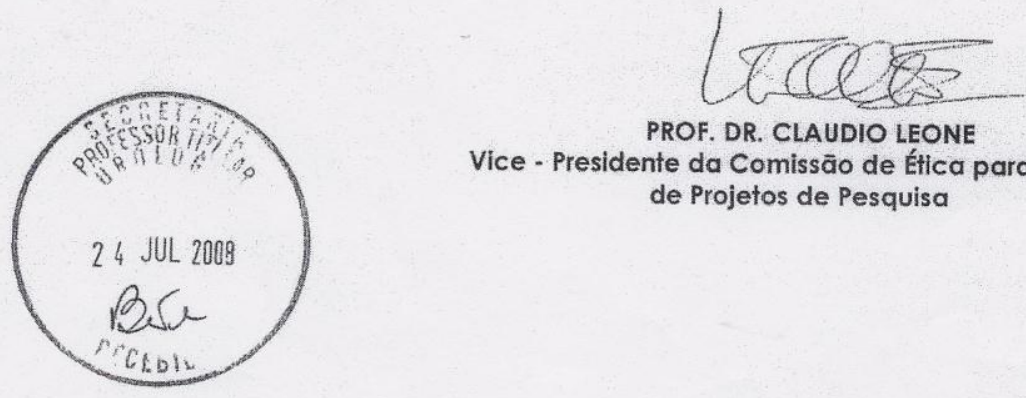

PROF. DR. CLAUDIO LEONE

Vice - Presidente da Comissāo de Ética para Análise de Projetos de Pesquisa

Comissăo de Ética para Análise de Projetos de Pesquisa do HCFMUSP e da FMUSP Diretoria Clínica do Hospital das Clínicas da Faculdade de Medicina da Universidade de Såo Paulo Rua Ovidio Pires de Campos, 255, $5^{\circ}$ andar - CEP 05403010 - Såo Paulo - SP Fone: 01130696442 Fax: 01130696492 e-mail:

cappesq@hcnet.usp.br/secretariacappesq2@hcnet.usp.br 